\title{
Combination formoterol and budesonide as maintenance and reliever therapy versus inhaled steroid maintenance for chronic asthma in adults and children (Review)
}

\author{
Cates CJ, Lasserson TJ
}

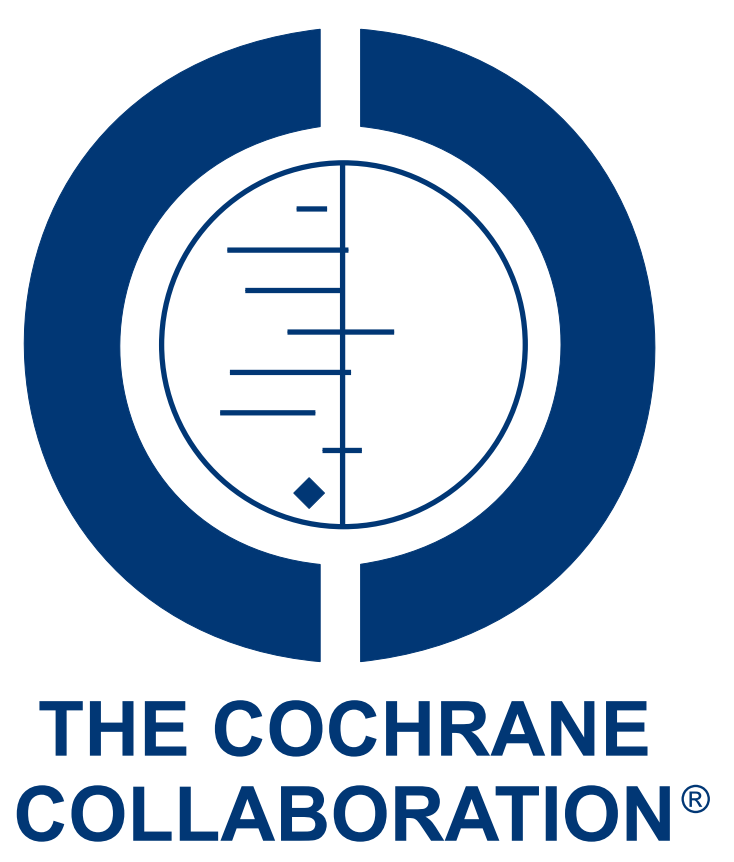

This is a reprint of a Cochrane review, prepared and maintained by The Cochrane Collaboration and published in The Cochrane Library 2010, Issue 1

http://www.thecochranelibrary.com

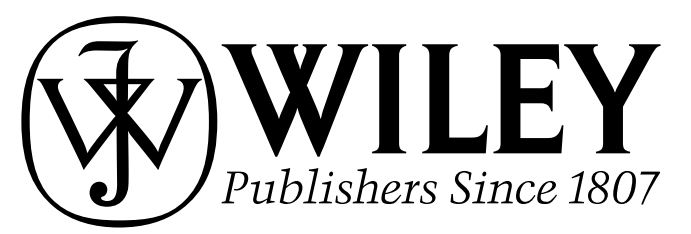

Combination formoterol and budesonide as maintenance and reliever therapy versus inhaled steroid maintenance for chronic asthma in adults and children (Review)

Copyright ( 2010 The Cochrane Collaboration. Published by John Wiley \& Sons, Ltd. 
TABLE OF CONTENTS

HEADER . . . . . . . . . . . . . . . . . . . . . . . . . . . . . . . . 1

ABSTRACT .. . . . . . . . . . . . . . . . . . . . . . . . . . . . . . . . . . . . . . . . . . . . . . . . .

PLAIN LANGUAGE SUMMARY . . . . . . . . . . . . . . . . . . . . . . . . . . . . . . . . . . . $\quad$. 2

BACKGROUND . . . . . . . . . . . . . . . . . . . . . . . . . . . . . . . . . . . . . 2

OBJECTIVES . . . . . . . . . . . . . . . . . . . . . . . . . . . . . . . . . . . . .

METHODS . . . . . . . . . . . . . . . . . . . . . . . . . . . . . . . . . . . . . . 3

RESUlTS . . . . . . . . . . . . . . . . . . . . . . . . . . . . . . . . . . . . . . . 5

Figure 1. . . . . . . . . . . . . . . . . . . . . . . . . . . . . . . . . . . . . . 7

Figure 2. . . . . . . . . . . . . . . . . . . . . . . . . . . . . . . . . . . . . . . . . . . . 9

Figure 3. . . . . . . . . . . . . . . . . . . . . . . . . . . . . . . . . . . . . . 9

Figure 4. . . . . . . . . . . . . . . . . . . . . . . . . . . . . . . . . . . . . . 10

Figure 5. . . . . . . . . . . . . . . . . . . . . . . . . . . . . . . . . . . . . . 11

Figure 6. . . . . . . . . . . . . . . . . . . . . . . . . . . . . . . . . . . . . . 11

Figure $7 . \quad$. . . . . . . . . . . . . . . . . . . . . . . . . . . . . . . . . . . . . 12

Figure 8. . . . . . . . . . . . . . . . . . . . . . . . . . . . . . . . . . . . . . . . 13

DISCUSSION . . . . . . . . . . . . . . . . . . . . . . . . . . . . . . . . . . . . . 14

AUTHORS' CONCLUSIONS . . . . . . . . . . . . . . . . . . . . . . . . . . . . . . . . . . . . 15

ACKNOWLEDGEMENTS . . . . . . . . . . . . . . . . . . . . . . . . . . . . . . . . . . . . . . . . . . 15

REFERENCES . . . . . . . . . . . . . . . . . . . . . . . . . . . . . . . . . . . . . 15

CHARACTERISTICS OF STUDIES . . . . . . . . . . . . . . . . . . . . . . . . . . . . . . . . . . . 19

DATA AND ANALYSES . . . . . . . . . . . . . . . . . . . . . . . . . . . . . . . . . . . . . . . . . . . . . . . . . . $\quad$.

Analysis 1.1. Comparison 1 Adults and Adolescents treated with Single Inhaler Therapy versus Current Best Practice,

Outcome 1 Patients with exacerbations causing hospitalisation. . . . . . . . . . . . . . . . . . . . . . . .

Analysis 1.2. Comparison 1 Adults and Adolescents treated with Single Inhaler Therapy versus Current Best Practice,

Outcome 2 Patients with exacerbations treated with oral steroids. . . . . . . . . . . . . . . . . . . .

Analysis 1.3. Comparison 1 Adults and Adolescents treated with Single Inhaler Therapy versus Current Best Practice,

Outcome 3 Serious Adverse Events (fatal). . . . . . . . . . . . . . . . . . . . . . . . . . . . . . . . . . .

Analysis 1.4. Comparison 1 Adults and Adolescents treated with Single Inhaler Therapy versus Current Best Practice,

Outcome 4 Serious Adverse Events (non-fatal). . . . . . . . . . . . . . . . . . . . . . . . . . . .

Analysis 1.5. Comparison 1 Adults and Adolescents treated with Single Inhaler Therapy versus Current Best Practice,

Outcome 5 Discontinuation due to Adverse Events. . . . . . . . . . . . . . . . . . . . . . . . . . . .

Analysis 1.6. Comparison 1 Adults and Adolescents treated with Single Inhaler Therapy versus Current Best Practice,

Outcome 6 Patients with "severe" exacerbation (time to event). . . . . . . . . . . . . . . . . . . . . . . .

Analysis 1.7. Comparison 1 Adults and Adolescents treated with Single Inhaler Therapy versus Current Best Practice,

Outcome 7 Change in PEF (\% predicted). . . . . . . . . . . . . . . . . . . . . . . . . . . . . . . . . .

Analysis 1.8. Comparison 1 Adults and Adolescents treated with Single Inhaler Therapy versus Current Best Practice,

Outcome 8 Rescue Medication Use (puffs per day). . . . . . . . . . . . . . . . . . . . . . . .

Analysis 1.9. Comparison 1 Adults and Adolescents treated with Single Inhaler Therapy versus Current Best Practice,

Outcome 9 Quality of Life (Change in ACQ score). $\quad . \quad$. . . . . . . . . . . . . . . . . . . . . . . . .

Analysis 1.10. Comparison 1 Adults and Adolescents treated with Single Inhaler Therapy versus Current Best Practice,

Outcome 10 ICS dose (micrograms per day). . . . . . . . . . . . . . . . . . . . . . . . . . . . .

Analysis 2.1. Comparison 2 Adults and Adolescents treated with Single Inhaler Therapy versus fixed dose ICS, Outcome 1

Patients with exacerbations causing hospitalisation. . . . . . . . . . . . . . . . . . . . . . .

Analysis 2.2. Comparison 2 Adults and Adolescents treated with Single Inhaler Therapy versus fixed dose ICS, Outcome 2 Patients with exacerbations treated with oral steroids. . . . . . . . . . . . . . . . . . . . . . . . .

Analysis 2.3. Comparison 2 Adults and Adolescents treated with Single Inhaler Therapy versus fixed dose ICS, Outcome 3 Serious Adverse Events (fatal).

Analysis 2.4. Comparison 2 Adults and Adolescents treated with Single Inhaler Therapy versus fixed dose ICS, Outcome 4 Serious Adverse Events (non-fatal). . . . . . . . . . . . . . . . . . . . . . . . . . . . . . . . . . . .

Analysis 2.5. Comparison 2 Adults and Adolescents treated with Single Inhaler Therapy versus fixed dose ICS, Outcome 5

Discontinuation due to Adverse Events. . . . . . . . . . . . . . . . . . . . . . . . . . 51

Combination formoterol and budesonide as maintenance and reliever therapy versus inhaled steroid maintenance for chronic asthma in adults and children (Review)

Copyright $\odot 2010$ The Cochrane Collaboration. Published by John Wiley \& Sons, Ltd. 
Analysis 2.6. Comparison 2 Adults and Adolescents treated with Single Inhaler Therapy versus fixed dose ICS, Outcome 6 Patients with "severe" exacerbation (time to event). . . . . . . . . . . . . . . . . . . . . . .

Analysis 2.7. Comparison 2 Adults and Adolescents treated with Single Inhaler Therapy versus fixed dose ICS, Outcome 7 PEF (Litres/min). . . . . . . . . . . . . . . . . . . . . . . . . . . . . . . . .

Analysis 2.8. Comparison 2 Adults and Adolescents treated with Single Inhaler Therapy versus fixed dose ICS, Outcome 8 FEV1 increase (Litres). . . . . . . . . . . . . . . . . . . . . . . . . . . . . . . . 54

Analysis 2.9. Comparison 2 Adults and Adolescents treated with Single Inhaler Therapy versus fixed dose ICS, Outcome 9 Rescue Medication Use (puffs per day). . . . . . . . . . . . . . . . . . . . . . . . . .

Analysis 2.10. Comparison 2 Adults and Adolescents treated with Single Inhaler Therapy versus fixed dose ICS, Outcome 10 Quality of Life (Fall in ACQ score). . . . . . . . . . . . . . . . . . . . . . . . . . .

Analysis 3.1. Comparison 3 Children treated with Single Inhaler Therapy versus higher fixed dose ICS, Outcome 1 Patients with exacerbations causing hospitalisation. . . . . . . . . . . . . . . . . . . . . . . . .

Analysis 3.2. Comparison 3 Children treated with Single Inhaler Therapy versus higher fixed dose ICS, Outcome 2 Serious Adverse Events (fatal). . . . . . . . . . . . . . . . . . . . . . . . . . . . . . . . 56

Analysis 3.3. Comparison 3 Children treated with Single Inhaler Therapy versus higher fixed dose ICS, Outcome 3 Serious Adverse Events (non-fatal). . . . . . . . . . . . . . . . . . . . . . . . . . . . . .

Analysis 3.4. Comparison 3 Children treated with Single Inhaler Therapy versus higher fixed dose ICS, Outcome 4 Annual Height gain $(\mathrm{cms}) . \quad$. . . . . . . . . . . . . . . . . . . . . . . . . . . . . . . .

Analysis 3.5. Comparison 3 Children treated with Single Inhaler Therapy versus higher fixed dose ICS, Outcome 5

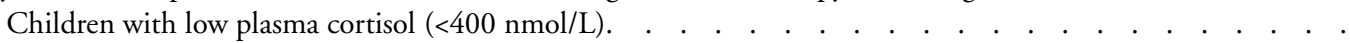

Analysis 3.6. Comparison 3 Children treated with Single Inhaler Therapy versus higher fixed dose ICS, Outcome 6 Patients with an exacerbation requiring increase in ICS or other treatment. . . . . . . . . . . . . . . . . . . .

Analysis 3.7. Comparison 3 Children treated with Single Inhaler Therapy versus higher fixed dose ICS, Outcome 7 Change

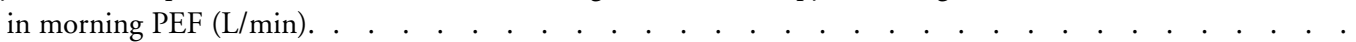

Analysis 3.8. Comparison 3 Children treated with Single Inhaler Therapy versus higher fixed dose ICS, Outcome 8 Change in clinic FEV1(Litres). . . . . . . . . . . . . . . . . . . . . . . . . . . . . . . . . . .

Analysis 3.9. Comparison 3 Children treated with Single Inhaler Therapy versus higher fixed dose ICS, Outcome 9 As needed medication use over 24 hours. $\quad . \quad$. . . . . . . . . . . . . . . . . . . . . . . . . . . . .

Analysis 3.10. Comparison 3 Children treated with Single Inhaler Therapy versus higher fixed dose ICS, Outcome 10

Nocturnal awakenings. . . . . . . . . . . . . . . . . . . . . . . . . . . . . . . .

WHAT'S NEW . . . . . . . . . . . . . . . . . . . . . . . . . . . . . . . . . . . . .

HISTORY . . . . . . . . . . . . . . . . . . . . . . . . . . . . . . . . . . . . . . .

CONTRIBUTIONS OF AUTHORS..$\quad$. . . . . . . . . . . . . . . . . . . . . . . . . . . . . . . . . . . . . . . .

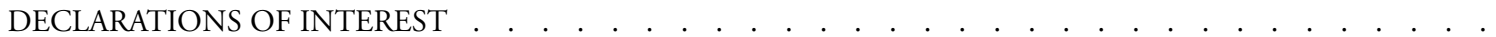

SOURCES OF SUPPORT . . . . . . . . . . . . . . . . . . . . . . . . . . . . . . . . .

DIFFERENCES BETWEEN PROTOCOL AND REVIEW . . . . . . . . . . . . . . . . . . . . . . 61

INDEX TERMS . . . . . . . . . . . . . . . . . . . . . . . . . . . . . . . . . . . . . . . . . . . . . . . . 61

Combination formoterol and budesonide as maintenance and reliever therapy versus inhaled steroid maintenance for chronic asthma in ii 


\title{
Combination formoterol and budesonide as maintenance and reliever therapy versus inhaled steroid maintenance for chronic asthma in adults and children
}

\author{
Christopher J Cates ${ }^{1}$, Toby J Lasserson ${ }^{2}$ \\ ${ }^{1}$ Community Health Sciences, St George's, University of London, London, UK. ${ }^{2}$ Cochrane Airways Group, Divison of Community \\ Health Sciences, St George's University of London, London, UK \\ Contact address: Christopher J Cates, Community Health Sciences, St George's, University of London, Cranmer Terrace, London, \\ SW17 0RE, UK. ccates@sgul.ac.uk.
}

Editorial group: Cochrane Airways Group.

Publication status and date: Edited (no change to conclusions), published in Issue 1, 2010.

Review content assessed as up-to-date: 9 February 2009.

Citation: Cates CJ, Lasserson TJ. Combination formoterol and budesonide as maintenance and reliever therapy versus inhaled steroid maintenance for chronic asthma in adults and children. Cochrane Database of Systematic Reviews 2009, Issue 2. Art. No.: CD007313. DOI: 10.1002/14651858.CD007313.pub2.

Copyright (C) 2010 The Cochrane Collaboration. Published by John Wiley \& Sons, Ltd.

\begin{abstract}
A B S T R A C T
Background

Traditionally inhaled treatment for asthma has been considered as preventer and reliever therapy. The combination of formoterol and budesonide in a single inhaler introduces the possibility of using a single inhaler for both prevention and relief of symptoms (single inhaler therapy).
\end{abstract}

Objectives

The aim of this review is to compare formoterol and corticosteroid in single inhaler for maintenance and relief of symptoms with inhaled corticosteroids for maintenance and a separate reliever inhaler.

Search methods

We last searched the Cochrane Airways Group trials register in September 2008.

Selection criteria

Randomised controlled trials in adults and children with chronic asthma.

Data collection and analysis

Two review authors independently assessed studies for inclusion and extracted the characteristics and results of each study. Authors or manufacturers were asked to supply unpublished data in relation to primary outcomes.

Main results

Five studies on 5,378 adults compared single inhaler therapy with current best practice, and did not show a significant reduction in participants with exacerbations causing hospitalisation (Peto OR 0.59; 95\% CI 0.24 to 1.45 ) or treated with oral steroids (OR 0.83; 95\% CI 0.66 to 1.03). Three of these studies on 4281 adults did not show a significant reduction in time to first severe exacerbation needing medical intervention (HR $0.96 ; 95 \%$ CI 0.85 to 1.07). These trials demonstrated a reduction in the mean total daily dose of

Combination formoterol and budesonide as maintenance and reliever therapy versus inhaled steroid maintenance for chronic asthma in $\mathrm{I}$ adults and children (Review)

Copyright (c) 2010 The Cochrane Collaboration. Published by John Wiley \& Sons, Ltd. 
inhaled corticosteroids with single inhaler therapy (mean reduction ranged from 107 to 267 micrograms/day, but the trial results were not combined due to heterogeneity). The full results from four further studies on 4,600 adults comparing single inhaler therapy with current best practice are awaited.

Three studies including 4,209 adults compared single inhaler therapy with higher dose budesonide maintenance and terbutaline for symptom relief. No significant reduction was found with single inhaler therapy in the risk of patients suffering an asthma exacerbation leading to hospitalisation (Peto OR 0.56; $95 \%$ CI 0.28 to 1.09), but fewer patients on single inhaler therapy needed a course of oral corticosteroids (OR 0.54; 95\% CI 0.45 to 0.64). These results translate into an eleven month number needed to treat of 14 ( $95 \%$ CI 12 to 18), to prevent one patient being treated with oral corticosteroids for an exacerbation. The run-in for these studies involved withdrawal of long-acting beta 2 -agonists, and patients were recruited who were symptomatic during run-in.

One study included children $(\mathrm{N}=224)$, in which single inhaler therapy was compared to higher dose budesonide. There was a significant reduction in participants who needed an increase in their inhaled steroids with single inhaler therapy, but there were only two hospitalisations for asthma and no separate data on courses of oral corticosteroids. Less inhaled and oral corticosteroids were used in the single inhaler therapy group and the annual height gain was also $1 \mathrm{~cm}$ greater in the single inhaler therapy group, [95\% CI 0.3 to $1.7 \mathrm{~cm}]$.

There was no significant difference found in fatal or non-fatal serious adverse events for any of the comparisons.

\section{Authors' conclusions}

Single inhaler therapy can reduce the risk of asthma exacerbations needing oral corticosteroids in comparison with fixed dose maintenance

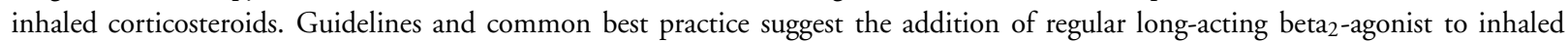
corticosteroids for uncontrolled asthma, and single inhaler therapy has not been demonstrated to significantly reduce exacerbations in comparison with current best practice, although results of five large trials are awaiting full publication. Single inhaler therapy is not currently licensed for children under 18 years of age in the United Kingdom.

\section{PLAIN LANGUAGE S UMMARY}

Combination of formoterol and budesonide as single inhaler therapy versus inhaled corticosteroid maintenance and a separate reliever inhaler, or current best practice

A single combination inhaler containing formoterol and budesonide has been advocated for regular maintenance of asthma, with the option to increase the dose if the asthma flares up. This is sometimes known as single inhaler therapy. Single inhaler therapy can reduce the risk of asthma exacerbations needing oral corticosteroids in comparison with fixed dose maintenance inhaled corticosteroids. The trials were in people with asthma who had their maintenance treatment reduced and became symptomatic. These results have not yet been replicated in trials comparing single inhaler therapy with current best practice, and the results of five large trials are awaiting publication. The place of this new approach to asthma management must remain somewhat uncertain until all the trials are fully reported.

\section{B A C K G R O U N D}

\section{Description of the condition}

There is currently no universally accepted definition of the term 'asthma'. This is in part due to an overlap of symptoms with other diseases such as chronic bronchitis, but is also due to the probable existence of more than one underlying pathophysiological process.
There are, for example, wide variations in the age of onset, symptoms, triggers, association with allergic disease and the type of inflammatory cell infiltrate seen in patients diagnosed with asthma. Patients will typically all have intermittent symptoms of cough, wheeze and/or breathlessness. Underlying these symptoms there is a process of variable, at least partially reversible airway obstruction, airway hyper responsiveness and (with the possible exception of solely exercise-induced asthma) chronic inflammation. 


\section{Description of the intervention}

People with persistent asthma can use preventer therapy (usually low dose inhaled corticosteroid (ICS)) to maintain symptom control, improve lung function and reduce emergency care requirement. However, when symptoms deteriorate reliever medication in the form of short-acting beta-agonists such as salbutamol or terbutaline, or formoterol (a fast-acting but longer lasting formulation) can be used on an 'as needed' basis (BTS/SIGN 2008). Since most exacerbations have an onset over several days (Tattersfield 1999) there is potential for the person with asthma to increase both budesonide and formoterol at an early stage in response to increased symptoms of asthma. The pharmacological properties of another long-acting beta 2 -agonist (LABA), salmeterol, result in slower onset of bronchodilation (Palmqvist 2001), and it is not licensed for use on an 'as needed' basis. The inclusion of ICS in a reliever inhaler for use during episodes of loss of control requires monitoring and assessment of overall ICS dose (BTS/SIGN 2008).

\section{How the intervention might work}

The combination of ICS and LABA in one inhaler is an effective way of delivering maintenance anti-inflammatory and bronchodilator therapy in chronic asthma (Greenstone 2005; Ni Chroinin 2005). The anti-inflammatory properties of the ICS and the bronchodilatory effect of the LABA play complementary roles in reducing inflammation in the airways and improving lung function with relief of symptoms related to bronchospasm (Adams 2008; Walters 2007). Both are recommended when low dose ICS alone is not sufficient to control asthma, which is at step three in British asthma guidelines (BTS/SIGN 2008). Concerns have been raised about the use of single inhaler LABA in chronic asthma, in particular where it is used without a regular ICS, in relation to the possible increased risk of severe adverse events and asthma-related death (Cates 2008; Cates 2008a; Walters 2007). The concomitant delivery of ICS and LABA avoids the inadvertent use of LABA without prescribed ICS treatment.

\section{Why it is important to do this review}

It is recognised that many patients who are prescribed ICS do not continue to take the treatment in clinical practice, and combination inhalers can increase ICS use both as maintenance Delea 2008 and single inhaler therapy Sovani 2008. Whilst the trials which have investigated doubling the dose of ICS early in exacerbations have been disappointing (FitzGerald 2004, Harrison 2004), there is the potential with single inhaler therapy for the patient to automatically increase both LABA and ICS when their asthma is worse and cut down again as their symptoms improve. This holds out the prospect of maintaining control of asthma and preventing exacerbations with lower overall exposure to ICS.
This review has identified and summarised clinical trials that compare single inhaler therapy for maintenance and relief with budesonide/formoterol against maintenance with ICS and a separate reliever therapy.

\section{O B J E C T I VES}

To assess the efficacy and safety of budesonide/formoterol in a single inhaler to be used for both maintenance and reliever therapy in asthma in comparison to maintenance with inhaled corticosteroids (alone or as part of current best practice) and any reliever therapy.

\section{METHODS}

\section{Criteria for considering studies for this review}

\section{Types of studies}

Randomised trials of parallel group design have been included in the review.

\section{Types of participants}

Adults and children with a diagnosis of chronic asthma. We accepted trialist-defined asthma, recording the definition of asthma used in the studies, and the entry criteria. We have summarised baseline severity of lung function and persistence of symptoms, and we collected data on pre-study maintenance therapies. We did not include studies conducted in an emergency department setting.

\section{Types of interventions}

Eligible treatment group intervention

This review included studies which have assessed the effects of using a combined inhaled steroid and long-acting beta 2 -agonist delivered through a single inhaler device for regular maintenance and the relief of asthma symptoms.

Eligible control group treatment

The control groups for the studies in this review consisted of a prescribed inhaled corticosteroid given as regular maintenance treatment with a separate reliever inhaler.

Study duration was at least 12 weeks.

We did not consider studies that compared different combination therapy inhalers (regular seretide versus regular symbicort has been reviewed elsewhere Lasserson 2008), or titration of maintenance 
dosing of combination therapy based on clinical signs and symptoms.

\section{Types of outcome measures}

\section{Primary outcomes}

- Patients with exacerbations requiring hospitalisation

- Patients with exacerbations requiring oral corticosteroids

- Serious adverse events (including mortality and lifethreatening events)

- Growth (in children)

\section{Secondary outcomes}

- Severe Exacerbations (composite outcome of hospitalisation/ER visit/oral steroid course)

- Diary card morning and evening peak expiratory flow (PEF)

- Clinic spirometry (FEV1)

- Number of rescue medication puffs required per day

- Symptoms/Symptom-free days

- Nocturnal awakenings

- Quality of life

\section{Search methods for identification of studies}

\section{Electronic searches}

Trials were identified using the Cochrane Airways Group Specialised Register of trials, which is derived from systematic searches of bibliographic databases including the Cochrane Central Register of Controlled Trials (CENTRAL), MEDLINE, EMBASE, CINAHL, AMED, and PsycINFO, and handsearching of respiratory journals and meeting abstracts. All records in the Specialised Register coded as' asthma' were searched using the following terms: ("single inhaler therapy" or SiT or SMART or relie* or "as need*" or as-need* or prn or flexible or titrat*) and ((combin* or symbicort or viani) or ((steroid* ${ }^{*}$ or corticosteroid* ${ }^{*}$ or ICS or budesonide or BUD or Pulmicort or beclomethasone or BDP or becotide) and ("beta*agonist" or "beta*adrenergic agonist" or formoterol or eformoterol or oxis or foradil)))

Date of last search was September 2008

\section{Searching other resources}

We contacted trialists and manufacturers in order to confirm data and to establish whether other unpublished or ongoing studies are available for assessment. We handsearched clinical trials web sites (www.clinicalstudyresults.org; www.clinicaltrials.gov; www.fda.gov) and the clinical trial web sites of combination inhaler manufacturers (www.ctr.gsk.co.uk; www.astrazenecaclinicaltrials.com).

\section{Data collection and analysis}

\section{Selection of studies}

Following electronic literature searches, two review authors (CC \& TL) independently selected articles on the basis of title and/or abstract for full text scrutiny. The authors agreed a list of articles which were retrieved, and subsequently assessed each study to determine whether it was a secondary publication of a primary study publication, and to determine whether the study met the entry criteria of the review.

\section{Data extraction and management}

We extracted information from each study for the following characteristics:

Design (description of randomisation, blinding, number of study centres and location, number of study withdrawals).

Participants $(\mathrm{N}$, mean age, age range of the study, gender ratio, baseline lung function, $\%$ on maintenance ICS or ICS/LABA combination \& average daily dose of steroid (BDP equivalent), entry criteria).

Intervention (type and dose of component ICS and LABA, control limb dosing schedule, intervention limb dose adjustment schedule, inhaler device, study duration \& run-in)

Outcomes (type of outcome analysis, outcomes analysed)

\section{Assessment of risk of bias in included studies}

We assessed trial bias protection in the following domains study quality according to whether studies meet the following pre-specified quality criteria (as met, unmet or unclear, Higgins 2008):

Sequence Generation

Allocation Concealment

Blinding of participants and investigators

Loss to follow-up

\section{Measures of treatment effect}

We extracted data for each of the outcomes considered by the review from the trial publication(s) or from correspondence with trialist or manufacturer. Exacerbations were the primary outcome for this review and were reported by subtype (hospitalisation and courses of oral steroids), rather than just as a composite outcome. Serious adverse events were considered separately as fatal and nonfatal events. 


\section{Unit of analysis issues}

We sought to obtain data from the trial sponsors that is reported with patients (rather than events) as the unit of analysis for the primary outcomes. Some patients may have suffered more than one exacerbation over the course of the studies and these events are not independent.

\section{Data synthesis}

Data were combined with RevMan 5.0, using a fixed effect mean difference (calculated as a weighted mean difference) for continuous data variables, and a fixed effect Odds Ratio for dichotomous variables. When zero cells were present for an outcome in any of the included studies the Peto Odds Ratio was used to combine the results as it does not require a continuity correction to be used. For the primary outcomes of exacerbations and serious adverse events, when a significant Odds Ratio was found, we calculated an NNT(benefit or harm) for the different levels of risk as represented by control group event rates over a specified time period using the pooled Odds Ratio and its confidence interval (Visual $\mathrm{Rx})$.

\section{Subgroup analysis and investigation of heterogeneity}

We pooled the data from adults and children in subgroups. Adult studies were considered as those which recruited participants from 18 years of age upwards. Adult and adolescent studies were considered as those which recruit participants from 12 years of age upwards. We considered participants in studies where the upper age limit was 12 years as children, and in studies where the upper age limit was 18 years as children and adolescents. Subgroup analysis were not possible in relation to asthma severity and degree of control of symptoms at baseline.

We measured statistical variation between combined studies by the $\mathrm{I}^{2}$ statistic (Higgins 2003). Where this exceeded $20 \%$ we will investigate the heterogeneity found, before deciding whether to combine the study results for the outcome.

\section{Sensitivity analysis}

Sensitivity analysis were planned on the basis of risk of bias in studies and methods of data analysis (fixed and random effects models).

\section{R E S U L T S}

\section{Description of studies}

See: Characteristics of included studies; Characteristics of excluded studies; Characteristics of ongoing studies.

\section{Results of the search}

The search was last carried out in September 2008 and included 198 citations. From these 51 were retrieved as full text articles, representing 24 unique studies. There were 10 studies (21 citations) included in the review and 14 studies (31 citations) that were excluded. Full details are given in the lists of Included studies and Excluded studies. Four further ongoing studies have been identified from handsearching clinicaltrials.gov (NCT00463866; NCT00628758; SYMPHONIE 2008; SPAIN 2008).

\section{Included studies}

All of the studies were on adults and adolescents with the exception of STAY - Children, in which the results from the 224 children included in the STAY study were reported in a separate paper by Bisgaard. This has therefore been regarded separately from STAY - Adults which reported the adult results from the STAY study.

The active treatment in most studies was budesonide/formoterol $160 / 4.5 \mathrm{mcg} 1$ Inhalation twice daily plus as-needed; this is the delivered dose and is the same as 200/6 mcg actuator dose described in some of the studies. In STEAM the maintenance treatment dose was the same but was given as two inhalations in the evening, and in STAY - Children the maintenance dose was budesonide/ formoterol $160 / 4.5 \mathrm{mcg}$ one inhalation in the evening.

Of the 10 adult studies, six studies compared single inhaler therapy (SiT) to current best practice; these were DE-SOLO; MONO; NCT00235911; SALTO; SOLO; STYLE. In these studies longacting beta 2 -agonists were allowed in the control arm, and many of the participants were already using long-acting beta 2 -agonists. The other four studies compare SiT to inhaled corticosteroids as maintenance and terbutaline as reliever (Scicchitano 2004; STAY - Adults; STEAM; Sovani 2008) and of these, the first three compared SiT to a higher dose of maintenance ICS. In these studies long-acting beta 2 -agonists were not allowed in the control arm, and were withdrawn from those patients previously taking them. Sovani 2008 compared to the same dose of ICS (as the main aim of this study was to assess compliance with ICS).

Two large completed studies have not yet been reported in a paper publication or on the sponsors web site of controlled trials. DESOLO aimed to randomise 1600 participants and STYLE 1000 participants. Both compared SiT to current best practice so for this comparison the results from 2600 patient remain unpublished out of 7000 patients who have completed trials, although for the purpose of this review AstraZeneca have provided data on file for the primary exacerbation outcomes from STYLE. There are also three studies of similar size that are nearing completion and will report on a further 3000 patients in comparison to current best practice (NCT00628758; SPAIN 2008; SYMPHONIE 2008).

The reported mean daily dose of inhaled corticosteroids previously used by participants was high in most of the studies: MONO (1035 mcg), SALTO (579 mcg), Scicchitano 2004 (746 mcg), SOLO (569 mcg), Sovani 2008 (590 mcg, but poor compliance

Combination formoterol and budesonide as maintenance and reliever therapy versus inhaled steroid maintenance for chronic asthma in 5 adults and children (Review)

Copyright ( 2010 The Cochrane Collaboration. Published by John Wiley \& Sons, Ltd. 
was an inclusion criterion), STAY - Adults (660 mcg), STAY Children $(315 \mathrm{mcg})$. The mean daily dose was lower in STEAM $(340 \mathrm{mcg})$ and is not available from the other three studies (DESOLO; NCT00235911; STYLE).

Inclusion criteria for DE-SOLO and SOLO were that the participants had to be stable on a combination of LABA and ICS or symptomatic on ICS maintenance, and MONO and SOLO reported that $74 \%$ to $75 \%$ of participants had previously taken LABA as well as ICS before the trial. Scicchitano 2004, STAY Adults, and STAY - Children included participants who had suffered a clinically important exacerbation in the previous year. In SALTO $27 \%$ of patients were reported to have mild persistent asthma, 37\% moderate persistent and 36\% severe persistent.

Some studies included a run-in of about two weeks in which LABA was withdrawn (Scicchitano 2004; STAY - All ages; STEAM) and in the case of STEAM, the maintenance dose of ICS was reduced from an average of $350 \mathrm{mcg} /$ day to $200 \mathrm{mcg} /$ day as well, and in order to secure "a symptomatic population that could respond differently to different treatments, patients were required to have at least 7 inhalations of as-needed medication during the last 10 days of the run-in period". SALTO and SOLO continued usual therapy over the two week run-in period, but details of any runin period are not currently available for the other studies.

The primary outcomes for the studies are shown in the
Characteristics of included studies. For the majority of studies this was time to first severe asthma exacerbation, which usually included hospitalisation, visits to an emergency department, a course of oral steroids and sometimes a 30\% drop in peak expiratory flow (PEF) such as in Scicchitano 2004; STEAM; STAY - Adults; STAY - Children. The definition of severe exacerbation was not specified in the current reports of DE-SOLO; MONO; NCT00235911; SALTO or STYLE. Sovani 2008 had a different design from the other studies and the primary outcome was the dose of inhaled corticosteroids.

All of the studies (apart from Sovani 2008 and possibly NCT00235911) are multi-centre studies, and no information has been found in relation to differences between centres or countries in any of these trials.

\section{Excluded studies}

The reasons for the exclusion of 14 studies is documented in the Characteristics of excluded studies.

\section{Risk of bias in included studies}

The overview of risk of bias is shown in Figure 1 
Figure I. Methodological quality summary: review authors' judgements about each methodological quality item for each included study.

\begin{tabular}{|c|c|c|c|c|}
\hline & 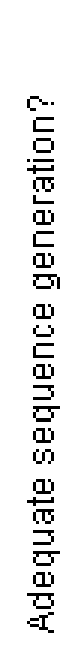 & 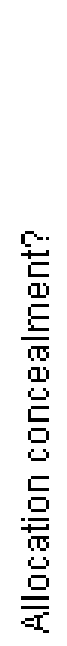 & 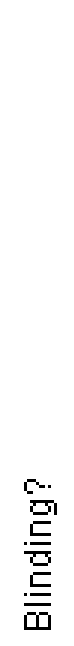 & 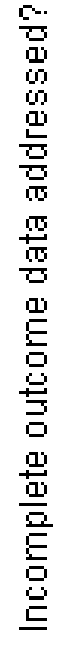 \\
\hline DE-SOLO & $?$ & $?$ & 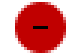 & $?$ \\
\hline MONO & $?$ & $?$ & 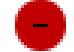 & + \\
\hline NCT00235911 & $?$ & $?$ & 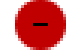 & $?$ \\
\hline SALTO & $?$ & $?$ & 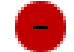 & $?$ \\
\hline Scicchitano 2004 & $?$ & $?$ & + & + \\
\hline SOLO & $?$ & $?$ & & + \\
\hline Sovani 2008 & + & + & & + \\
\hline STAY-Adults & + & $?$ & + & + \\
\hline STAY - All ages & + & $?$ & + & + \\
\hline STAY - Children & + & $?$ & + & + \\
\hline STEAM & $?$ & $?$ & + & + \\
\hline STYLE & $?$ & $?$ & & $?$ \\
\hline
\end{tabular}

Combination formoterol and budesonide as maintenance and reliever therapy versus inhaled steroid maintenance for chronic asthma in adults and children (Review)

Copyright ( 2010 The Cochrane Collaboration. Published by John Wiley \& Sons, Ltd. 


\section{Allocation}

Few details are reported in relation to sequence generation and allocation concealment.

\section{Blinding}

The studies comparing SiT with current best practice are unblinded, whilst those comparing with higher doses of inhaled corticosteroids are double-blind. Sovani 2008 was also unblinded as adherence was the primary outcome for this study.

\section{Incomplete outcome data}

The trial reports are clear about the proportion of randomised patients who were analysed in MONO; Scicchitano 2004; SOLO; STAY - All ages; Sovani 2008, and the dropout rate does not raise serious concerns.

\section{Selective reporting}

\section{Missing trial reports}

No reported results have been found for two large studies including around 2,600 participants (DE-SOLO; STYLE) out of around 7,000 patients comparing SiT to current best practice. Moreover two other studies for this comparison have only been reported in the form of a summary on the sponsors' trial register (MONO; SALTO).

\section{Missing details of outcome data}

Publication bias is a problem from the web reports which do not present sufficient information to use for many outcomes. Hospitalisations tend to be reported as part of a combined outcome of "severe" asthma exacerbation and are much rarer than courses of oral corticosteroids. Separate outcome data for patients with at least one asthma hospitalisation (or asthma SAE) and patients with at least one course of oral corticosteroids have been requested from the sponsor and have been obtained from MONO; Scicchitano 2004; STAY - Adults; STEAM; NCT00235911 and STYLE.

\section{Other potential sources of bias}

All of the included studies are sponsored or supported by AstraZeneca, the manufacturers of Symbicort.

\section{Effects of interventions}

The primary outcomes for this review are exacerbations leading to hospitalisation, exacerbations treated with a course of oral corticosteroids and serious adverse events. In general the trials have reported composite outcomes that include the above types of exacerbation combined with Emergency Room (ER) visits and sometimes a $30 \%$ drop in peak flow. We have obtained data on our primary outcomes from the trial sponsors. Most of the studies are also multi-site randomised controlled trials and have not reported data from any of the individual sites.

\section{Adults and Adolescents treated with Single inhaler Therapy compared to current best practice}

\section{Primary Outcomes}

\section{Exacerbations of asthma causing hospital admissions}

There were 19 hospitalisations from a total of 5,378 participants in the five trials providing data for this review (seven in the single inhaler therapy arms and 12 in the current best practice arms of MONO; NCT00235911; SALTO; SOLO and STYLE). SALTO reports 2 asthma exacerbations that require hospitalisation in the single inhaler therapy arm of the study, so this could represent 1 or 2 patients. In either case there is no significant difference in the pooled outcome: (Peto OR 0.59; 95\% CI 0.24 to 1.45 ) if this is two patients, (Peto OR 0.51; 95\% CI 0.20 to 1.29 ) if the two events were in the same patient, see Figure 2. 
Figure 2. Forest plot of comparison: I Adults and Adolescents treated with Single Inhaler Therapy versus Conventional Best Practice, outcome: I.I Patients with exacerbations causing hospitalisation.

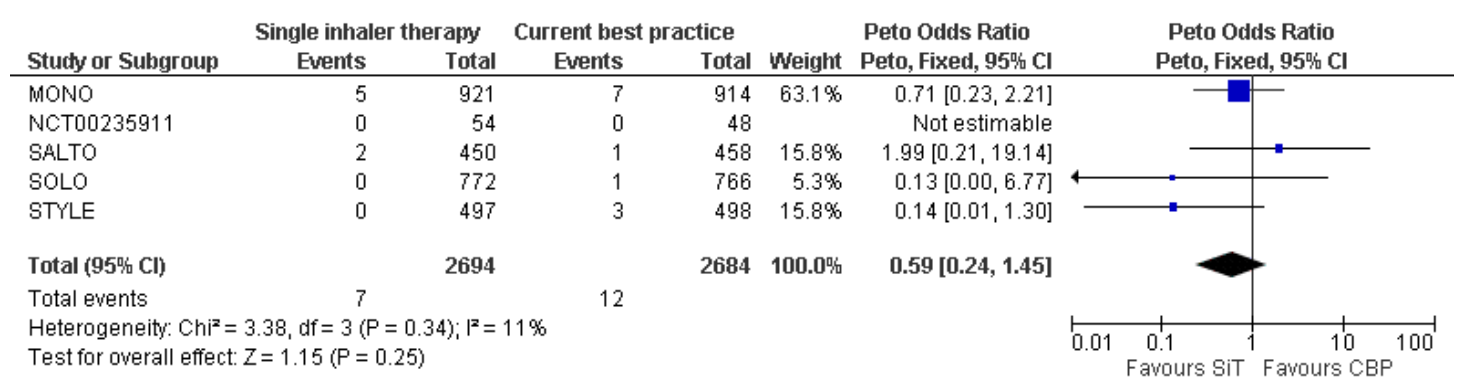

Results from a further 4,600 patients in DE-SOLO; NCT00628758; SPAIN 2008 and SYMPHONIE 2008 are awaited.

Exacerbations of asthma treated with oral corticosteroids

We have obtained data from four studies (MONO, NCT00235911, SOLO and STYLE, 4,470 participants) on patients with one or more courses of oral corticosteroids and the reduction with single inhaler therapy was not significant (OR 0.83; 95\% CI 0.66 to 1.03). There were 153 of 2244 in the SiT arm and 181 of 2226 in the current best practice arm who needed one or more courses of oral steroids, see Figure 3. No data has been made available from SALTO for this outcome, and again results are awaited from the four trials described above.

Figure 3. Forest plot of comparison: I Adults and Adolescents treated with Single Inhaler Therapy versus Conventional Best Practice, outcome: I.2 Patients with exacerbations treated with oral steroids.

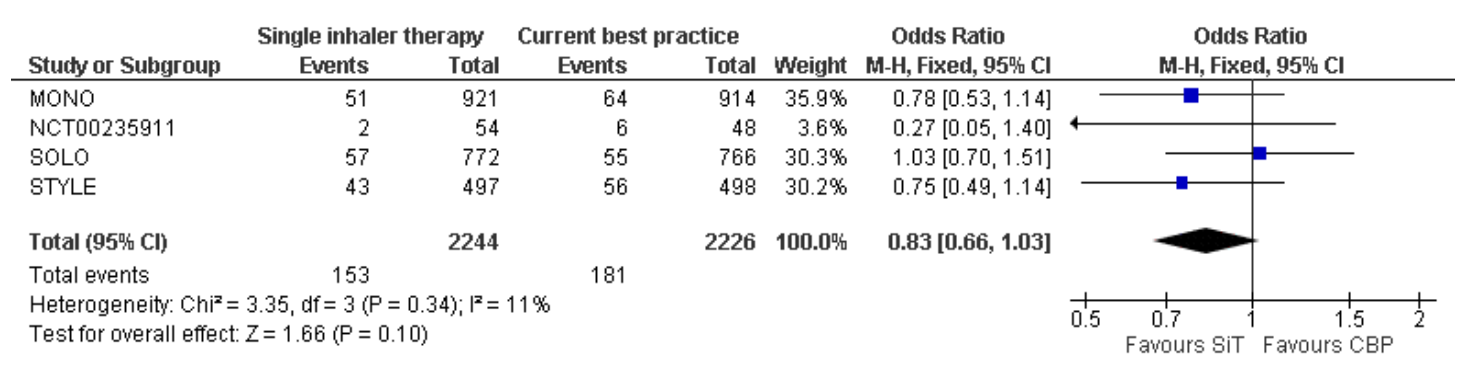

Serious adverse events

No significant difference was seen in either fatal or non-fatal serious adverse events from the combined results of MONO, SALTO and SOLO; for fatal events (Peto OR 1.95; 95\% CI 0.39 to 9.67) Analysis 1.3, and for non-fatal events (OR 1.02; 95\% CI 0.68 to 1.52) Analysis 1.4. However it should be pointed out that the overall number of events ( 6 fatal and 102 non-fatal SAEs) was too small to rule out the possibility of a clinically important increase or decrease. Results from the currently unpublished studies above may throw further light on these outcomes. Peto OR was used for the fatal SAE analysis in view of the presence of two trials with no deaths in the current best practice arms (MONO; SALTO).

Combination formoterol and budesonide as maintenance and reliever therapy versus inhaled steroid maintenance for chronic asthma in 9 adults and children (Review)

Copyright ( 2010 The Cochrane Collaboration. Published by John Wiley \& Sons, Ltd. 
A post-hoc observation was that each of these three studies found a higher number of discontinuations due to adverse events with single inhaler therapy, and these were significantly raised in MONO and SOLO, see Analysis 1.5. This finding requires further clarification from the currently unpublished studies, and was attributed by the investigators to patients in the SiT arm who changed from MDI to dry-powder inhaler devices.

\section{Secondary Outcomes}

\section{Severe exacerbations requiring medical intervention}

There were 2143 patients on SiT compared with 2138 patients on current best practice in MONO, SALTO and SOLO. There was no overall significant reduction in the time to a serious exacerbation, as defined by the investigators, (Hazard Ratio 0.96; 95\% CI 0.85 to 1.07$)$, Figure 4 .

Figure 4. Forest plot of comparison: I Adults and Adolescents treated with Single Inhaler Therapy versus Conventional Best Practice, outcome: I.6 Patients with "severe" exacerbation (time to event).

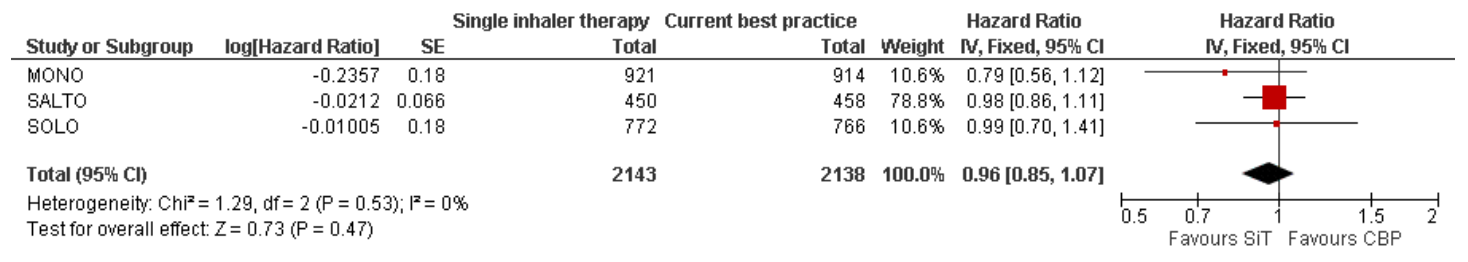

\section{Change in morning Peak Expiratory Flow}

The change in morning PEF (\% predicted) in SOLO was $1.00 \%$ [95\% CI -0.96 to 2.96] which was in favour of SiT, but neither clinically nor statistically significant (Analysis 1.7). Data were not available for this outcome from MONO and SALTO.

\section{Rescue Medication use}

There was a difference of $-0.16[-0.27,-0.05]$ puffs per day of rescue medication use in the SiT arm of SOLO compared to current best practice, Analysis 1.8 .

\section{Quality of Life (Change in ACQ score)}

The two studies reporting this outcome had heterogeneous findings (Analysis 1.9). SALTO demonstrated an improvement in the ACQ score in favour of SiT, whilst in SOLO the direction of effect favoured current best practice. The results have not been combined in view of the heterogeneity $\left(\mathrm{I}^{2}=84 \%\right)$ and quality of life results are awaited from the other studies that have not yet been reported.

\section{Steroid load}

All three published studies demonstrated a significantly lower intake of inhaled steroids in the SiT arms in comparison with current best practice but again heterogeneity was high $\left(\mathrm{I}^{2}=91 \%\right)$ and the results were therefore not combined. It is expected that the size of the reduction in ICS dose will reflect the trial design for each study, giving rise to the heterogeneity, and in the mean differences ranged from $107 \mathrm{mcg} /$ day in SALTO to $267 \mathrm{mcg} /$ day in SOLO (Analysis 1.10).

\section{Adults and Adolescents treated with Single inhaler Therapy compared to maintenance Inhaled Corticosteroids with separate reliever inhaler}

\section{Primary Outcomes}

\section{Exacerbations of asthma causing hospital admissions}

Scicchitano 2004, STAY - Adults and STEAM contributed 4,209 participants to this outcome, and overall there were fewer admissions on SiT in comparison to ICS, but this was not statistically significant. The number of admitted patients was small (12 in total on SiT and 22 on ICS) and the pooled result is (Peto OR 0.56; 95\% CI 0.28 to 1.09 ), as shown in Figure 5. 
Figure 5. Forest plot of comparison: 2 Adults and Adolescents treated with Single Inhaler Therapy versus higher fixed dose ICS, outcome: 2.I Patients with exacerbations causing hospitalisation.

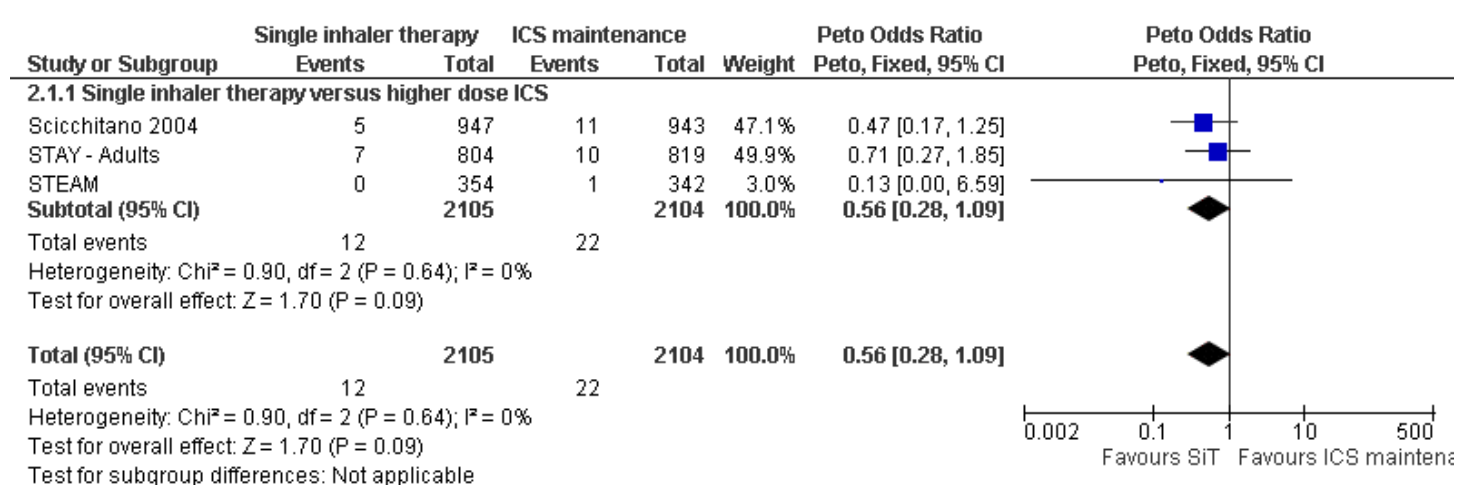

The data used for Scicchitano 2004, STEAM were on file from AstraZeneca, and were reported as patients with at least one asthmaaggravated serious adverse event that required hospitalisation. The composite outcome of hospitalisation or ED visits was dominated by participants attending ED and was therefore not used for this outcome. In total 17 patients were admitted to hospital in comparison to 38 seen in ED from these two studies. Peto OR was chosen for this meta-analysis as this method does not require a continuity correction for zero cells. Sensitivity analysis using Mantel-Haenszel OR gave very similar results (OR 0.56; 95\% CI 0.28 to 1.11 )

Exacerbations of asthma treated with oral corticosteroids
Scicchitano 2004, Sovani 2008, STAY - Adults and STEAM contribute data on this outcome from 4,280 participants; unpublished data on file from AstraZeneca has been obtained from Scicchitano 2004 and STAY - Adults. The STAY - Adults paper reported descriptive statistics only of courses of oral steroids per year, and in adults this was 0.19 on SiT and 0.38 on budesonide. The pooled result showed a significant reduction in the number of patients requiring a course of steroids (OR 0.54; $95 \%$ CI 0.45 to 0.64 ) and with a total of 228 patients with an event on SiT and 387 on budesonide, Figure 6 . This translates into a number needed to treat to prevent one patient needing oral corticosteroids over an eleven month period of 14 (95\% CI 12 to 18), see Figure 7.

Figure 6. Forest plot of comparison: 2 Adults and Adolescents treated with Single Inhaler Therapy versus higher fixed dose ICS, outcome: 2.2 Patients with exacerbations treated with oral steroids.

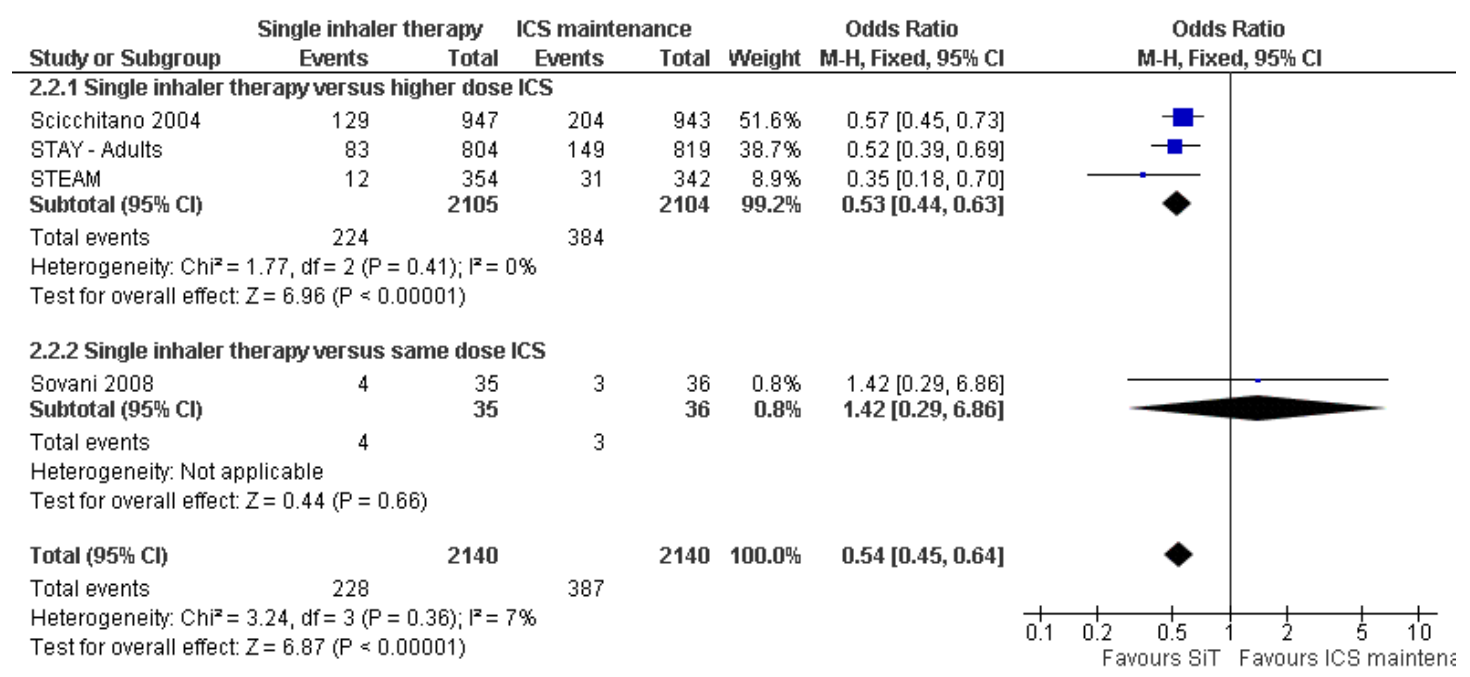

Combination formoterol and budesonide as maintenance and reliever therapy versus inhaled steroid maintenance for chronic asthma in $\quad$ I adults and children (Review) 
Figure 7. In the control group 18 people out of 100 had exacerbation treated with oral steroids over I I months, compared to II $(95 \% \mathrm{Cl} 9$ to I2) out of 100 for the active treatment group. NNT(B) $=14,(95 \% \mathrm{Cl} I 2$ to (8).

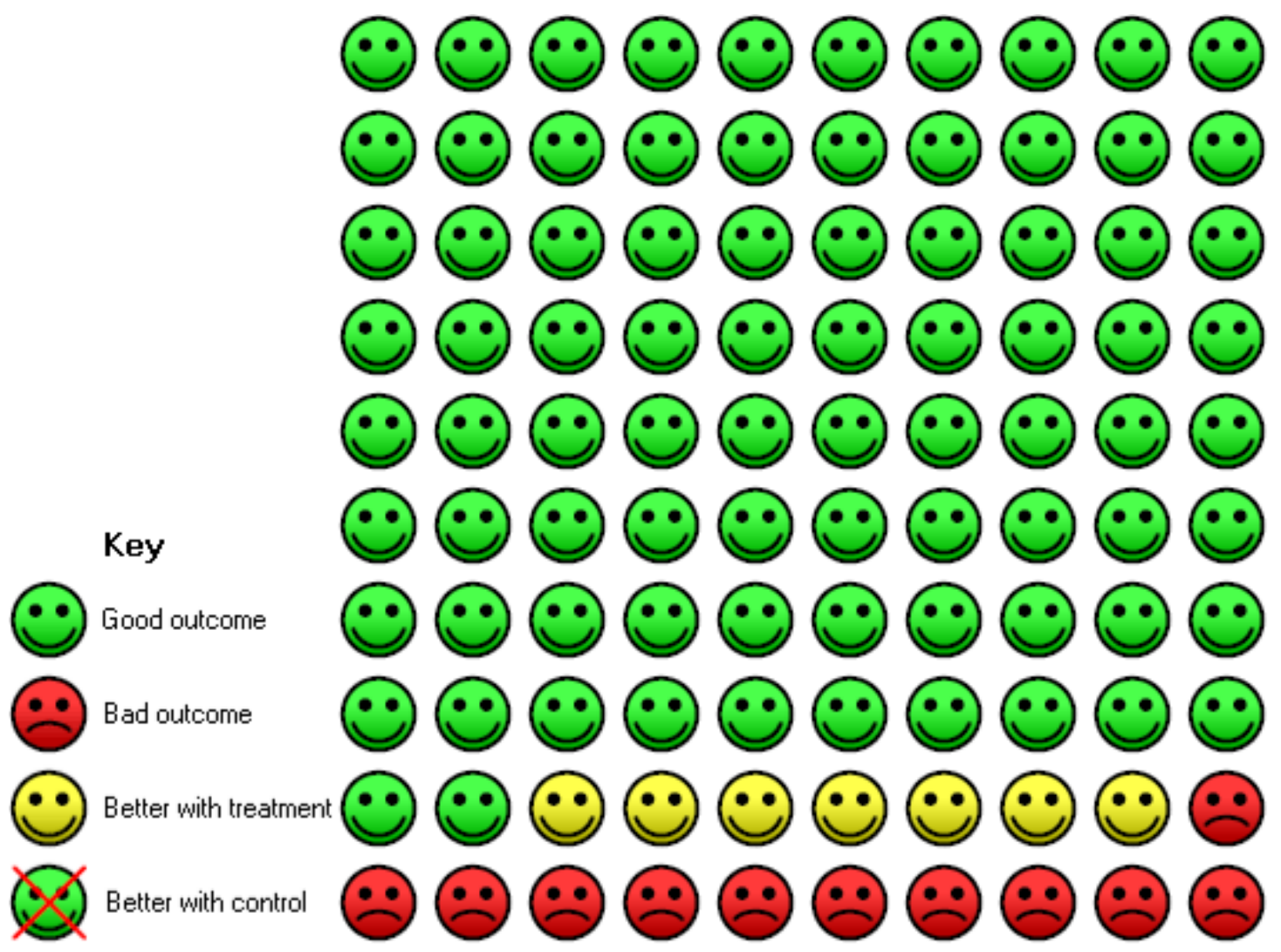

Sensitivity analysis using random effects Mantel-Haenszel OR gave a marginally wider confidence interval (OR 0.54; $95 \% \mathrm{CI}$ 0.44 to 0.65 ). The design of Sovani 2008 was different from the other studies in that adherence with inhaled corticosteroids was the primary concern of the study.

\section{Serious adverse events}

No significant difference was seen in either fatal or non-fatal serious adverse events from the combined results of Scicchitano 2004, STAY - Adults and STEAM; for fatal events (Peto OR 0.37; 95\% CI 0.05 to 2.62), and for non fatal events (OR 0.97; 95\% CI 0.73 to 1.29). Again the number of events is small ( 4 fatal and 201 non-fatal) so the confidence interval includes the possibility of important increase or decrease with SiT.

In contrast to the studies comparing $\mathrm{SiT}$ to current best practice, a post hoc inspection of discontinuations due to adverse events in Scicchitano 2004 and STEAM found a significant decrease in favour of SiT.

\section{Secondary Outcomes}

\section{Severe exacerbations requiring medical intervention}

There were 1301 on SiT compared with 1285 on twice the dose of budesonide in Scicchitano 2004 and STEAM. There was a significant reduction in the time to a serious exacerbation, as defined by the investigators, (Hazard Ratio 0.59 ; $95 \%$ CI 0.49 to 0.70 ), Figure 8.

Combination formoterol and budesonide as maintenance and reliever therapy versus inhaled steroid maintenance for chronic asthma in 12 adults and children (Review) 
Figure 8. Forest plot of comparison: 2 Adults and Adolescents treated with Single Inhaler Therapy versus higher fixed dose ICS, outcome: 2.6 Patients with "severe" exacerbation (time to event).

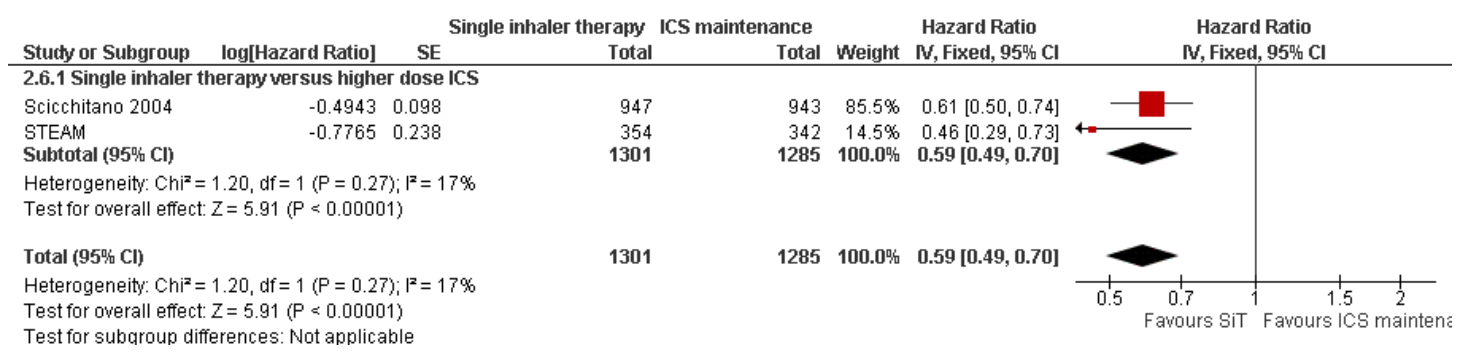

Change in morning Peak Expiratory Flow and clinic FEV 1

There was a significant increase in PEF in the SiT arms of Scicchitano 2004, STAY - Adults and STEAM compared to higher doses of budesonide (MD 22.29 L/min; 95\% CI 17.62 to 26.95), Analysis 2.7. Similarly an increase of FEV1 in favour of SiT was found (MD 0.10 L; 95\% CI 0.07 to 0.13), Analysis 2.8.

\section{Rescue Medication use}

There was a reduction in rescue medication use in favour of SiT (MD -0.37 puffs per day; $95 \%$ CI -0.49 to -0.25 ), Analysis 2.9.

\section{Quality of Life (Change in ACQ score)}

The only study reporting ACQ scores was Sovani 2008 and no significant difference was found, Analysis 2.10.

\section{Steroid load}

Scicchitano 2004 reported a mean daily budesonide dose of 466 $\mathrm{mcg} /$ day in the SiT arm in comparison with $640 \mathrm{mcg} /$ day in the ICS arm, and 1776 days on oral corticosteroids in comparison with 3177 days. STAY - Adults does not report the mean daily doses of budesonide, but does report 0.19 courses of oral corticosteroids per year for SiT compared to 0.38 per year for higher dose budesonide. STEAM reports a mean daily budesonide dose of $240 \mathrm{mcg} /$ day with SiT and $320 \mathrm{mcg} /$ day in the higher dose ICS arm. However the paper also reports five patients on SiT who had a mean daily dose of $>640 \mathrm{mcg} /$ day on SiT. Again STEAM reported a total of 114 days of oral corticosteroids with SiT and 498 days with higher dose budesonide.

Sovani 2008 was designed to investigate whether single inhaler therapy could overcome poor adherence with inhaled corticosteroids, and found an increase in mean daily use of budesonide (448 versus $252 \mathrm{mcg} /$ day, mean difference $196 \mathrm{mcg} /$ day, 95\% CI 113 to $279 \mathrm{mcg} /$ day).

\section{Children treated with Single inhaler Therapy compared to higher doses of Inhaled Corticosteroids}

\section{Primary Outcomes}

\section{Exacerbations of asthma causing hospital admissions}

It has been possible to obtain clarification from the sponsors in relation to the hospitalisations for children in each treatment arm of STAY - Children. Hospitalisations related to asthma are reported as none on SiT and one with ICS (this does not quite match the asthma SAE data, as one child was already in hospital with laryngitis, and the stay was prolonged due to an asthma exacerbation) Analysis 3.1. These events are too few to draw any conclusions.

\section{Exacerbations of asthma treated with oral corticosteroids}

The only information in the report of STAY - Children in relation to oral corticosteroid use relates to the total number of treatment days in each group (32 days for SiT and 141 days for ICS). This is not suitable for use in meta-analysis as there is no report of how many children were treated with oral corticosteroids in each group. The sponsors have not been able to provide this data.

\section{Serious Adverse Events}

There were no fatal serious adverse events in STAY - Children and non-fatal events occurred in 2 out of 118 children on SiT compared to 5 out of 106 on ICS (a non-significant reduction) Analysis 3.3.

\section{Annual Height gain}

The mean increase in height over one year in the SiT group was $5.3 \mathrm{~cm}$ (range 1 to $14 \mathrm{cms}$ ) and in the ICS group the mean increase was $4.3 \mathrm{~cm}$ (range -2 to $15 \mathrm{~cm}$ ). The fact that some children appear to have become shorter raises concerns about the accuracy of the

Combination formoterol and budesonide as maintenance and reliever therapy versus inhaled steroid maintenance for chronic asthma in 13 adults and children (Review) 
measurements carried out in some of the 246 centres (as the paper reports that local procedures were used to measure height), but the average advantage of $1 \mathrm{~cm}$ for SiT was statistically significant (95\% CI 0.3 to $1.7 \mathrm{cms}$ ) Analysis 3.4.

\section{Secondary Outcomes}

\section{Severe exacerbations requiring medical intervention}

There were nine patients on SiT with exacerbations requiring medical intervention (hospitalisation or ER visit or course of oral steroids) which was significantly less than the 21 patients given ICS, (OR from this single study $0.33[0.15,0.77])$.

\section{Change in morning Peak Expiratory Flow}

The children given SiT therapy in STAY - Children had an average increase in morning PEF of 12 Litres/min [95\% CI: 4.55 to 19.45] in comparison with those given ICS.

\section{Clinic Spirometry $\left(\mathrm{FEV}_{1}\right)$}

There was no significant difference in $\mathrm{FEV}_{1}$ between the SiT and ICS groups in STAY - Children (0.10 Litres [95\% CI: -0.14, $0.34])$.

\section{Nocturnal Awakenings}

There were, on average, two less nocturnal awakenings per night for children on SiT than those on ICS in STAY - Children (-2.00 $[-3.33,-0.67])$.

\section{Steroid load}

The mean daily dose of budesonide in children given SiT in STAY - Children was $126 \mathrm{mcg} /$ day in comparison to $320 \mathrm{mcg} /$ day in the group randomised to fixed dose budesonide. There were also less days spent on oral corticosteroids in the SiT group (32 v 141 days). Two of 51 children given SiT had abnormally low cortisol levels in comparison with three of 41 on ICS, a non significant reduction $(\mathrm{OR}=0.52[0.08,3.25])$.

\section{DISCUSSION}

\section{Summary of main results}

In comparison to common best practice, which allowed the use of long-acting beta 2 -agonists in the control arms, four large studies (MONO; SALTO, SOLO and STYLE) on 5,378 patients have not demonstrated significant advantages for SiT in exacerbations needing medical intervention. There was no significant difference found in fatal or non-fatal serious adverse events. All three published studies found a reduction in ICS dose when using SiT. The full results from further studies, which aimed to recruit a further 5600 patients, are awaited (DE-SOLO; STYLE; SPAIN 2008; SYMPHONIE 2008; NCT00628758).

In contrast, in comparison to higher maintenance doses of budesonide (with no long-acting beta 2 -agonists in the control arms), four studies (Scicchitano 2004, STAY - Adults, STEAM and Sovani 2008) on 4,280 patients demonstrated significant reductions in patients with an exacerbation needing oral steroids (OR 0.54; $95 \%$ CI 0.45 to 0.64 ) but not on exacerbations leading to hospitalisation (Peto OR 0.56 ; 95\% CI 0.28 to 1.09 ). There was no significant difference found in fatal or non-fatal serious adverse events. The studies found a reduction in ICS dose when using SiT. Sovani 2008 demonstrated increased adherence with inhaled corticosteroids using single inhaler therapy in comparison to maintenance budesonide at the same dose.

Only one study included 224 children (STAY - Children) and compared SiT to four times the dose of regular budesonide. There was a significant reduction in exacerbations needing increase in inhaled steroid treatment and/or additional treatment in this study, but only two hospitalised patients and no separate data on courses of oral corticosteroids. There was no significant difference found in fatal or non-fatal serious adverse events. Less inhaled and oral corticosteroids were used in the SiT group and the annual height gain was also greater in the SiT group.

\section{Overall completeness and applicability of evidence}

All the included studies have been sponsored by AstraZeneca, and large numbers of patients that have been studied or are in ongoing trials are still unreported. For this reason we would regard the current evidence as provisional until further data becomes available. This is especially relevant to trials comparing $\mathrm{SiT}$ with current best practice, and the results in children, in whom the use of longacting beta2-agonists is more contentious (Bisgaard 2003).

It is possible that the difference between the results in trials comparing $\mathrm{SiT}$ with current best practice as opposed to higher doses of ICS alone as a comparison arm could relate to the design of the trials. Many of the patients in the control arm of the current best practice trials were probably taking long-acting beta 2 -agonists (as previous long-acting beta2-agonists was around $75 \%$ in $\mathrm{MONO}$ and SOLO), whereas none of the control arm patients in the higher dose maintenance ICS were taking long-acting beta 2 agonists (as they were withdrawn from those patients previously using them).

The inclusion of patients who were symptomatic during run-in periods in which LABA was withdrawn may favour SiT, as formoterol would be expected to control symptoms more quickly than inhaled corticosteroids in Scicchitano 2004, STEAM and 
STAY - All ages. There is some suggestion that this may have occurred from the plots of individual patient exacerbations that show steeper gradients initially for the budesonide arms of these trials but similar gradients in the two groups towards the end of the study period.

This implies that the current evidence comparing SiT to fixed doses of ICS can be applied directly only to patients who become symptomatic when maintenance treatment with ICS (with or without LABA) is reduced. How these results should be extrapolated to other groups of patients remains a matter for debate.

\section{Quality of the evidence}

Despite sparse information on sequence generation and allocation concealment, we concluded that as all the studies were regulatory studies, the risk of bias in these domains is low. The studies comparing SiT with current best practice were not blinded, whilst those that compared SiT to fixed doses of ICS were blinded. Although bias could have been introduced in the former, the treatment effects in comparison with current best practice are generally smaller.

\section{Agreements and disagreements with other studies or reviews}

We agree with the reservations voiced by Lipworth 2008 in his response in the BMJ to the review by Barnes 2007. The run-in for the trials comparing SiT with fixed dose inhaled corticosteroids was designed to select patients who became symptomatic when their maintenance treatment was reduced or when long-acting beta 2 agonists were withdrawn. This feature of the trial design may contribute to the improvement in time to first asthma exacerbation on SiT, because the onset of action of higher dose inhaled corticosteroids would be expected to be slower, and more patients may therefore have suffered an early exacerbation in the higher dose inhaled corticosteroid arm of the trials.

\section{A U THORS' CONCLUSIONS}

\section{Implications for practice}

Single inhaler therapy can reduce the risk of asthma exacerbations needing oral corticosteroids in comparison with fixed dose maintenance inhaled corticosteroids. Guidelines and common best practice suggest the addition of regular long-acting beta 2 -agonist to inhaled corticosteroids for uncontrolled asthma, and single inhaler therapy has not been demonstrated to significantly reduce exacerbations in comparison with current best practice, although results of five large trials are awaiting publication. Single inhaler therapy is not currently licensed for children under 18 years of age in the United Kingdom.

\section{Implications for research}

The majority of trials comparing single inhaler therapy to current best practice have not been fully published, and we have chosen not to suggest implications for further research on adults until these results are known. There is very little current evidence with respect to children.

\section{ACKNOWLEDGEMENTS}

We thank Susan Hansen and Elizabeth Arnold of the Cochrane Airways Group for their assistance in searching for trials and obtaining the abstracts and full reports, and John White for editorial help. We also thank Robyn Von Maltzahn and Joe Gray from AstraZeneca for help in obtaining data from MONO, Scicchitano 2004, STEAM, STAY - All ages and STYLE. Thanks also to Helen Reddel for pointing out the typological errors that have been corrected in this amendment.

\section{REFERENCES}

\section{References to studies included in this review}

\section{DE-SOLO \{unpublished data only\}}

* AstraZeneca (D5890L00011). DESOLO - SiT Peri-

Launch: a comparison of symbicort single inhaler therapy and conventional best practice for the treatment of persistent asthma in adults. clinicaltrials.gov 2005:http:// www.clinicaltrials.gov/ct/show/NCT00252863 [Accessed 3rd September 2008]

MONO \{published data only\}

AstraZeneca (D5890L00008). MONO: Symbicort single inhaler therapy and conventional best standard treatment for the treatment of persistent asthma in adolescents and adults. clinicaltrials.gov 2006:http://www.clinicaltrials.gov/ ct/show/NCT00242411 [Accessed 12/04/2006].

NCT00235911 \{unpublished data only\} AstraZeneca (BN-00S-0011). Symbicort single inhaler therapy for asthma in a general practice setting. www.clinicaltrials.gov 2005:http://www.clinicaltrials.gov/ ct/show/NCT00235911 [Accessed 22/02/2008].

SALTO \{published data only\}

AstraZeneca (D5890L00009). SALTO - symbicort single inhaler therapy use in adolescent adults and adults with persistent asthma. www.clinicaltrials.gov 2006:http:// 
www.clinicaltrials.gov/ct/show/NCT00290264 [Accessed 22/02/2008]

Scicchitano 2004 \{published data only\}

Scicchitano R, Aalbers R, Ukena D, Manjra A, Fouquert L, Centann S, et al.Efficacy and safety of budesonide/ formoterol single inhaler therapy versus a higher dose of budesonide in moderate to severe asthma. Current Medical Research \& Opinion 2004;20(9):1403-18.

\section{SOLO \{published data only\}}

Sears MR, Boulet L-P, Laviolette M, FitzGerald J Mark,

Bai TR, et al.Budesonide/formoterol maintenance and reliever therapy: impact on airway inflammation in asthma. European Respiratory Journal 2008:Epub: doi: 10.1183/ 09031936.00104007.

Sears R, Boulet L-P, Laviolette M, FitzGerald JM, Bai $\mathrm{R}$, SmiljanicGeorijev N, et al.Budesonide/formoterol maintenance and reliever therapy for asthma compared to conventional best practice a randomised real life study. European Respiratory Journal 2006;28(Suppl 50):613s.

Sovani 2008 \{published data only\} Sovani MP, Whale CI, Oborne J, Cooper S, Mortimer K, Ekström T, et al.Poor adherence with inhaled corticosteroids for asthma: can using a single inhaler containing budesonide and formoterol help?. British Journal of General Practice 2008;58(546):37-43

\section{STAY - Adults \{published and unpublished data\}}

Bateman ED, Palmqvist M, Juniper EF, Zhu Y, Ekstrom T. Single inhaler therapy with budesonide/formoterol has superior efficacy to fixed-dose budesonide/formoterol or a higher dose of budesonide alone. American Thoracic Society 100th International Conference, May 21-26, 2004 , Orlando. 2004.

Bruce SA, Scherer YK. Maintenance and symptom relief with budesonide plus formoterol reduced severe asthma exacerbations. Evidence-Based Nursing 2005;8(3):78. Jönsson BG, Berggren FE, Svensson K, O’Byrne PM. Budesonide and formoterol in mild persistent asthma compared with doubling the dose of budesonide - a costeffectiveness analysis. European Respiratory Journal. 2001; Vol. 18, issue Suppl 33:517s.

Jönsson BG, Berggren FE, Svensson K, O’Byrne PM. Economic results of adding formoterol to budesonide in mild persistent asthma. European Respiratory Journal 2001; Vol. 18, issue Suppl 33:331s.

O'Byrne PM. Acute asthma intervention: Insights from the STAY study. Journal of Allergy \& Clinical Immunology 2007; 119(6):1332-6.

O’Byrne PM, Bisgaard H, Godard PP, Pistolesi M, Palmqvist M, Zhu Y, Ekstrom T, Bateman ED. Budesonide/ formoterol combination therapy as both maintenance and reliever medication in asthma. American Journal of Respiratory \& Critical Care Medicine 2005;171(2):129-36. O’Byrne PM, Godard P, Pistolesi M, Ekstrom T. Single inhaler therapy with budesonide/formoterol improves asthma control compared with fixed dosing with budesonide/formoterol or a higher dose of budesonide alone
[Abstract]. American Thoracic Society 100th International Conference, May 21-26, 2004, Orlando. 2004:Poster J93. SD-039-673. Efficacy and safety of budesonide/formoterol (Symbicort) Turbuhaler ${ }^{\circledR}$ as Single Therapy in patients with mild-moderate asthma. Comparison with Symbicort Turbuhaler and Pulmicort ${ }^{\circledR}$ Turbuhaler as maintenance therapy, both complemented with Bricanyl@ Turbuhaler (STAY). http://www.astrazenecaclinicaltrials.com 2006.

\section{STAY - All ages \{published and unpublished data\}}

O’Byrne PM, Bisgaard H, Godard PP, Pistolesi M, Palmqvist M, Zhu Y, Ekstrom T, Bateman ED. Budesonide/ formoterol combination therapy as both maintenance and reliever medication in asthma. American Journal of Respiratory \& Critical Care Medicine 2005;171(2):129-36.

STAY - Children \{published and unpublished data\}

Bisgaard H, Hultquist C. Budesonide/formoterol for maintenance and as needed - a new approach to asthma management in children [Abstract]. European Respiratory Journal 2005;26(Suppl 49):Abstract No. 1060.

* Bisgaard H, Le Roux P, Bjamer D, Dymek A, Vermeulen JH, Hultquist C. Budesonide/formoterol maintenance plus reliever therapy - a new strategy in pediatric asthma. Chest 2006;130(6): 1733-43.

O'Byrne PM. Acute asthma intervention: Insights from the STAY study. Journal of Allergy \& Clinical Immunology 2007; 119(6):1332-6.

O’Byrne PM, Bisgaard H, Godard PP, Pistolesi M, Palmqvist M, Zhu Y, Ekstrom T, Bateman ED. Budesonide/ formoterol combination therapy as both maintenance and reliever medication in asthma. American Journal of Respiratory \& Critical Care Medicine 2005;171(2):129-36. SD-039-673. Efficacy and safety of budesonide/formoterol (Symbicort) Turbuhaler ${ }^{\circledR}$ as Single Therapy in patients with mild-moderate asthma. Comparison with Symbicort Turbuhaler and Pulmicort ${ }^{\circledR}$ Turbuhaler as maintenance therapy, both complemented with Bricanyl ${ }^{\circledR}$ Turbuhaler (STAY). http://www.astrazenecaclinicaltrials.com 2006.

\section{STEAM \{published data only\}}

Astrazenca (SD-039-0667). Efficacy and Safety of Symbicort ${ }^{\circledR}$ Turbuhaler ${ }^{\circledR}$ as Single Therapy in Patients with Mild to Moderate Asthma - STEAM (SD-0390667). Astrazeneca Clinical Trials Register 2005:http:// www.astrazenecaclinicaltrials.com (accessed 20th February 2008).

Rabe KF, Pizzichini E, Stallberg B, Romero S, Balanzat AM, Atienza $\mathrm{T}$, et al.Budisonide/formoterol in a single inhaler for maintenance and relief in mild-to-moderate asthma: A randomized, double-blind trial. Chest 2006;129:245-56.

\section{STYLE \{published data only\}}

* AstraZeneca (D5890L00014). STYLE - symbicort single inhaler therapy vs. conventional therapy in treatment of persistent asthma. www.clinicaltrials.gov 2005:http:// www.clinicaltrials.gov/ct/show/NCT00252824 [Accessed 22/02/2008]

\section{References to studies excluded from this review}




\section{Balanzat 2004 \{published data only\}}

Balanzat A, Centanni S, Palmqvist M, Rabe K. Budesonide/ formoterol single inhaler therapy reduces over reliance on rapid acting reliever medication [Abstract]. European Respiratory Journal 2004;24(Suppl 48):344s.

Bousquet 2007 \{unpublished data only\}

Astrazeneca (D5890C00002). Efficacy and safety of Symbicort ${ }^{\circledR}$ Turbuhaler ${ }^{\circledR} 160 / 4.5 \mathrm{mcg} /$ inhalation, two inhalations twice daily plus as-needed compared with Seretide ${ }^{\mathrm{TM}}$ Diskus $^{\mathrm{TM}} 50 / 500 \mathrm{mcg} /$ inhalation, one inhalation twice daily plus terbutaline Turbuhaler $0.4 \mathrm{mg} /$ inhalation as-needed - a 6-month, randomised, doubleblind, parallel-group, active controlled, multinational phase IIIB study in adult and adolescent patients with persistent asthma. AstraZeneca Clinical Trials Register 2006, issue www.astrazenecaclinicaltrials.com (accessed 21/02/2008). Bousquet J, Boulet L-P, Peters MJ, Magnussen H, Quiralte J, Martinez-Aguilar NE, et al.Budesonide/formoterol for maintenance and relief in uncontrolled asthma vs. highdose salmeterol/fluticasone. Respiratory Medicine 2007;101 (12):2437-46.

\section{COMPASS \{published and unpublished data\}}

AstraZeneca. SYM/050/DEC2007. Data on File. Bleecker ER, Postma DS, Lawrance R, Meyers DA, Ambrose H, Goldman M. Effect of polymorphisms in the beta2-adrenergic receptor gene (ADRB2) on response to long-acting beta2-agonist (LABA) therapy. Journal Allergy and Clinical Immunology 2007;119(2):523

Buhl R, Vogelmeier C. Budesonide/formoterol maintenance and reliever therapy: a new treatment approach for adult patients with asthma. Current Medical Research and Opinion 2007;23(8):1867-78.

Kuna P, Peters MJ, Buhl R. Budesonide/formoterol as maintenance and reliever therapy reduces asthma exacerbations a higher maintenance dose of budesonide/ versus formoterol or salmeterol/fluticasone. European Respiratory Journal 2006;28(Suppl 50):205s.

Kuna P, Peters MJ, Manjra AI, Jorup C, Naya IP, MartinezJimenez NE, et al.Effect of budesonide/formoterol maintenance and reliever therapy on asthma exacerbations. International Journal of Clinical Practice 2007;61(5): 725-36.

Price D, Wiren A, Kuna P. Budesonide/formoterol (B/F) as maintenance and relief for asthma improves efficacy and is cost saving versus higher maintenance dose of $\mathrm{B} / \mathrm{F}$ or salmeterol/fluticasone (S/F) [Abstract]. European Respiratory Journal 2006;28(Suupl 50):214s.

Price D, Wiren A, Kuna P. Cost-effectiveness of budesonide/ formoterol for maintenance and reliever asthma therapy. Allergy 2007;62(10):1189-98.

\section{COSMOS \{published data only\}}

Buhl R, Vogelmeier C. Budesonide/formoterol maintenance and reliever therapy: a new treatment approach for adult patients with asthma. Current Medical Research and Opinion 2007;23(8):1867-78

D'Urzo A, Vogeimeier C, Jaspal M, Merino JM, Boulet S. Symbicort (budesonide/formoterol) for both maintenance and relief reduces the exacerbation burden compared with titration of seretide (salmeterol/fluticasone) in patients with asthma, a real life stud. American Thoracic Society International Conference; May 20-25; San Diego, California. 2005:Poster G24.

Johansson G, Andreasson EB, Larsson PE, Vogelmeier CF. Cost effectiveness of budesonide/formoterol for maintenance and reliever therapy versus salmeterol/ fluticasone plus salbutamol in the treatment of asthma. Pharmacoeconomics 2006;24(7):695-708.

Vogelmeier C, D'Urzo A. Maintenance plus as-needed budesonide/formoterol vs salmeterol/fluticasone in a reallife setting. European Respiratory Journal 2005;26(Suppl 49):Abstract No. 2770.

Vogelmeier C, D’Urzo A, Jaspal M, Merino JM, Johansson G, Boulet S. Symbicort for both maintenance and relief reduces exacerbations compared with a titration of Seretide (Advair) in patients with asthma: a real life study. American Thoracic Society 2005 International Conference; May 2025; San Diego, California. 2005:Poster F67.

Vogelmeier C, D'Urzo A, Pauwels R, Merino JM, Jaspal M, Boutet $\mathrm{S}$, et al.Budesonide/formoterol maintenance and reliever therapy: An effective asthma treatment option?. European Respiratory Journal 2005;26(5):819-28.

\section{D5890C00003 \{published data only\}}

AstraZeneca (D5890C00003). A comparison of the control of asthma inflammation provided by Symbicort turbuhaler $160 / 4.5 \mathrm{mcg} /$ inhalation bid plus as-needed versus symbicort turbuhaler 320/9 mcg/inhalation bid plus Pulmicort turbuhaler $400 \mathrm{mcg} / \mathrm{dose}$ bid plus terbutaline turbuhaler $0.4 \mathrm{mg} /$ inhalation as-needed. www.clinicaltrials.gov 2006: http://www.clinicaltrials.gov/ct/show/NCT00244608 [Accessed22/02/2008].

\section{Ind 2002 \{published data only\}}

Ind PW, Villasante C, Shiner RJ, Pietinalho A, Boszormenyi NG, Soliman S, Selroos O. Safety of formoterol by Turbuhaler as reliever medication compared with terbutaline in moderate asthma. European Respiratory Journal 2002;20 (4):859-66.

\section{Jenkins 2007 \{published data only\}} Jenkins CR, Marks GB, Gibson PG, Wark PAB, Thien FC, Belousova EG, et al.A randomised controlled trial of two algorithms for maintaining asthma control on long-acting bronchodilators (LABA) and inhaled corticosteroids (ICS). Thoracic Society of Australia and New Zealand Annual Scientific Meeting, 25-28 March 2007, Auckland. 2007: Abstract TP044.

\section{Jonkers 2006 \{published data only\}}

Jonkers RE, Bantje TA, Aalbers R. Onset of relief of dyspnoea with budesonide/formoterol or salbutamol following methacholine-induced severe bronchoconstriction in adults with asthma: a double-blind, placebo-controlled study. Respiratory Research 2006;7:141.

Loukides 2005 \{published data only\} Loukides S, Papageorgiou M, Karokis A, Zervas E, Christodoulopoulou A, Papageorgiou N, et al.Single inhaler therapy (SiT) with budesonide/formoterol (BUD/FUM) is 
effective in asthma control. European Respiratory Journal. 2005; Vol. 26(Suppl 49):124S.

\section{Lundborg 2006 \{published data only\}}

Astrazeneca (LD-039-0003). An open, randomized, parallel-group, multicentre, phase IIIB study to evaluate the efficacy of Symbicort ${ }^{\circledR}$ Turbuhaler ${ }^{\circledR}$ single inhaler therapy (SiT), given as a low maintenance dose once or twice daily plus as needed, compared to a higher maintenance dose of Symbicort Turbuhaler given twice daily plus Oxis ${ }^{\circledR}$ Turbuhaler ${ }^{\circledR}$ as needed during 24 weeks in asthmatic patients (LD-039-0003).

AstraZeneca Clinical Trials Register 2006, issue http:// www.astrazenecaclinicaltrials.com/ncmprint.aspx?type= article\&param=516829 (accessed 21st February 2008). Lundborg M, Wille S, Bjermer L, Tilling B, Lundgren M, Telg G, et al.Maintenance plus reliever budesonide/ formoterol compared with a higher maintenance dose of budesonide/formoterol plus formoterol as reliever in asthma: An efficacy and cost-effectiveness study. Current Medical Research \& Opinion 2006;22(5):809-21.

Richter 2007 \{published data only\}

Richter K, Hartmann U, Metzenauer P, Magnussen H. Randomised trial comparing as-needed versus regular treatment with formoterol in patients with persistent asthma. Respiratory Medicine 2007;101(3):467-75.

\section{SMILE \{published and unpublished data\}}

Rabe F, Atienza T, Magyar P, Larsoon P, Jorup C, Lalloo G. A new combination therapeutic approach challenging the current dogma of using inhaled corticosteroids as maintenance only to control asthma. European Respiratory Journal 2006;28(Suppl 50):666s.

Rabe KF, Atienza T, Magyar P, Larsson P, Jorup C, Lalloo UG. Effect of budesonide in combination with formoterol for reliever therapy in asthma exacerbations: a randomised controlled, double-blind study. Lancet 2006;938(9537): 744-53.

\section{SOMA \{published and unpublished data\}}

Haahtela T, Tamminen K, Malmberg LP, Zetterstrom O, Karjalainen J, Yla-Outinen H, et al.Formoterol as needed with or without budesonide in patients with intermittent asthma and raised NO levels in exhaled air: A SOMA study. European Respiratory Journal 2006;28(4):748-55.

Haahtela T, Tamminen K, Malmberg P, Karjalainen J, YiaOutinen $\mathrm{H}$, Zetterstrom $\mathrm{O}$, et al.As-needed treatment with a b2-agonist/ corticosteroid combination in mild intermittent asthma (SOMA). European Respiratory Journal 2005;26(Suppl 45):Abstract No. 1722.

\section{Tattersfield 2001 \{published data only\}}

Berggren F, Ekström T. A cost-effectiveness study comparing the as-needed use of formoterol (Oxis) and terbutaline (Bricanyl) in patients with moderate to severe asthma. Respiratory Medicine 2001;98(9):753-8.

Tattersfield AE, Löfdahl CG, Postma DS, Eivindson A, Schreurs AGM, Rasidakis A, et al.Comparison of formoterol and terbutaline for as-needed treatment of asthma: a randomised trial. Lancet 2001;357(9252):257-61.

\section{References to ongoing studies}

NCT00463866 \{unpublished data only\}

NCT00463866. Ongoing study March 2007.

NCT00628758 \{unpublished data only\}

NCT00628758. Ongoing study March 2006.

SPAIN 2008 \{unpublished data only\}

Study SPAINA Comparison of Symbicort Single Inhaler Therapy (Symbicort Turbuhaler 160/4.5 mcg, 1 Inhalation b.i.d. Plus as Needed) and Conventional Best Practice for the Treatment of Persistent Asthma in Adults - a 26-Week, Randomised, Open-Label, Parallel-Group, Multicentre Study. Estimated enrolment: 1000. Ongoing study Sept 2006.

SYMPHONIE 2008 \{unpublished data only\} SYMPHONIE. Ongoing study Sept 2005.

\section{Additional references}

\section{Adams 2008}

Adams NP, Bestall JC, Lasserson TJ, Jones PW, Cates CJ. Fluticasone versus placebo for chronic asthma in adults and children. Cochrane Database of Systematic Reviews 2008, Issue 4. [DOI: 10.1002/14651858.CD003135.pub4]

Barnes 2007

Barnes PJ. Using a combination inhaler (budesonide plus formoterol) as rescue therapy improves asthma control. Bmj 2007; Vol. 335, issue 7618:513-.

Bisgaard 2003

Bisgaard H. Effect of long-acting Beta2 agonists on exacerbation rates of asthma in children. Pediatric Pulmonology 2003; Vol. 36, issue 5:391-8. [: 1099-0496]

\section{BTS/SIGN 2008}

British Thoracic Society. British Guidelines on Asthma Management. Thorax 2008; Vol. 63, issue Suppl 1.

Cates 2008

Cates CJ, Cates MJ. Regular treatment with salmeterol for chronic asthma: serious adverse events (Cochrane Review). Cochrane Database of Systematic Reviews 2008, Issue 3. [DOI: 10.1002/14651858.CD006363.pub2]

Cates 2008a

Cates Christopher J, Cates Matthew J, Lasserson Toby J. Regular treatment with formoterol for chronic asthma: serious adverse events. Cochrane Database of Systematic Reviews 2008, Issue 4. [DOI: 10.1002/ 14651858.CD006923.pub2]

\section{Delea 2008}

Delea TE, Hagiwara M, Stanford RH, Stempel DA. Effects of fluticasone propionate/salmeterol combination on asthma-related health care resource utilization and costs and adherence in children and adults with asthma. Clinical Therapeutics 2008; Vol. 30, issue 3:560-71.

\section{FitzGerald 2004}

FitzGerald JM, Becker A, Sears MR, Mink S, Chung K, Lee J. Doubling the dose of budesonide versus maintenance

Combination formoterol and budesonide as maintenance and reliever therapy versus inhaled steroid maintenance for chronic asthma in 18 adults and children (Review) 
treatment in asthma exacerbations. Thorax 2004; Vol. 59, issue 7:550-6.

\section{Greenstone 2005}

Greenstone IR, Ni Chroinin MN, Masse V, Danish A, Magdalinos H, Zhang X, et al.Combination of inhaled long-acting beta2-agonists and inhaled steroids versus higher dose of inhaled steroids in children and adults with persistent asthma. Cochrane Database of Systematic Reviews 2005, Issue 4. [DOI: 10.1002/14651858.CD005533]

\section{Harrison 2004}

Harrison T, Oborne J, Newton S, Tattersfield A. Doubling the dose of inhaled corticosteroid to prevent asthma exacerbations: randomised controlled trial. Lancet 2004; Vol. 363, issue 9405:271-5.

\section{Higgins 2003}

Higgins JPT, Thompson SG, Deeks JJ, Altman DG. Measuring inconsistency in meta-analyses. BMJ 2003;327: 557-60.

\section{Higgins 2008}

Higgins JPT, Green S (editors). Cochrane Handbook for Systematic Reviews of Interventions Version 5.0.0 [updated February 2008] Available from: www.cochrane-handbook.org. The Cochrane Collaboration, 2008.

\section{Lasserson 2008}

Lasserson TJ, Cates CJ, Ferrara G, Casali L. Combination fluticasone and salmeterol versus fixed dose combination budesonide and formoterol for chronic asthma in adults and children. Cochrane Database of Systematic Reviews 2008, Issue 3. [DOI: 10.1002/14651858.CD004106.pub3]

\section{Lipworth 2008}

Lipworth BJ, Jackson C. A SMART choice for primary care asthma therapy?. http://www.bmj.com/cgi/eletters/335/ 7618/513\#178078 13 October 2007.

Ni Chroinin 2005

Ni Chroinin M, Greenstone IR, Danish A, Magdolinos H, Masse V, Zhang X, et al.Long-acting beta2-agonists versus placebo in addition to inhaled corticosteroids in children and adults with chronic asthma. Cochrane Database of Systematic Reviews 2005, Issue 4. [Art. No.: CD005535. DOI: 10.1002/14651858.CD005535]

\section{Palmqvist 2001}

Palmqvist M, Arvidsson P, Beckman O, Peterson S, Lotvall J. Onset of bronchodilation of budesonide/formoterol vs. salmeterol/fluticasone in single inhalers. Pulmonary Pharmacology \& Therapeutics 2001;14(1):29-34.

\section{Tattersfield 1999}

Tattersfield AE, Postma DS, Barnes PJ, Svensson K, Bauer CA, O'Byrne PM, et al.Exacerbations of asthma: a descriptive study of 425 severe exacerbations. The FACET International Study Group. American Journal of Respiratory \& Critical Care Medicine 1999;160(2):594-9.

Walters 2007

Walters EH, Gibson PG, Lasserson TJ, Walters JAE. Longacting beta2-agonists for chronic asthma in adults and children where background therapy contains varied or no inhaled corticosteroid. Cochrane Database of Systematic Reviews 2007, Issue 1. [Art. No.: CD001385. DOI: 10.1002/14651858.CD001385.pub2]

* Indicates the major publication for the study 
CHARACTERISTICS OF STUDIES

Characteristics of included studies [ordered by study ID]

DE-SOLO

Methods

A Comparison of Symbicort Single Inhaler Therapy (Symbicort Turbuhaler 160/4.5 $\mu \mathrm{g}$, 1 Inhalation b.i.d. Plus as Needed) and Conventional Best Practice for the Treatment of Persistent Asthma in Adults - a 26-Week, Randomised, Open-Label, Parallel-Group, Multicentre Study. Dec 2004 to October 2006. 169 centres in Germany. No report of run-in

The purpose of this study is to determine whether Symbicort dosed according to the Symbicort Maintenance and Reliever Therapy (SMART) concept is superior to standard asthma treatment according to the local German treatment guidelines

Participants

Estimated enrolment: 1600. Patients 18 years or older Inclusion Criteria:

- Patients with asthma, either well-controlled on a regular therapy with a combination of long-acting beta-agonists and inhaled corticosteroids or symptomatic on therapy with inhaled corticosteroids alone.

Exclusion Criteria:

- Any other significant lung disease other than asthma

- Any disease that might put patients at risk if they participate in the study

Interventions

1. Symbicort Turbuhaler 160/4.5 $\mu$ g, 1 Inhalation b.i.d. Plus as Needed

2. Conventional Best Practice

Outcomes

Primary Outcome Measures:

- Time to first severe asthma exacerbation

Secondary Outcome Measures:

- Number of severe asthma exacerbations

- Mean use of as-needed medication

- Change in forced expiratory volume in 1 second (FEV1) from the end of run-in to the end of the study period

- Prescribed asthma medication during the treatment period

- Asthma Control Questionnaire (ACQ)

- Patient's satisfaction with the treatment question

- Health care contacts

- Asthma medication

- Time lost from paid and unpaid work

- Serious adverse events (SAEs)

- Discontinuations due to adverse events (AEs)

Definition of severe exacerbation

Not specified

No published results found for this study in September 2008

Risk of bias

Item

Authors' judgement

Description

Combination formoterol and budesonide as maintenance and reliever therapy versus inhaled steroid maintenance for chronic asthma in adults and children (Review)

Copyright ( 2010 The Cochrane Collaboration. Published by John Wiley \& Sons, Ltd. 
DE-SOLO (Continued)

\begin{tabular}{lll}
\hline Adequate sequence generation? & Unclear & No details \\
\hline Allocation concealment? & Unclear & No details \\
\hline $\begin{array}{l}\text { Blinding? } \\
\text { All outcomes }\end{array}$ & No & Open \\
\hline $\begin{array}{l}\text { Incomplete outcome data addressed? } \\
\text { All outcomes }\end{array}$ & Unclear & No details \\
\hline
\end{tabular}

\section{MONO}

Methods

This was a randomised, open-label, parallel-group, Multicentre study in 1900 patients (planned number) with persistent asthma. Patients were treated with either Symbicort ${ }^{\circledR}$ SMART (i.e. Symbicort ${ }^{\circledR}$ Turbuhaler ${ }^{\circledR}$ (budesonide/formoterol) 160/4.5 $\mu \mathrm{g}$ (delivered dose), 1 inhalation b.i.d. plus as needed), or conventional best practice according to the investigator's judgement, following GINA guidelines (Ref: Global Initiative for Asthma 2002). The treatment period lasted for 26 weeks, with no mention of any run-in period This study was conducted in Denmark (123 centres), Finland (69 centres) and Norway (83 centres) between September 2004 and October 2006

Participants

1854 patients were randomised, 1835 took at least one treatment and contributed to the analysis, and 1667 completed the study. $75 \%$ were taking LABA and daily ICS dose was $1035 \mathrm{mcg} /$ day (BDP equivalence).

Male and female patients, > 12 years of age, with persistent asthma who were currently treated with inhaled glucocorticosteroids (IGCSs) and long-acting $\beta 2$-agonist (LABA)

Interventions

Investigational product was Symbicort ${ }^{\circledR}$ Turbuhaler ${ }^{\circledR}, 160 / 4.5 \mu \mathrm{g} /$ dose budesonide/ formoterol (delivered dose), 1 inhalation b.i.d. as maintenance treatment plus as needed, in response to symptoms

Comparator products were any conventional best practice treatments, except Symbicort ${ }^{\circledR}$ SMART and/or maintenance with oral glucocorticosteroids prescribed at the discretion of the investigator according to GINA treatment guidelines Ref: Global Initiative for Asthma 2002)

Outcomes

Primary variable

- Time to first severe asthma exacerbation

Secondary variables

- Total number of severe asthma exacerbations

- Mean use of as needed medication

- Prescribed asthma medications

Patient reported outcomes (PRO)

- Change in Asthma Control Questionnaire (ACQ) score

Safety

Only information regarding SAEs and discontinuations due to AE (DAEs) were collected in this study

\section{Definition of severe exacerbation}

Not specified 


\begin{tabular}{ll} 
& $\begin{array}{l}\text { Additional Data } \\
\text { Data on file from AstraZeneca indicated 51/64 patients with at least one course of oral } \\
\text { steroids and } 5 / 7 \text { with at least one hospitalisation on single inhaler therapy/current best } \\
\text { practice }(921 / 914)\end{array}$ \\
\hline Notes & $\begin{array}{l}\text { One }(1) \text { death was reported in the study in the single inhaler therapy group in Denmark. } \\
\text { The patient contacted the investigator } 16 \text { August due to asthma deterioration. The } \\
\text { patient discontinued the study and study medication on } 9 \text { September } 2005 \text { due to } \\
\text { "Subject not willing to continue study" and experienced asthma exacerbation on } 30 \\
\text { September } 2005 . \text { The event was considered serious due to hospitalization, and the patient } \\
\text { died the same day. The events pneumonia and in compensatio cordis lead to death } \\
\text { and not the event of asthma exacerbation. The investigator considered the event to be } \\
\text { unrelated to the study therapy }\end{array}$ \\
\hline
\end{tabular}

Risk of bias

\begin{tabular}{l|ll}
\hline Item & Authors' judgement & Description \\
\hline Adequate sequence generation? & Unclear & No details \\
\hline Allocation concealment? & Unclear & No details \\
\hline $\begin{array}{l}\text { Blinding? } \\
\text { All outcomes }\end{array}$ & No & Open study \\
\hline $\begin{array}{l}\text { Incomplete outcome data addressed? } \\
\text { All outcomes }\end{array}$ & Yes & $\begin{array}{l}90 \% \text { of randomised patients completed the } \\
\text { study and analyses was ITT }\end{array}$ \\
\hline
\end{tabular}

\section{NCT00235911}

Methods

Participants
Treatment, Randomized, Open Label, Active Control, Parallel Assignment, Efficacy Study. August 2003 start

Effects of Symbicort Single Inhaler Therapy on Bronchial Hyper Responsiveness, Asthma Control and Safety in Mild to Moderate Asthmatics in General Practice, Compared to Usual Care Therapy. The primary objective is to compare the effects of Symbicort SiT and treatment according to NHG-guidelines on bronchial hyper responsiveness in asthmatic patients, as measured by PD20 histamine, and to validate the Bronchial Hyperresponsiveness Questionnaire (BHQ). Two research centres in the Netherlands

Enrolment planned: 100

Inclusion Criteria:

- diagnosis of mild to moderate asthma, FEV1 $>60 \%$ of predicted normal values pre-bronchodilator, daily use of inhaled GCS during the last 3 months Exclusion Criteria:

- Regular need of $>4$ inhalations of a short-acting b2-agonist/day, known or suspected hypersensitivity to any of the investigational drugs or inhaled lactose, use of any beta-blocking agent, having smoked $>10$ pack-years 
NCT00235911 (Continued)

\begin{tabular}{|c|c|c|}
\hline Interventions & \multicolumn{2}{|c|}{$\begin{array}{l}\text { 1. Symbicort SiT } \\
\text { 2. Treatment according to NHG-guidelines }\end{array}$} \\
\hline Outcomes & \multicolumn{2}{|c|}{$\begin{array}{l}\text { Primary Outcome Measures: } \\
\text { - Change in PD20 histamine } \\
\text { Secondary Outcome Measures } \\
\text { - Number of asthma-control days } \\
\text { - Time to first mild asthma exacerbation } \\
\text { - Number of mild asthma exacerbation days } \\
\text { - Asthma symptom scores (day and night) } \\
\text { - FEV1 } \\
\text { - PEF (morning and evening) } \\
\text { - Number of inhalations with iGCS } \\
\text { - Mean dose of iGCS } \\
\text { Definition of severe exacerbation } \\
\text { Not specified } \\
\text { Additional Data } \\
\text { Data on file from AstraZeneca indicate that no patients were hospitalised, and } 2 / 54 \\
\text { compared to } 6 / 48 \text { patients had at least one course of oral steroids on SMART and current } \\
\text { best practice respectively }\end{array}$} \\
\hline Notes & \multicolumn{2}{|c|}{$\begin{array}{l}\text { Study BN-00S-0011 is reported on the clinical trials register as completed, but no study } \\
\text { report summary had been posted by AstraZeneca on the trials web site (www.astrazeneca- } \\
\text { clinicaltrials.com/ncmprintchapter.aspx?type=article\&param }=528362 \text { ) by September } \\
2008\end{array}$} \\
\hline \multicolumn{3}{|l|}{ Risk of bias } \\
\hline Item & Authors' judgement & Description \\
\hline Adequate sequence generation? & Unclear & No details \\
\hline Allocation concealment? & Unclear & No details \\
\hline $\begin{array}{l}\text { Blinding? } \\
\text { All outcomes }\end{array}$ & No & Open \\
\hline $\begin{array}{l}\text { Incomplete outcome data addressed? } \\
\text { All outcomes }\end{array}$ & Unclear & No details \\
\hline
\end{tabular}




\begin{tabular}{|c|c|}
\hline Methods & $\begin{array}{l}\text { This was a randomised, open-label, phase IIIB, multicenter study with a parallel group } \\
\text { design. Patients were treated with either SMART i.e. Symbicort }{ }^{\circledR} \text { Turbohaler }{ }^{\circledR} 160 / \\
4.5 \mu \text { g/inhalation (delivered dose), } 1 \text { inhalation b.i.d. plus as needed (in response to } \\
\text { symptoms), or conventional best practice. The study consisted of the following periods: } \\
2 \text {-week run-in period followed by a } 26 \text {-week randomised treatment period. Usual therapy } \\
\text { used in run-in period } \\
\text { A total of } 194 \text { centres in Belgium and Luxembourg participated in this study, between } \\
\text { December } 2004 \text { and June } 2006\end{array}$ \\
\hline
\end{tabular}

Participants

Population: 908 adults and adolescents were randomised. All were analysed for efficacy and safety and 867 completed the study. 38\% classified as moderate persistent asthma, $36 \%$ severe persistent asthma and $27 \%$ mild persistent asthma. Mean ICS daily dose during run-in $579 \mathrm{mcg} /$ day (range 100 to 2000).

Inclusion criteria: Male and female, adolescent ( $\geq 12$ years of age) and adult patients with persistent asthma, currently treated with inhaled glucocorticosteroid (IGCS) or IGCS and long-acting $\beta 2$-agonist (LABA)

Interventions

1. Investigation medication was Symbicort ${ }^{\circledR}$ Turbohaler ${ }^{\circledR} 160 / 4.5 \mu \mathrm{g} /$ inhalation (delivered dose), 1 inhalation b.i.d. + as needed in response to symptoms.

2. Comparators were conventional best practice, active stepwise individualized treatment according to the Global Initiative for Asthma (GINA) treatment guidelines.

Primary variable
- Time to first severe asthma exacerbation
Secondary variables
- Number of severe asthma exacerbations
- Mean use of as-needed medication
- Prescribed asthma medication
- Peak Expiratory Flow (PEF)
Patient-reported outcomes (PROs)
- Asthma Control Questionnaire (ACQ) score
- Satisfaction with Asthma Treatment Questionnaire (SATQ) score
Safety
- SAEs
- Discontinuation due to AE(s)
Definition of severe exacerbation
Not specified

Risk of bias

\begin{tabular}{lll}
\hline Item & Authors' judgement & Description \\
\hline Adequate sequence generation? & Unclear & No details
\end{tabular}

Combination formoterol and budesonide as maintenance and reliever therapy versus inhaled steroid maintenance for chronic asthma in 


\begin{tabular}{lll}
\hline Allocation concealment? & Unclear & No details \\
\hline $\begin{array}{l}\text { Blinding? } \\
\text { All outcomes }\end{array}$ & No & Open \\
\hline $\begin{array}{l}\text { Incomplete outcome data addressed? } \\
\text { All outcomes }\end{array}$ & Unclear & No details \\
\hline
\end{tabular}

\section{Scicchitano 2004}

\begin{tabular}{|c|c|}
\hline Methods & $\begin{array}{l}\text { This was a double-blind, double-dummy, randomised, active-controlled, parallel-group, } \\
\text { Multicentre study comparing the efficacy and safety of Symbicort } 160 / 4.5 \mu \mathrm{g} / \text { inhalation, } \\
\text { two inhalations once daily + Symbicort } 160 / 4.5 \mu \mathrm{g} / \text { inhalation as-needed (Symbicort } \\
\text { single-inhaler therapy (SiT)) with Pulmicort } 160 \mu \mathrm{g} \text { /inhalation, two inhalations bid } \\
\text { + Bricanyl } 0.4 \mathrm{mg} \text { /inhalation as-needed, in adults and adolescents ( } 12-80 \text { years) for a } \\
\text { period of } 12 \mathrm{months} \text { in the treatment of asthma.(Carried out between May } 2001 \text { and } \\
\text { January } 2003) \text {. The run-in period was on usual ICS dose but LABA was withdrawn } \\
\text { This was a Multicentre study with } 211 \text { centres participating from the following } 18 \\
\text { countries: Argentina ( } 6 \text { centres), Australia ( } 10 \text { centres), Canada ( } 22 \text { centres), Czech } \\
\text { republic ( } 5 \text { centres), Finland ( } 6 \text { centres), France ( } 29 \text { centres), Germany ( } 20 \text { centres) } \\
\text {, Hungary ( } 7 \text { centres), Israel ( } 17 \text { centres), Italy ( } 11 \text { centres), Mexico ( } 5 \text { centres), the } \\
\text { Netherlands ( } 24 \text { centres), New Zealand ( } 4 \text { centres), Norway ( } 13 \text { centres), Portugal ( } 7 \\
\text { centres), Russia ( } 6 \text { centres), South Africa ( } 11 \text { centres) and Turkey ( } 8 \text { centres) }\end{array}$ \\
\hline
\end{tabular}

Participants

Population: Mean age: 43 years. FEV1 70\% predicted. Mean ICS dose at enrolment $746 \mathrm{mcg} /$ day. Hospital admission for asthma in the past year: unknown\%. Course of oral steroids for asthma in past year: unknown\%. Previous clinically important exacerbation required for eligibility. $45 \%$ of enrolled patients were already on LABA as well as ICS Inclusion criteria: Male and female subjects, 12 to 80 years with asthma, previously treated with inhaled glucocorticosteroids (IGCS) 400-1600 $\mu \mathrm{g}$ per day, with a forced expiratory volume in one second (FEV1) of 50-90\% of predicted normal (\% P.N.), a history of at least one clinical important asthma exacerbation 1-12 months prior to inclusion, a reversibility in FEV1 from baseline of at least 12\%, and who had an asthma symptom score $\geq 1$ during 4 of the last 7 days of the run-in period (in which usual dose of ICS was used but LABA was withdrawn from the $45 \%$ taking LABA previously)

Interventions

1. Budesonide/formoterol $200 / 6 \mathrm{mcg}$ two inhalation in the evening [ $400 \mathrm{mcg}$ budesonide/day], with additional doses as needed as reliever (3 turbuhalers for morning, evening and relief)

2. Budesonide $\mathbf{2 0 0} \mathbf{m c g}$ two inhalations twice daily [ $\mathbf{8 0 0} \mathbf{m c g}$ budesonide/day], with terbutaline reliever ( 3 turbuhalers as above with placebo in the morning)

Maximum of 10 as needed inhalations could be used per day before contacting the investigator

${ }^{*} 200 / 6 \mathrm{mcg}$ actuator dose is described as $160 / 4.5 \mathrm{mcg}$ delivered dose in the paper

Outcomes

Primary efficacy variable

- Severe asthma exacerbations.

- The associated primary efficacy outcome variable was time to first severe asthma

Combination formoterol and budesonide as maintenance and reliever therapy versus inhaled steroid maintenance for chronic asthma in 25 adults and children (Review)

Copyright @ 2010 The Cochrane Collaboration. Published by John Wiley \& Sons, Ltd. 


\begin{tabular}{|c|c|c|}
\hline & \multicolumn{2}{|c|}{$\begin{array}{l}\text { Additional secondary efficacy variables } \\
\text { - The number of severe asthma exacerbations was a secondary outcome variable } \\
\text { - Morning and evening peak expiratory flow (mPEF and ePEF) } \\
\text { - Asthma symptom scores } \\
\text { - Nights with awakening(s) due to asthma symptom } \\
\text { - Inhalations of as-needed medication } \\
\text { - Asthma-control days } \\
\text { - Mild asthma exacerbation days } \\
\text { - As-needed-free days } \\
\text { - Symptom-free days, } \\
\text { FEV1, overall treatment evaluation, and asthma quality of life questionnaire, standardised } \\
\text { version (AQLQ(S)) overall and domain scores } \\
\text { N.B. As-needed-free days and symptom-free days were added as variables to the statistical } \\
\text { analyses to conform with previous Symbicort studies. It was done after finalisation of } \\
\text { the study protocol, but before un blinding of study data } \\
\text { Safety } \\
\text { Safety assessments including physical examination, adverse events (AEs), pulse and blood } \\
\text { pressure, were obtained in all subjects } \\
\text { Definition of severe exacerbation } \\
\text { Included PEF less than } 70 \% \text { baseline on two consecutive days, severe exacerbations } \\
\text { requiring medical intervention were also reported (hospitalisation, ED visit or course of } \\
\text { oral steroids), but all severe exacerbations were to be treated with a } 10 \text { day course of oral } \\
\text { prednisolone } \\
\text { Additional Data } \\
\text { Data on file from AstraZeneca indicated the number patients given at least one course of } \\
\text { oral steroids was } 129 / 947 \text { on SMART and } 204 / 943 \text { on Pulmicort. For Hospitalisation/ } \\
\text { ER treatment there were } 12 / 947 \text { and } 20 / 947 \text { respectively. Asthma SAE was } 5 / 947 \text { and } \\
11 / 943 \text { which have been used as the hospital admission outcomes for this study }\end{array}$} \\
\hline Notes & \multicolumn{2}{|c|}{$\begin{array}{l}\text { There were three deaths reported in the study, two in the Pulmicort group and one in } \\
\text { the Symbicort SiT group. None of the deaths were related to asthma or, as judged by } \\
\text { the investigator causally related to investigational } \\
\text { product. }\end{array}$} \\
\hline \multicolumn{3}{|l|}{ Risk of bias } \\
\hline Item & Authors' judgement & Description \\
\hline Adequate sequence generation? & Unclear & No details \\
\hline Allocation concealment? & Unclear & No details \\
\hline $\begin{array}{l}\text { Blinding? } \\
\text { All outcomes }\end{array}$ & Yes & Double blind \\
\hline $\begin{array}{l}\text { Incomplete outcome data addressed? } \\
\text { All outcomes }\end{array}$ & Yes & $1573 / 1890$ completed $(83 \%)$ \\
\hline
\end{tabular}

Combination formoterol and budesonide as maintenance and reliever therapy versus inhaled steroid maintenance for chronic asthma in 26 adults and children (Review) 


\begin{tabular}{ll} 
Methods & $\begin{array}{l}\text { Randomised, open, parallel group study over a } 6 \text { month period. In the two week run-in } \\
\text { patients used current asthma treatment (pre-study ICS +/- LABA). Unknown number } \\
\text { of centres in Canada }\end{array}$ \\
\hline Participants & $\begin{array}{l}\text { Population: } 1538 \text { asthmatic adults aged } 12 \text { years and over with asthma on at least } 400 \\
\text { mcg/day ICS and symptomatic unless also on LABA (74\% of those randomised were } \\
\text { on LABA and ICS) } \\
\text { Inclusion Criteria: Aged } 12 \text { years or more and asthma diagnosis for a minimum of three } \\
\text { months. Previous treatment with ICS for at least } 3 \text { months (at least } 400 \text { mcg/day) with } \\
\text { at least } 3 \text { inhalations of relief medication in the last } 7 \text { days of run in, or concurrent use of } \\
\text { LABA. Patients with a smoking history of over } 10 \text { pack-years or exacerbation requiring } \\
\text { a change in asthma treatment in the past } 14 \text { days were not included; nor were patients } \\
\text { already using Single inhaler Therapy } \\
\text { Baseline Characteristics: Mean age: } 40 \text { years. FEV1 not measured but PEF } 94 \% \\
\text { predicted. Mean ICS dose at enrolment } 569 \text { mcg/day, and } 74 \% \text { were also using LABA. } \\
\text { Hospital admission for asthma in the past year:unknown. Course of oral steroids for } \\
\text { asthma in past year: unknown }\end{array}$ \\
\hline
\end{tabular}

Interventions

1. Budesonide/formoterol $200 / 6$ mcg one inhalation twice daily [ 400 mcg budesonide/ day], as maintenance and reliever

2. Current best practice.

\begin{tabular}{|c|c|c|}
\hline Outcomes & \multicolumn{2}{|c|}{$\begin{array}{l}\text { Primary outcome: } \\
\text { - Time to first severe exacerbation } \\
\text { Secondary outcomes } \\
\text { - Number of severe exacerbations } \\
\text { - Mean use of as-needed treatment } \\
\text { - Prescribed asthma medications } \\
\text { - PEF } \\
\text { - ACQ. A subgroup used induced sputum eosinophils as a primary outcome. } \\
\text { Definition of severe exacerbation } \\
\text { Hospitalisation, or emergency room visit or course of oral corticosteroids for at least } 3 \\
\text { days due to asthma }\end{array}$} \\
\hline Notes & \multicolumn{2}{|c|}{$\begin{array}{l}\text { Study D5890L00004 is reported on the clinical trials register as completed in September } \\
\text { 2005, but no study report summary had been posted by AstraZeneca on the trials web } \\
\text { site (http://www.astrazenecaclinicaltrials.com/article/514143.aspx) by September } 2008\end{array}$} \\
\hline \multicolumn{3}{|l|}{ Risk of bias } \\
\hline Item & Authors' judgement & Description \\
\hline Adequate sequence generation? & Unclear & No details \\
\hline Allocation concealment? & Unclear & No details \\
\hline $\begin{array}{l}\text { Blinding? } \\
\text { All outcomes }\end{array}$ & No & Open \\
\hline
\end{tabular}


All outcomes

\section{Sovani 2008}

Methods

Participants

Randomised, open, parallel group study over a 6 month period

Population: 71 asthmatic adults aged 18-70 years with asthma on at least 400-1000 $\mathrm{mcg} /$ day ICS who demonstrated poor compliance and were poorly controlled.

Inclusion Criteria: Aged 18-70 years. Previous treatment with ICS (400-1000 mcg/day beclometasone equivalent) who demonstrated poor compliance by collecting less than $70 \%$ of expected ICS prescriptions in the previous year. Poor control demonstrated by at least two prescriptions of prednisolone or 10 canisters of reliever inhaler in previous year. At least four puffs of reliever for at least 4 days per week over past 4 weeks. Patients with a smoking history of over 20 pack-years or exacerbation requiring oral steroids in the past 4 weeks were not included

Baseline characteristics: Mean age: 36 years. FEV1 85\% predicted. Mean ICS dose at enrolment $590 \mathrm{mcg} / \mathrm{day}$, but only $\mathbf{2 7 8} \mathrm{mcg} /$ day was being taken! Hospital admission for asthma in the past year: unknown. Course of oral steroids for asthma in past year: mean of one course per year (SD 1)

1. Budesonide/formoterol $200 / 6$ mcg one inhalation twice daily [400 mcg budesonide/day], as maintenance and reliever.

2. Budesonide $\mathbf{2 0 0} \mathbf{m c g}$ [ $400 \mathbf{m c g}$ budesonide/day], one inhalation twice daily via Turbohaler and usual reliever

\begin{tabular}{l|l}
\hline Outcomes & Primary outcome: \\
& - Dose of inhaled budesonide. \\
Secondary outcomes & - FEV1 \\
& - MiniAQLQ \\
& - ACQ scores \\
& - Oral corticosteroid use \\
& - Visits to GP for asthma-related problems. \\
\hline Notes & Supported by an unconditional grant from AstraZeneca \\
\hline
\end{tabular}

\section{Risk of bias}

\begin{tabular}{l|l|l}
\hline Item & Authors' judgement & Description \\
\hline Adequate sequence generation? & Yes & computer-generated random numbers \\
\hline Allocation concealment? & Yes & $\begin{array}{l}\text { An independent pharmacist used com- } \\
\text { puter-generated random numbers to ran- } \\
\text { domise each participant to one of two } \\
\text { groups }\end{array}$
\end{tabular}

Combination formoterol and budesonide as maintenance and reliever therapy versus inhaled steroid maintenance for chronic asthma in 28 
Sovani 2008 (Continued)

\begin{tabular}{|c|c|c|}
\hline $\begin{array}{l}\text { Blinding? } \\
\text { All outcomes }\end{array}$ & No & Open \\
\hline $\begin{array}{l}\text { Incomplete outcome data addressed? } \\
\text { All outcomes }\end{array}$ & Yes & $\begin{array}{l}55 / 71(77 \%) \text { completed the study and } \\
\text { there were more withdrawals in the control } \\
\text { arm: } 13 \text { compared to } 3 \text { in active arm (all } 3 \\
\text { reported difficulty using the inhaler) }\end{array}$ \\
\hline
\end{tabular}

\section{STAY - Adults}

Methods

Study Design: Randomised, double-blind, parallel group study over a 12 month period in 246 centres in 22 countries (between Jan 2001 and Jan 2003). In the 14-18 day runin patients used pre-study ICS with terbutaline for symptom relief (LABA had to be discontinued at least 3 days before run-in)

Participants

Adult Population: 2419 asthmatic adults aged 12 years or more with asthma uncontrolled on ICS (400-1000 mcg/day) and a history of at least one "clinically important" exacerbation in the past year. The maintenance ICS dose was cut to a quarter with additional Formoterol (SiT) or maintenance with Terbutaline for relief

Adults Mean age: 40 years. FEV1 73\% predicted pre bronchodilator. Mean ICS dose at enrolment $\mathbf{6} 60 \mathrm{mcg} /$ day. Hospital admission for asthma in the past year: unknown proportion. Course of oral steroids for asthma in past year: unknown proportion Inclusion Criteria: Aged 12-80 years, with a constant dose of ICS (400-1000 mcg/day) at least 3 months. Prebronchodilator FEV1 of $60-90 \%$ predicted normal value and at least $12 \%$ reversibility following Terbutaline. To be included patients had to need at least 12 rescue inhalations in the last 10 days of run-in. Adults using ten or more rescue inhalations in a single day or with an exacerbation during run-in were not randomised

Interventions

1. Budesonide/formoterol $\mathbf{1 0 0 / 6} \mathrm{mcg}$ twice daily [ $200 \mathrm{mcg}$ budesonide/day] and as needed (one maintenance and one relief Turbuhaler)

2. Budesonide/formoterol $100 / 6 \mathrm{mcg}$ twice daily [ $200 \mathrm{mcg}$ budesonide/day] and Terbutaline as needed (one maintenance and one relief Turbuhaler)

3. Budesonide $400 \mathrm{mcg}$ twice daily [ $\mathbf{8 0 0} \mathbf{~ m c g}$ budesonide/day] and Terbutaline as needed (one maintenance and one relief Turbuhaler)

Maximum of 10 as needed inhalations could be used per day before contacting the investigator

Outcomes

\section{Primary outcome}

- Time to first severe exacerbations

Secondary outcomes

- Number of severe exacerbations

- Time to mild exacerbations

- Number of mild exacerbations

- Symptom free days

- QOL scores

- No particular variable was chosen to assess safety.

Exacerbation Definition: Severe - Deterioration in asthma requiring hospital or emergency room treatment, or oral steroids (or other additional treatment) or morning PEF

Combination formoterol and budesonide as maintenance and reliever therapy versus inhaled steroid maintenance for chronic asthma in 29 adults and children (Review)

Copyright ( 2010 The Cochrane Collaboration. Published by John Wiley \& Sons, Ltd. 


\begin{tabular}{|c|c|c|}
\hline & \multicolumn{2}{|c|}{$\begin{array}{l}70 \% \text { or less of baseline on two consecutive days. Severe exacerbations requiring med- } \\
\text { ical intervention were analysed separately. Mild exacerbation day - PEF } 80 \% \text { or less } \\
\text { of baseline, relief medication } 2 \text { or more inhalations above baseline, or awakenings due } \\
\text { to asthma. Mild exacerbation defined as } 2 \text { consecutive mild exacerbation days using the } \\
\text { same criteria } \\
\text { Additional Data } \\
\text { Data on file from AstraZeneca indicate that } 7 / 804 \text { adults and adolescents had at least } \\
\text { one asthma related SAE on SMART and } 10 / 819 \text { on Pulmicort. Similarly } 83 / 804 \text { on } \\
\text { SMART and } 149 / 819 \text { on Pulmicort had at least one course of oral corticosteroids }\end{array}$} \\
\hline Notes & \multicolumn{2}{|c|}{ SAE data $(44,46,42)$ in the adult population; deaths given for whole trial $(0,2,1)$} \\
\hline \multicolumn{3}{|l|}{ Risk of bias } \\
\hline Item & Authors' judgement & Description \\
\hline Adequate sequence generation? & Yes & $\begin{array}{l}\text { Computer generated randomisation } \\
\text { scheme }\end{array}$ \\
\hline Allocation concealment? & Unclear & $\begin{array}{l}\text { Eligible patients were randomised in bal- } \\
\text { anced blocks by allocating patient numbers } \\
\text { in consecutive order }\end{array}$ \\
\hline $\begin{array}{l}\text { Blinding? } \\
\text { All outcomes }\end{array}$ & Yes & $\begin{array}{l}\text { Double blind. All study medication was } \\
\text { given by turbuhalers. Maintenance and as } \\
\text { needed medication distinguished by the } \\
\text { colour of the label and its wording }\end{array}$ \\
\hline $\begin{array}{l}\text { Incomplete outcome data addressed? } \\
\text { All outcomes }\end{array}$ & Yes & $\begin{array}{l}\text { Withdrawals and Dropouts: 2039/2419 } \\
\text { (84\%) completed the study }\end{array}$ \\
\hline \multicolumn{3}{|l|}{ STAY - All ages } \\
\hline Methods & \multicolumn{2}{|c|}{ see STAY - Adults \& STAY - children } \\
\hline Participants & \multicolumn{2}{|c|}{$\begin{array}{l}\text { Combined data on Children and Adults aged } 4 \text { to } 60 \text { years with a history of one or more } \\
\text { exacerbations in the past year }\end{array}$} \\
\hline Interventions & \multicolumn{2}{|c|}{ see STAY - Adults \& STAY - children } \\
\hline Outcomes & \multicolumn{2}{|c|}{ see STAY - Adults \& STAY - children } \\
\hline Notes & \multicolumn{2}{|c|}{$\begin{array}{l}\text { Data presented for adults and children. P values based on ANOVA and changes from } \\
\text { baseline calculated from Tables } 1 \& 2 \text { in the primary publication. Standard Errors esti- } \\
\text { mated from P values }\end{array}$} \\
\hline
\end{tabular}

Risk of bias 
STAY - All ages (Continued)

\begin{tabular}{lll}
\hline Item & Authors' judgement & Description \\
\hline Adequate sequence generation? & Yes & See STAY - Adults \\
\hline $\begin{array}{l}\text { Allocation concealment? } \\
\begin{array}{l}\text { Blinding? } \\
\text { All outcomes }\end{array}\end{array}$ & Unclear & See STAY - Adults \\
\hline $\begin{array}{l}\text { Incomplete outcome data addressed? } \\
\text { All outcomes }\end{array}$ & Yes & See STAY - Adults \\
\hline
\end{tabular}

\section{STAY - Children}

Methods

Participants
Study Design: Randomised, double-blind, parallel group study over a 12 month period in 41 centres in 12 countries (between Jan 2001 and Jan 2003). In the 14-18 day runin patients used pre-study ICS with terbutaline for symptom relief (LABA had to be discontinued at least 3 days before run-in)

\begin{tabular}{|c|c|}
\hline Participants & $\begin{array}{l}\text { Children in Study: } 341 \text { asthmatic children aged } 4-11 \text { years with asthma uncontrolled on } \\
\text { ICS ( } 200-500 \mathrm{mcg} / \text { day) and a history of at least one "clinically important" exacerbation } \\
\text { in the past year. } \\
\text { Mean age: } 8 \text { years. Mean morning PEF: } 220 \mathrm{~L} / \mathrm{min} \text {. FEV1 } \mathbf{7 6} \% \text { predicted pre bron- } \\
\text { chodilator. Mean ICS dose at enrolment } 315 \mathrm{mcg} / \text { day. Hospital admission for asthma } \\
\text { in the past year: unknown proportion. Course of oral steroids for asthma in past year: } \\
\text { unknown proportion } \\
\text { Inclusion Criteria: Aged } 4-11 \text { years, with a constant dose of ICS ( } 200-500 \mathrm{mcg} / \text { day) at } \\
\text { least } 3 \text { months. Prebronchodilator FEV1 of } 60-100 \% \text { predicted normal value and at least } \\
12 \% \text { reversibility following Terbutaline. To be included patients had to need at least } 8 \\
\text { rescue inhalations in the last } 10 \text { days of run-in. Children using seven or more rescue } \\
\text { inhalations in a single day or with an exacerbation during run-in were not randomised }\end{array}$ \\
\hline Interventions & $\begin{array}{l}\text { 1. Budesonide } \mathbf{1 0 0} \mathrm{mcg}(80 \mathrm{mcg} \text { delivered dose) and Formoterol } 4.5 \mathrm{mcg} \text { in the } \\
\text { evening and as needed (one maintenance and one relief Turbuhaler) } \\
\text { 2. Budesonide } \mathbf{1 0 0} \mathrm{mcg}(80 \mathrm{mcg} \text { delivered dose) and Formoterol } 4.5 \mathrm{mcg} \text { in the } \\
\text { evening and Terbutaline as needed (one maintenance and one relief Turbuhaler) } \\
\text { 3. Budesonide } \mathbf{4 0 0} \mathrm{mcg}(320 \mathrm{mcg} \text { delivered dose) in the evening and Terbutaline } \\
\text { as needed (one maintenance and one relief Turbuhaler) }\end{array}$ \\
\hline Outcomes & $\begin{array}{l}\text { Primary outcome } \\
\text { - Time to first severe exacerbations } \\
\text { Secondary outcomes } \\
\text { - Number of severe exacerbations } \\
\text { - Time to mild exacerbations } \\
\text { - Number of mild exacerbations } \\
\text { - Symptom free days } \\
\text { - QOL scores } \\
\text { - No particular variable was chosen to assess safety. }\end{array}$ \\
\hline
\end{tabular}




\begin{tabular}{|c|c|c|}
\hline & \multicolumn{2}{|c|}{$\begin{array}{l}\text { Exacerbation Definition: Severe - Deterioration in asthma requiring hospital or emer- } \\
\text { gency room treatment, or oral steroids (or an increase in ICS or other additional } \\
\text { treatment) or morning PEF } 70 \% \text { or less of baseline on two consecutive days. Severe } \\
\text { exacerbations requiring medical intervention were analysed separately. Mild exac- } \\
\text { erbation day - PEF } 80 \% \text { or less of baseline, relief medication } 2 \text { or more inhalations above } \\
\text { baseline, or awakenings due to asthma. Mild exacerbation defined as } 2 \text { consecutive mild } \\
\text { exacerbation days using the same criteria } \\
\text { Additional Data } \\
\text { Data on file from AstraZeneca indicate that } 0 / 118 \text { children under the age of } 12 \text { years had } \\
\text { at least one asthma related SAE on SMART and } 2 / 106 \text { on Pulmicort. Data on children } \\
\text { given a course of oral corticosteroids has not been obtained }\end{array}$} \\
\hline Notes & \multicolumn{2}{|c|}{$\begin{array}{l}\text { Adverse Events:SAE data given }(2,16,5) \text { of these }(0,7,2) \text { were related to asthma. Change } \\
\text { from baseline nights with awakenings were the same in both groups, P value in the paper } \\
\text { not used as it related to post treatment levels not changes. No SD data published in } \\
\text { the paper with respect to growth comparing budesonide/formoterol to Terbutaline as } \\
\text { reliever, so SD calculated from the other comparisons presented }\end{array}$} \\
\hline \multicolumn{3}{|l|}{ Risk of bias } \\
\hline Item & Authors' judgement & Description \\
\hline Adequate sequence generation? & Yes & See STAY - Adults \\
\hline Allocation concealment? & Unclear & See STAY - Adults \\
\hline $\begin{array}{l}\text { Blinding? } \\
\text { All outcomes }\end{array}$ & Yes & See STAY - Adults \\
\hline $\begin{array}{l}\text { Incomplete outcome data addressed? } \\
\text { All outcomes }\end{array}$ & Yes & See STAY - Adults \\
\hline
\end{tabular}

\section{STEAM}

Methods

The study was double-blind, randomised, active-controlled, multi-centre and multinational with a parallel group design comparing the efficacy and safety of Symbicort $80 / 4.5 \mu \mathrm{g} /$ inhalation, 2 inhalations once daily plus Symbicort 80/4.5 $\mu \mathrm{g} /$ inhalation asneeded (Symbicort single-inhaler therapy, SiT) with that of Pulmicort $160 \mu \mathrm{g} /$ inhalation, 2 inhalations once daily plus Bricanyl $0.4 \mathrm{mg} / \mathrm{dose}$ as-needed when given to adults and adolescents (12-80 years) for a period of 6 months in the treatment of asthma

This was a Multicentre study with 77 centres participating from the following countries: Argentina (5 centres), Brazil (7 centres), China ( 4 centres), Denmark (15 centres), Indonesia ( 6 centres), Norway (10 centres), The Philippines (10 centres), Spain (9 centres) , and Sweden (11 centres)

Participants

Population: Male and female subjects, 12 to 80 years with asthma, previously treated with 200-500 $\mu \mathrm{g}$ per day of inhaled glucocorticosteroids (IGCS). They had to have a forced expiratory volume in one second (FEV1 ) of $60-100 \%$ of predicted normal at Visit 1 and a reversibility in FEV1 from baseline of at least $12 \%$ at Visit 1 or 2, or a peak

Combination formoterol and budesonide as maintenance and reliever therapy versus inhaled steroid maintenance for chronic asthma in 32 adults and children (Review)

Copyright @ 2010 The Cochrane Collaboration. Published by John Wiley \& Sons, Ltd. 
expiratory flow (PEF) variability of at least $12 \%$ on at least 3 out of the last 10 days of the run-in. During the last 10 days of the run-in period the subjects also had to have used at least 7 inhalations of the as-needed medication. Run-in was on Budesonide $100 \mathrm{mcg}$ bd with Terbutaline prn (this represents around half the previous dose of ICS and LABA was withdrawn from the $20 \%$ participants who were taking LABA previously)

Baseline Characteristics: Mean age: 38 years. FEV1 75\% predicted. Mean ICS dose at enrolment $\mathbf{3 4 8} \mathrm{mcg} / \mathrm{day}$ and $\mathbf{2 0} \%$ were also on LABA. Hospital admission for asthma in the past year: unknown. Course of oral steroids for asthma in past year: unknown. Previous exacerbation not required for eligibility.

Interventions

1. Budesonide/formoterol $100 / 6 \mathrm{mcg}$ two inhalation in the evening [200 mcg budesonide/day], with additional doses as needed as reliever

2. Budesonide $\mathbf{2 0 0} \mathrm{mcg}$ two inhalations once daily [ $400 \mathrm{mcg}$ budesonide/day], with terbutaline reliever

*200 mcg actuator dose is described as $160 \mathrm{mcg}$ delivered dose in the paper

Outcomes

(1)

Primary outcome:

- Morning PEF.

Secondary outcomes

- Number of severe exacerbations

- FEV1

- Evening PEF

- Asthma symptom score

- As-needed medication

- Nights with awakenings due to asthma

- Asthma-control days

- Number of mild and severe exacerbation days

- As-needed free days

- Symptom-free days were added as outcomes before the data was unblinded.

Exacerbation Definition: Severe - Deterioration in asthma requiring hospital or emergency room treatment, or oral steroids, or at least $30 \%$ fall in PEF from baseline on two consecutive days. If prednisone was needed beyond 10 days this was counted as a second exacerbation. Mild exacerbation day - defined in other studies as PEF $80 \%$ or less of baseline(average of last 10 days of run-in), relief medication 2 or more inhalations above baseline, or a night with awakenings due to asthma. No report of definition in trial report Additional Data

Data on file from AstraZeneca indicate 12/354 patients with at least one course of oral steroids on SMART and 31/342 on Pulmicort. For asthma-aggravated SAE the figures were $0 / 1$ and for hospitalisation or ER visits $1 / 9$ (which suggests that most of these were ER visits as hospitalisation for asthma is a mandatory category for asthma SAE)

Risk of bias

\begin{tabular}{lll}
\hline Item & Authors' judgement & Description \\
\hline Adequate sequence generation? & Unclear & No details
\end{tabular}




\begin{tabular}{l|ll}
\hline Allocation concealment? & Unclear & No details \\
\hline $\begin{array}{l}\text { Blinding? } \\
\text { All outcomes }\end{array}$ & Yes & Double blind \\
\hline $\begin{array}{l}\text { Incomplete outcome data addressed? } \\
\text { All outcomes }\end{array}$ & Yes & $639 / 697(\mathbf{9 2 \% )}$ completed the study \\
\hline
\end{tabular}

\section{STYLE}

Methods

buhaler ${ }^{\circledR} 160 / 4.5 \mathrm{mcg} 1$ Inhalation b.i.d. Plus as-Needed) and Conventional Best Prac-
tice for the Treatment of Persistent Asthma in Adolescents and Adults - a 26 Weeks,
Randomised, Open-Label, Parallel-Group, Multicentre Study. July 2005 to December
2006
53 study locations in Chile, Croatia, Czech Republic, Greece, Iceland, Latvia, Lithuania,
Portugal, Slovakia and Slovenia

Age at least 12 years. Aim to enrol 1000 participants.

Inclusion Criteria: - - Diagnosis of asthma at least 3 months - Prescribed daily use of glucocorticosteroids at a dose $>320 \mathrm{mcg} /$ day for at least 3 months prior to Visit 1

Exclusion Criteria: - Smoking history $>10$ pack-years - Asthma exacerbation requiring change in asthma treatment during the last 14 days prior to inclusion - Any significant disease or disorder that may jeopardize the safety of the patient

Interventions

The purpose of the study is to compare the efficacy of a flexible dose of Symbicort with conventional stepwise treatment according to asthma treatment guidelines in patients with persistent asthma

1. Symbicort Turbuhaler ${ }^{\circledR} 160 / 4.5 \mathrm{mcg} 1$ Inhalation b.i.d. Plus as-Needed

2. Conventional Best Practice

\section{Primary outcome:}

- Time to first severe asthma exacerbation

\section{Secondary outcome:}

- Number of asthma exacerbations

- Mean use of as-needed medication

- Prescribed asthma medication

- Asthma Control Questionnaire

- Asthma related costs (direct asthma medication, direct non-medication costs and indirect costs)

Safety: Serious Adverse Events and discontinuations due to adverse eventsAll variables assessed over the 6 months treatment period

Definition of severe exacerbation

Not specified

\section{Additional Data}

Data on file from AstraZeneca indicates no patients with admission for asthma and 43 with at least one course of oral steroids $(\mathrm{N}=497)$ on SMART and 3/498 and 56/498 respectively on current best practice 
STYLE (Continued)

\begin{tabular}{|c|c|c|}
\hline Notes & \multicolumn{2}{|c|}{$\begin{array}{l}\text { This study was completed in December } 2006 \text { but no results have yet been published in } \\
\text { medical journals or on the AstraZeneca web site }\end{array}$} \\
\hline \multicolumn{3}{|l|}{ Risk of bias } \\
\hline Item & Authors' judgement & Description \\
\hline Adequate sequence generation? & Unclear & No details \\
\hline Allocation concealment? & Unclear & No details \\
\hline $\begin{array}{l}\text { Blinding? } \\
\text { All outcomes }\end{array}$ & No & Open \\
\hline $\begin{array}{l}\text { Incomplete outcome data addressed? } \\
\text { All outcomes }\end{array}$ & Unclear & No details \\
\hline
\end{tabular}

Characteristics of excluded studies [ordered by study ID]

\begin{tabular}{ll}
\hline Study & Reason for exclusion \\
\hline Balanzat 2004 & Overview of three existing trials \\
\hline Bousquet 2007 & Budesonide/formoterol for maintenance and relief in uncontrolled asthma vs. high-dose salmeterol/fluticasone \\
\hline COMPASS & Different doses of Symbicort used for maintenance \\
\hline COSMOS & Comparison with maintenance on Fluticasone/Salmeterol \\
\hline D5890C00003 & SiT compared to higher dose maintenance regimen on BDF and Budesonide \\
\hline Ind 2002 & Formoterol v Terbutaline as reliever \\
\hline Jenkins 2007 & budesonide/formoterol dose adjustment with FeNO (not used as reliever) \\
\hline Jonkers 2006 & Single dose study \\
\hline Loukides 2005 & SiT compared to separate inhalers for maintenance treatment and Formoterol relief \\
\hline Lundborg 2006 & Higher dose combination maintenance therapy but no ICS maintenance arm \\
\hline Richter 2007 & Formoterol not combination therapy as reliever \\
\hline SMILE & No comparison with maintenance ICS arm \\
\hline
\end{tabular}

Combination formoterol and budesonide as maintenance and reliever therapy versus inhaled steroid maintenance for chronic asthma in 35 


\begin{tabular}{ll}
\hline SOMA & No maintenance ICS arm \\
\hline Tattersfield 2001 & Formoterol v Terbutaline as reliever \\
\hline
\end{tabular}

\section{Characteristics of ongoing studies [ordered by study ID]}

\section{NCT00463866}

\begin{tabular}{|c|c|}
\hline Trial name or title & NCT00463866 \\
\hline Methods & $\begin{array}{l}\text { The purpose of this study is to evaluate the effect of two different maintenance doses of Symbicort SMART } \\
\text { (Symbicort Maintenance And Reliever Therapy) in adult asthmatic patients. A } 6 \text { month treatment period. } \\
\text { Estimated enrolment } 8000\end{array}$ \\
\hline Participants & $\begin{array}{l}\text { Inclusion Criteria: } \\
\text { - Patients at out-patient clinics } \\
\text { - > } 18 \text { years with a minimum of } 6 \text { months documented history of persistent asthma who have used } \\
\text { inhaled glucocorticosteroids for at least one month and have a history of use in rapid-acting B2 agonists for } \\
\text { symptom relief } \\
\text { Exclusion Criteria: } \\
\text { - Asthma exacerbation within the last } 14 \text { days prior to study start } \\
\text { - subject aged }>40 \text { years with a smoking history of }>10 \text { pack-years } \\
\text { - subjects with chronic obstructive lung disease or other significant respiratory disease }\end{array}$ \\
\hline Interventions & Two different doses of SMART therapy - unclear if there is a placebo arm \\
\hline Outcomes & Not described \\
\hline Starting date & March 2007 \\
\hline \multicolumn{2}{|l|}{ Contact information } \\
\hline Notes & \\
\hline
\end{tabular}

\section{NCT00628758}

\begin{tabular}{ll} 
Trial name or title & NCT00628758 \\
\hline Methods & $\begin{array}{l}\text { The primary objective is to compare the efficacy of Symbicort Single inhaler Therapy with treatment according } \\
\text { to conventional best practice in adult patients with persistent asthma. Treatment, Randomized, Open Label, } \\
\text { Active Control, Parallel Assignment, Efficacy Study. Estimated enrolment 1000 }\end{array}$ \\
\hline Participants & No details \\
\hline Interventions & $\begin{array}{l}\text { A Comparison of Symbicort Single Inhaler Therapy (Symbicort Turbuhaler 160/4.5mcg, 1 Inhalation b.i.d. } \\
\text { Plus as Needed) and Conventional Best Practice for the Treatment of Persistent Asthma in Adults a -26-Week, } \\
\text { Randomized, Open-Label, Parallel-Group, Multicentre Study }\end{array}$
\end{tabular}

Combination formoterol and budesonide as maintenance and reliever therapy versus inhaled steroid maintenance for chronic asthma in 36 


\begin{tabular}{l|l}
\hline Outcomes & $\begin{array}{l}\text { Primary Outcome Measures: Time to first severe asthma exacerbation. Defined deterioration in asthma leading } \\
\text { to at least one of the following: } 1 \text { Hospitalisation/Emergency room (or equivalent) treatment due to asthma } \\
\text { 2.Oral GC treatment due to asthma for at least 3 days }\end{array}$ \\
& $\begin{array}{l}\text { Secondary Outcome Measures: Number of severe asthma exacerbations } \\
\text { Change in AQLQ(S) score from randomisation (visit 1) to Visits } 4 \\
\text { Mean use of as-needed medication per day during treatment period } \\
\text { Prescribed asthma medication during the treatment period }\end{array}$ \\
\hline Starting date & March 2006 \\
\hline Contact information & \\
\hline Notes & \\
\hline
\end{tabular}

\section{SPAIN 2008}

Trial name or title Study SPAIN

A Comparison of Symbicort Single Inhaler Therapy (Symbicort Turbuhaler 160/4.5 mcg, 1 Inhalation b.i. d. Plus as Needed) and Conventional Best Practice for the Treatment of Persistent Asthma in Adults - a 26Week, Randomised, Open-Label, Parallel-Group, Multicentre Study. Estimated enrolment: 1000

\begin{tabular}{|c|c|}
\hline Methods & Treatment, Randomized, Open Label, Active Control, Parallel Assignment, Efficacy Study \\
\hline Participants & $\begin{array}{l}\text { Inclusion Criteria: } \\
\text { - Age } 18 \text { years or over } \\
\text { - Minimum of } 3 \text { months history of asthma, diagnosed according to the American Thoracic Society } \\
\text { (ATS) definition (9). } \\
\text { - Prescribed inhaled GCS at a dose of } ? 320 \mu \mathrm{g} / \text { day and within the approved label for the relevant drug } \\
\text { during the last } 3 \text { months prior to Visit } 1 . \\
\text { - Either daily maintenance treatment with both inhaled GCS and long-acting b2-agonist(LABA) or } \\
\text { daily treatment with inhaled GCS alone (i.e. without LABA) } \\
\text { - A history of sub optimal asthma control the month prior to enrolment as judged by the investigator } \\
\text { - Use of at least } 3 \text { inhalations of as needed medication for symptom relief during the last } 7 \text { days before } \\
\text { enrolment } \\
\text { Exclusion Criteria: } \\
\text { - Previous treatment with Symbicort Single Inhaler; } \\
\text { - Use of any beta-blocking agent, including eye-drops and oral GCS as maintenance treatment. } \\
\text { - Known or suspected hypersensitivity to study therapy or excipients. } \\
\text { - A history of smoking less than } 10 \text { pack years. } \\
\text { - Asthma exacerbation reguiring change in asthma treatment during the last } 14 \text { days prior to or at Visit } 1 .\end{array}$ \\
\hline
\end{tabular}

Interventions A Comparison of Symbicort Single Inhaler Therapy (Symbicort Turbuhaler 160/4.5 mcg, 1 Inhalation b.i.d. Plus as Needed) and Conventional Best Practice

Outcomes

The primary outcome variable will be time to first severe asthma exacerbations. Exacerbations are considered an appropriate outcome variable by CPMP The definition of a severe asthma exacerbation is based on the same guideline 
SPAIN 2008 (Continued)

A secondary objective is to collect safety data for treatment in the two treatment groups in adult patients with persistent asthma

\begin{tabular}{l|l}
\hline Starting date & Sept 2006 \\
\hline Contact information & \\
\hline Notes & \\
\hline
\end{tabular}

\section{SYMPHONIE 2008}

\begin{tabular}{|c|c|}
\hline Trial name or title & SYMPHONIE \\
\hline Methods & $\begin{array}{l}\text { A Comparison of Symbicort Single Inhaler and Conventional Best Practice for the Treatment of Persistent } \\
\text { Asthma in Adolescents and Adults. A 26-Week, Randomised, Open, Parallel Group Multicentre Study. } \\
\text { Estimated enrolment: } 1000\end{array}$ \\
\hline Participants & $\begin{array}{l}\text { Inclusion Criteria: } \\
\text { - Age } 12 \text { years and older } \\
\text { - Minimum of } 3 \text { months history of asthma, diagnosed according to the American Thoracic Society } \\
\text { (ATS) definition. Prescribed inhaled GCS at a dose of } 3400 \mu \mathrm{g} / \mathrm{day} \text { and within the approved label for the } \\
\text { relevant drug during the last } 3 \text { months prior to Visit } 1 . \\
\text { Exclusion Criteria: } \\
\text { - Use of any beta-blocking agent, including eye-drops, Use of oral GCS as maintenance treatment, A } \\
\text { history of smoking }{ }^{3} 10 \text { pack years ( } 1 \text { pack year }=1 \text { pack ( } 20 \text { cigarettes) per day for one year or equivalent). }\end{array}$ \\
\hline Interventions & $\begin{array}{l}\text { A flexible dose of Symbicort compared with conventional stepwise treatment according to asthma treatment } \\
\text { guidelines in patients with persistent asthma }\end{array}$ \\
\hline Outcomes & $\begin{array}{l}\text { Primary Outcome Measures: Time to first severe asthma exacerbation } \\
\text { Secondary Outcome Measures: Number of asthma exacerbations, Mean use of as-needed medication, Pre- } \\
\text { scribed asthma medication, Asthma Control Questionnaire, Satisfaction with Asthma Treatment Question- } \\
\text { naire, Safety: Serious Adverse Events and discontinuations due to adverse events }\end{array}$ \\
\hline Starting date & Sept 2005 \\
\hline \multicolumn{2}{|l|}{ Contact information } \\
\hline Notes & \\
\hline
\end{tabular}


DATA AND ANALYSES

Comparison 1. Adults and Adolescents treated with Single Inhaler Therapy versus Current Best Practice

\begin{tabular}{|c|c|c|c|c|}
\hline Outcome or subgroup title & $\begin{array}{l}\text { No. of } \\
\text { studies }\end{array}$ & $\begin{array}{c}\text { No. of } \\
\text { participants }\end{array}$ & Statistical method & Effect size \\
\hline $\begin{array}{l}1 \text { Patients with exacerbations } \\
\text { causing hospitalisation }\end{array}$ & 5 & 5378 & Peto Odds Ratio (Peto, Fixed, 95\% CI) & $0.59[0.24,1.45]$ \\
\hline $\begin{array}{l}2 \text { Patients with exacerbations } \\
\text { treated with oral steroids }\end{array}$ & 4 & 4470 & Odds Ratio (M-H, Fixed, 95\% CI) & $0.83[0.66,1.03]$ \\
\hline 3 Serious Adverse Events (fatal) & 3 & 4281 & Peto Odds Ratio (Peto, Fixed, 95\% CI) & $1.95[0.39,9.67]$ \\
\hline $\begin{array}{l}4 \text { Serious Adverse Events } \\
\text { (non-fatal) }\end{array}$ & 3 & 4281 & Odds Ratio (M-H, Fixed, 95\% CI) & $1.02[0.68,1.52]$ \\
\hline $\begin{array}{l}5 \text { Discontinuation due to Adverse } \\
\text { Events }\end{array}$ & 3 & 4281 & Odds Ratio (M-H, Fixed, 95\% CI) & $2.92[1.70,5.01]$ \\
\hline $\begin{array}{l}6 \text { Patients with "severe" } \\
\text { exacerbation (time to event) }\end{array}$ & 3 & 4281 & Hazard Ratio (Fixed, 95\% CI) & $0.96[0.85,1.07]$ \\
\hline 7 Change in PEF (\% predicted) & 1 & & Mean Difference (Fixed, 95\% CI) & Subtotals only \\
\hline $\begin{array}{l}8 \text { Rescue Medication Use (puffs } \\
\text { per day) }\end{array}$ & 1 & & Mean Difference (Fixed, 95\% CI) & Subtotals only \\
\hline $\begin{array}{l}9 \text { Quality of Life (Change in ACQ } \\
\text { score) }\end{array}$ & 2 & & Mean Difference (Fixed, 95\% CI) & Totals not selected \\
\hline 10 ICS dose (micrograms per day) & 3 & & Mean Difference (Fixed, 95\% CI) & Totals not selected \\
\hline
\end{tabular}

Comparison 2. Adults and Adolescents treated with Single Inhaler Therapy versus fixed dose ICS

\begin{tabular}{|c|c|c|c|c|}
\hline Outcome or subgroup title & $\begin{array}{l}\text { No. of } \\
\text { studies }\end{array}$ & $\begin{array}{c}\text { No. of } \\
\text { participants }\end{array}$ & Statistical method & Effect size \\
\hline $\begin{array}{l}1 \text { Patients with exacerbations } \\
\text { causing hospitalisation }\end{array}$ & 3 & 4209 & Peto Odds Ratio (Peto, Fixed, 95\% CI) & $0.56[0.28,1.09]$ \\
\hline $\begin{array}{l}\text { 1.1 Single inhaler therapy } \\
\text { versus higher dose ICS }\end{array}$ & 3 & 4209 & Peto Odds Ratio (Peto, Fixed, 95\% CI) & $0.56[0.28,1.09]$ \\
\hline $\begin{array}{l}2 \text { Patients with exacerbations } \\
\text { treated with oral steroids }\end{array}$ & 4 & 4280 & Odds Ratio (M-H, Fixed, 95\% CI) & $0.54[0.45,0.64]$ \\
\hline $\begin{array}{l}2.1 \text { Single inhaler therapy } \\
\text { versus higher dose ICS }\end{array}$ & 3 & 4209 & Odds Ratio (M-H, Fixed, 95\% CI) & $0.53[0.44,0.63]$ \\
\hline $\begin{array}{l}2.2 \text { Single inhaler therapy } \\
\text { versus same dose ICS }\end{array}$ & 1 & 71 & Odds Ratio (M-H, Fixed, 95\% CI) & $1.42[0.29,6.86]$ \\
\hline 3 Serious Adverse Events (fatal) & 3 & 4209 & Peto Odds Ratio (Peto, Fixed, 95\% CI) & $0.37[0.05,2.62]$ \\
\hline $\begin{array}{l}\text { 3.1 Single inhaler therapy } \\
\text { versus higher dose ICS }\end{array}$ & 3 & 4209 & Peto Odds Ratio (Peto, Fixed, 95\% CI) & $0.37[0.05,2.62]$ \\
\hline $\begin{array}{l}4 \text { Serious Adverse Events } \\
\text { (non-fatal) }\end{array}$ & 3 & 4209 & Odds Ratio (M-H, Fixed, 95\% CI) & $0.97[0.73,1.29]$ \\
\hline $\begin{array}{l}\text { 4.1 Single inhaler therapy } \\
\text { versus higher dose ICS }\end{array}$ & 3 & 4209 & Odds Ratio (M-H, Fixed, 95\% CI) & $0.97[0.73,1.29]$ \\
\hline
\end{tabular}

Combination formoterol and budesonide as maintenance and reliever therapy versus inhaled steroid maintenance for chronic asthma in 39 adults and children (Review)

Copyright @ 2010 The Cochrane Collaboration. Published by John Wiley \& Sons, Ltd. 


\begin{tabular}{|c|c|c|c|c|}
\hline $\begin{array}{l}5 \text { Discontinuation due to Adverse } \\
\text { Events }\end{array}$ & 2 & 2586 & Odds Ratio (M-H, Fixed, 95\% CI) & $0.57[0.35,0.93]$ \\
\hline $\begin{array}{l}5.1 \text { Single inhaler therapy } \\
\text { versus higher dose ICS }\end{array}$ & 2 & 2586 & Odds Ratio (M-H, Fixed, 95\% CI) & $0.57[0.35,0.93]$ \\
\hline $\begin{array}{l}6 \text { Patients with "severe" } \\
\text { exacerbation (time to event) }\end{array}$ & 2 & 2586 & Hazard Ratio (Fixed, 95\% CI) & $0.59[0.49,0.70]$ \\
\hline $\begin{array}{l}\text { 6.1 Single inhaler therapy } \\
\text { versus higher dose ICS }\end{array}$ & 2 & 2586 & Hazard Ratio (Fixed, 95\% CI) & $0.59[0.49,0.70]$ \\
\hline 7 PEF (Litres/min) & 3 & & Mean Difference (Fixed, 95\% CI) & $22.29[17.62,26.95]$ \\
\hline $\begin{array}{l}7.1 \text { Single inhaler therapy } \\
\text { versus higher dose ICS }\end{array}$ & 3 & & Mean Difference (Fixed, 95\% CI) & $22.29[17.62,26.95]$ \\
\hline 8 FEV1 increase (Litres) & 3 & & Mean Difference (Fixed, 95\% CI) & $0.10[0.07,0.13]$ \\
\hline $\begin{array}{l}8.1 \text { Single inhaler therapy } \\
\text { versus higher dose ICS }\end{array}$ & 2 & & Mean Difference (Fixed, 95\% CI) & $0.10[0.08,0.13]$ \\
\hline $\begin{array}{l}8.2 \text { Single inhaler therapy } \\
\text { versus same dose ICS }\end{array}$ & 1 & & Mean Difference (Fixed, 95\% CI) & $0.01[-0.19,0.21]$ \\
\hline $\begin{array}{l}9 \text { Rescue Medication Use (puffs } \\
\text { per day) }\end{array}$ & 3 & & Mean Difference (Fixed, 95\% CI) & $-0.37[-0.49,-0.25]$ \\
\hline $\begin{array}{l}9.1 \text { Single inhaler therapy } \\
\text { versus higher dose ICS }\end{array}$ & 3 & & Mean Difference (Fixed, 95\% CI) & $-0.37[-0.49,-0.25]$ \\
\hline $\begin{array}{l}10 \text { Quality of Life (Fall in ACQ } \\
\text { score) }\end{array}$ & 1 & & Mean Difference (Fixed, 95\% CI) & $0.15[-0.46,0.76]$ \\
\hline $\begin{array}{l}10.1 \text { Single inhaler therapy } \\
\text { versus same dose ICS }\end{array}$ & 1 & & Mean Difference (Fixed, 95\% CI) & $0.15[-0.46,0.76]$ \\
\hline
\end{tabular}

\section{Comparison 3. Children treated with Single Inhaler Therapy versus higher fixed dose ICS}

$\begin{array}{llccc}\text { Outcome or subgroup title } & \begin{array}{l}\text { No. of } \\ \text { studies }\end{array} & \begin{array}{c}\text { No. of } \\ \text { participants }\end{array} & \text { Statistical method } & \text { Effect size }\end{array}$

\begin{tabular}{|c|c|c|c|c|}
\hline $\begin{array}{l}1 \text { Patients with exacerbations } \\
\text { causing hospitalisation }\end{array}$ & 1 & & Peto Odds Ratio (Peto, Fixed, 95\% CI) & Totals not selected \\
\hline 2 Serious Adverse Events (fatal) & 1 & 224 & Odds Ratio (M-H, Fixed, 95\% CI) & Not estimable \\
\hline $\begin{array}{l}3 \text { Serious Adverse Events } \\
\text { (non-fatal) }\end{array}$ & 1 & & Odds Ratio (M-H, Fixed, 95\% CI) & Totals not selected \\
\hline 4 Annual Height gain $(\mathrm{cms})$ & 1 & & Mean Difference (IV, Fixed, 95\% CI) & Totals not selected \\
\hline $\begin{array}{l}5 \text { Children with low plasma } \\
\text { cortisol }(<400 \mathrm{nmol} / \mathrm{L})\end{array}$ & 1 & & Odds Ratio (M-H, Fixed, 95\% CI) & Totals not selected \\
\hline $\begin{array}{l}6 \text { Patients with an exacerbation } \\
\text { requiring increase in ICS or } \\
\text { other treatment }\end{array}$ & 1 & & Odds Ratio (M-H, Fixed, 95\% CI) & Totals not selected \\
\hline 7 Change in morning PEF (L/min) & 1 & & Mean Difference (Fixed, 95\% CI) & Totals not selected \\
\hline 8 Change in clinic FEV1(Litres) & 1 & & Mean Difference (Fixed, 95\% CI) & Totals not selected \\
\hline $\begin{array}{l}9 \text { As needed medication use over } \\
24 \text { hours }\end{array}$ & 1 & & Mean Difference (Fixed, 95\% CI) & Totals not selected \\
\hline 10 Nocturnal awakenings & 1 & & Mean Difference (Fixed, 95\% CI) & Totals not selected \\
\hline
\end{tabular}

Combination formoterol and budesonide as maintenance and reliever therapy versus inhaled steroid maintenance for chronic asthma in 40 adults and children (Review) 
Analysis I.I. Comparison I Adults and Adolescents treated with Single Inhaler Therapy versus Current Best Practice, Outcome I Patients with exacerbations causing hospitalisation.

Review: Combination formoterol and budesonide as maintenance and reliever therapy versus inhaled steroid maintenance for chronic asthma in adults and children Comparison: I Adults and Adolescents treated with Single Inhaler Therapy versus Current Best Practice

Outcome: I Patients with exacerbations causing hospitalisation

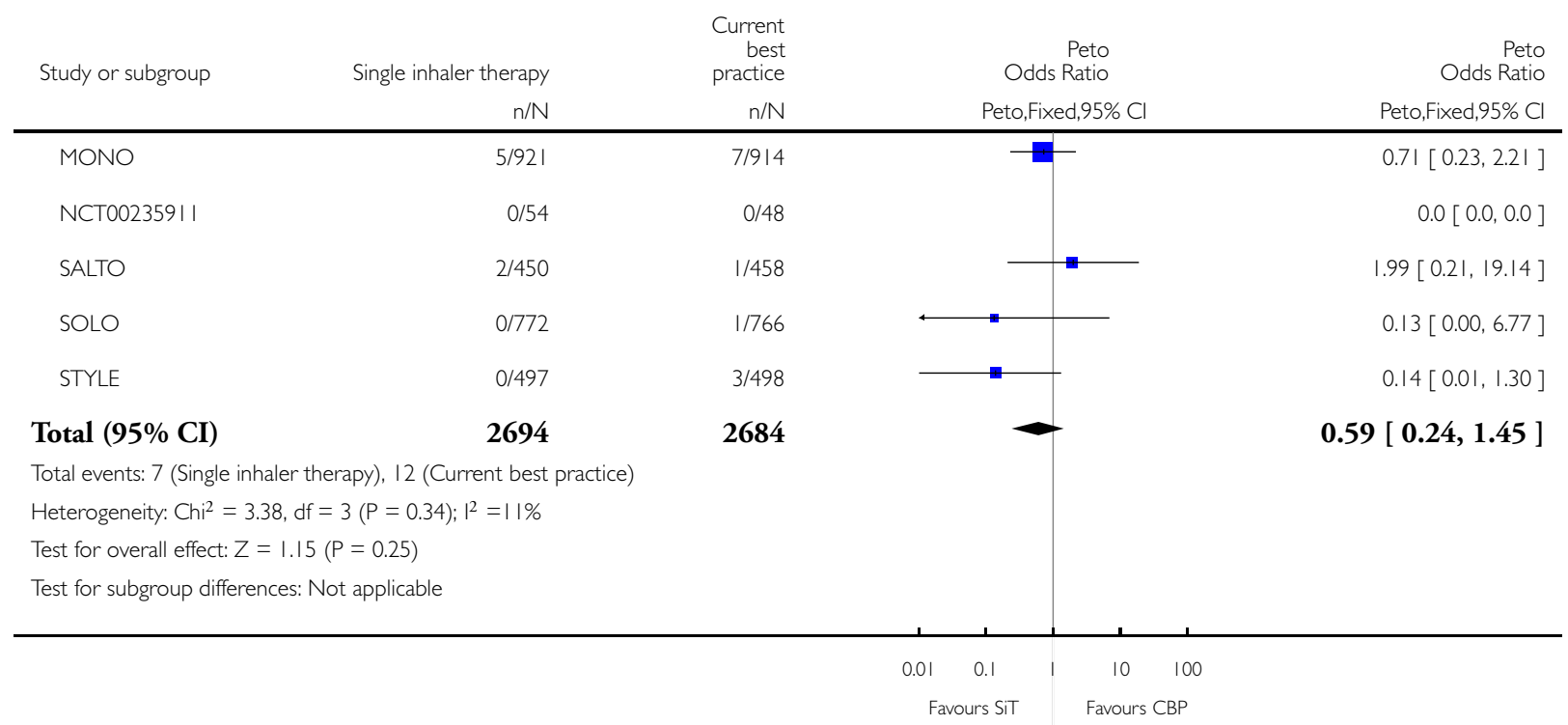

Combination formoterol and budesonide as maintenance and reliever therapy versus inhaled steroid maintenance for chronic asthma in $4 \mathrm{I}$ adults and children (Review)

Copyright (C) 2010 The Cochrane Collaboration. Published by John Wiley \& Sons, Ltd. 
Analysis I.2. Comparison I Adults and Adolescents treated with Single Inhaler Therapy versus Current Best Practice, Outcome 2 Patients with exacerbations treated with oral steroids.

Review: Combination formoterol and budesonide as maintenance and reliever therapy versus inhaled steroid maintenance for chronic asthma in adults and children

Comparison: I Adults and Adolescents treated with Single Inhaler Therapy versus Current Best Practice

Outcome: 2 Patients with exacerbations treated with oral steroids

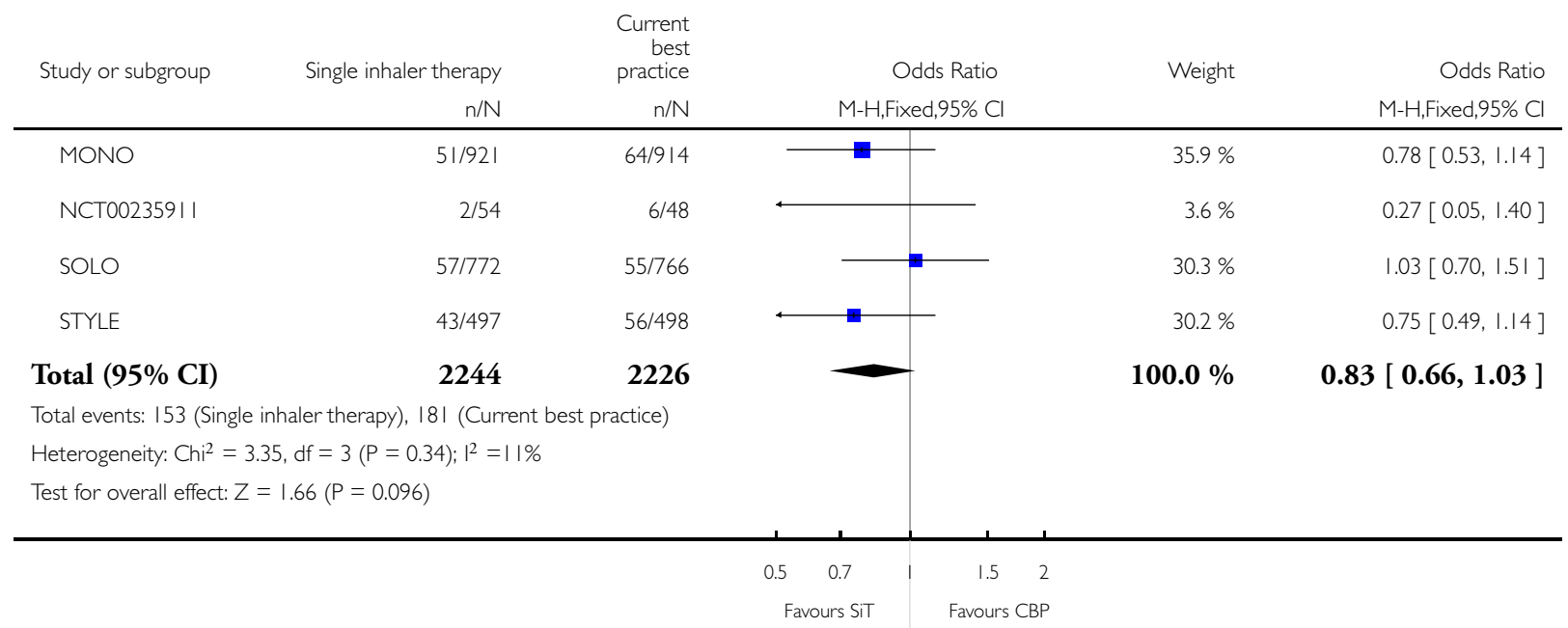

Combination formoterol and budesonide as maintenance and reliever therapy versus inhaled steroid maintenance for chronic asthma in 
Analysis I.3. Comparison I Adults and Adolescents treated with Single Inhaler Therapy versus Current Best Practice, Outcome 3 Serious Adverse Events (fatal).

Review: Combination formoterol and budesonide as maintenance and reliever therapy versus inhaled steroid maintenance for chronic asthma in adults and children Comparison: I Adults and Adolescents treated with Single Inhaler Therapy versus Current Best Practice

Outcome: 3 Serious Adverse Events (fatal)

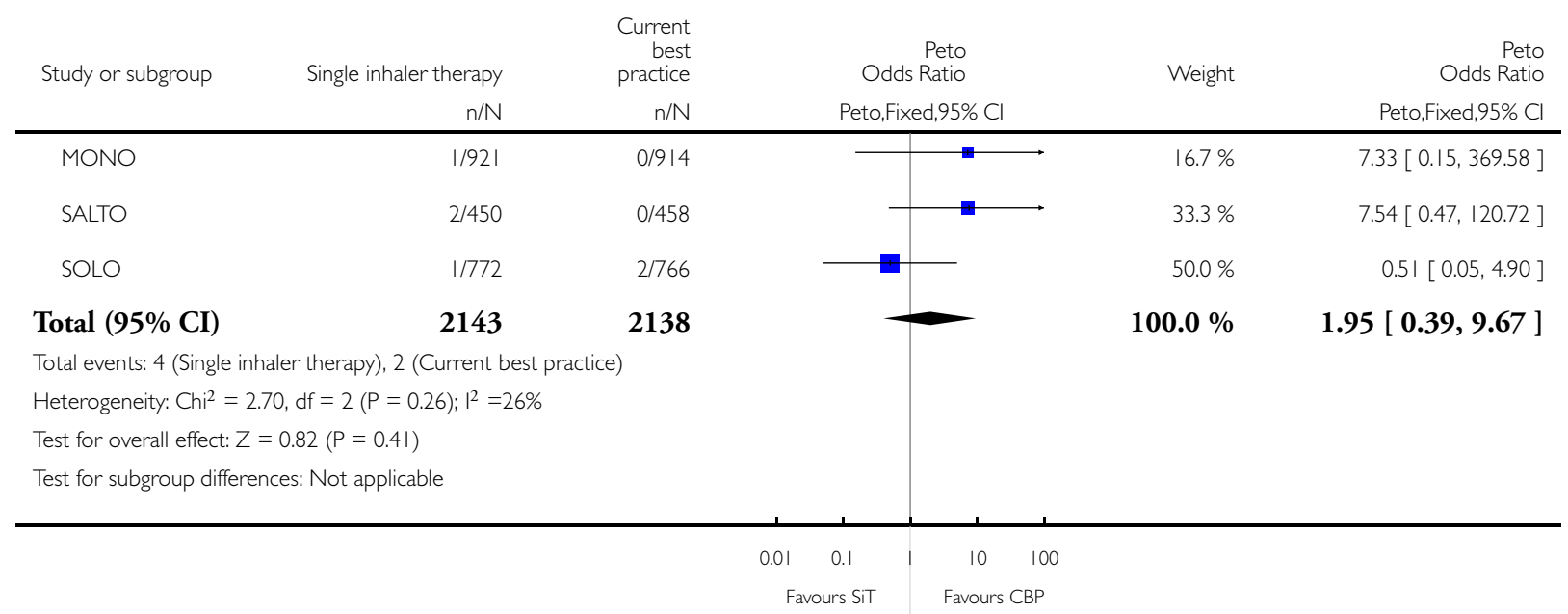


Analysis I.4. Comparison I Adults and Adolescents treated with Single Inhaler Therapy versus Current Best Practice, Outcome 4 Serious Adverse Events (non-fatal).

Review: Combination formoterol and budesonide as maintenance and reliever therapy versus inhaled steroid maintenance for chronic asthma in adults and children Comparison: I Adults and Adolescents treated with Single Inhaler Therapy versus Current Best Practice

Outcome: 4 Serious Adverse Events (non-fatal)

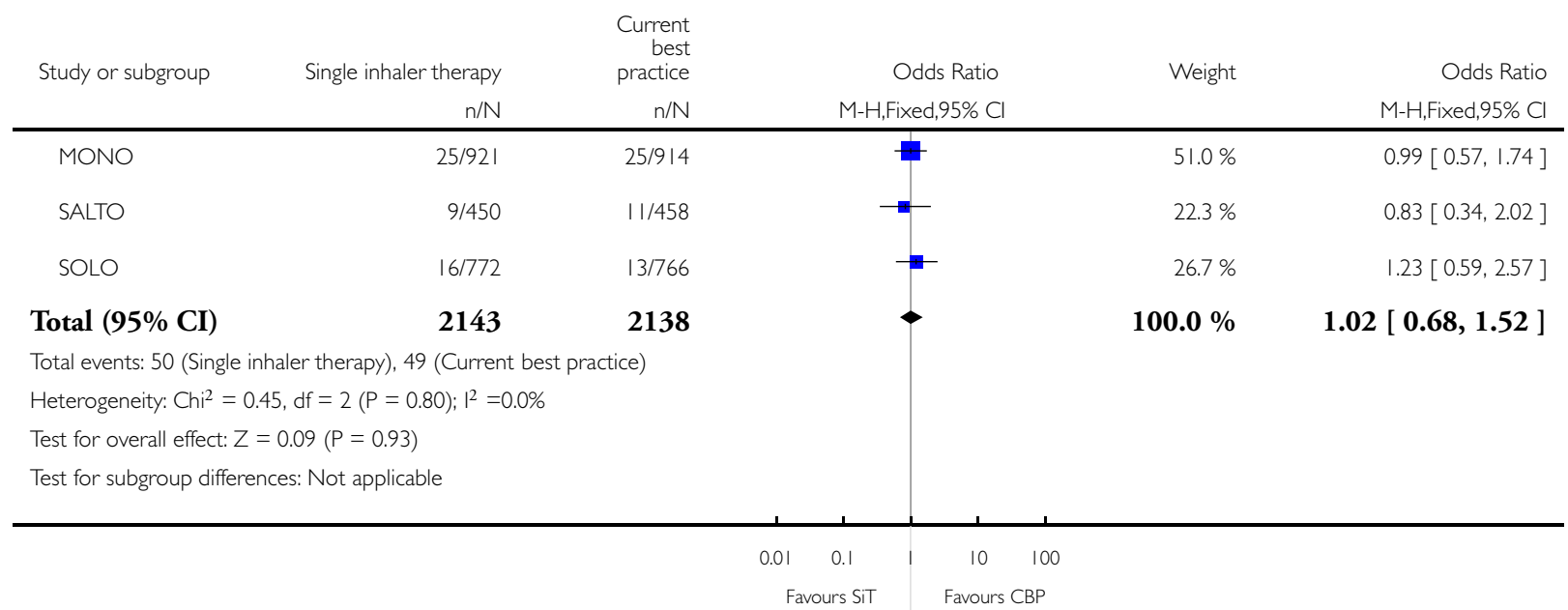

Analysis I.5. Comparison I Adults and Adolescents treated with Single Inhaler Therapy versus Current Best Practice, Outcome 5 Discontinuation due to Adverse Events.

Review: Combination formoterol and budesonide as maintenance and reliever therapy versus inhaled steroid maintenance for chronic asthma in adults and children Comparison: I Adults and Adolescents treated with Single Inhaler Therapy versus Current Best Practice

Outcome: 5 Discontinuation due to Adverse Events

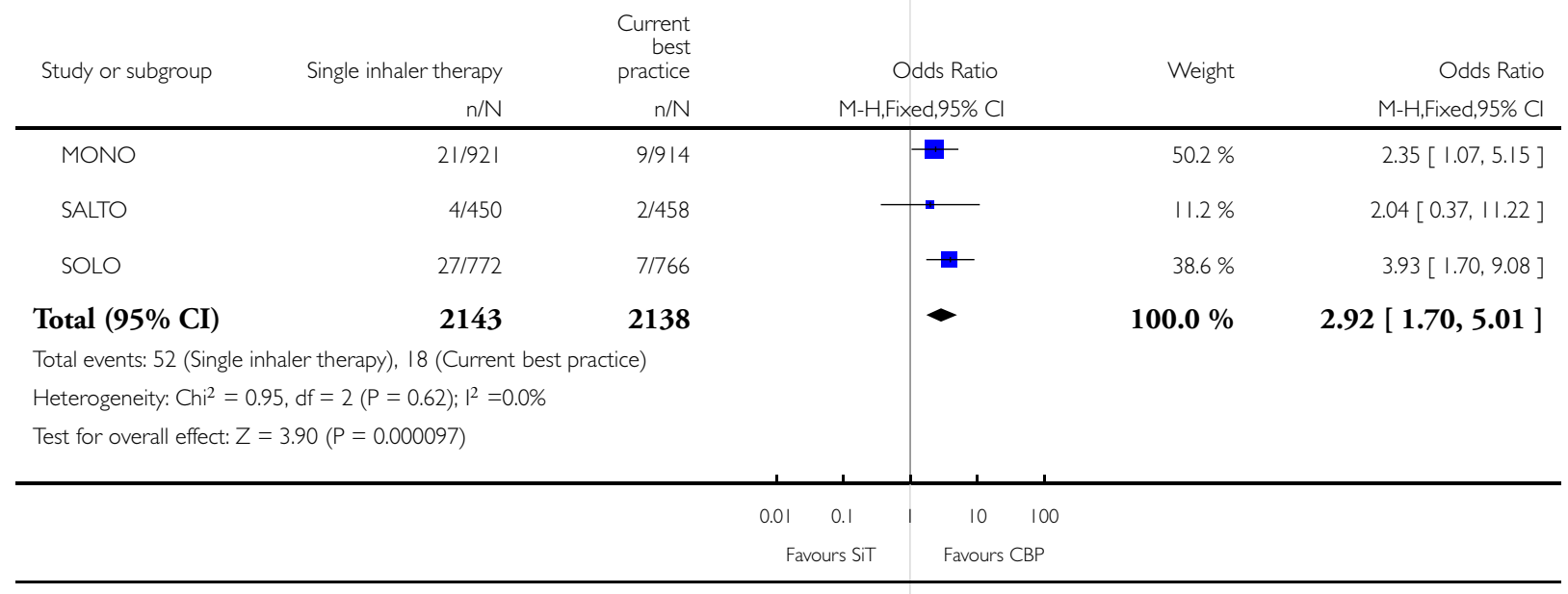

Combination formoterol and budesonide as maintenance and reliever therapy versus inhaled steroid maintenance for chronic asthma in adults and children (Review)

Copyright ( 2010 The Cochrane Collaboration. Published by John Wiley \& Sons, Ltd. 
Analysis I.6. Comparison I Adults and Adolescents treated with Single Inhaler Therapy versus Current Best Practice, Outcome 6 Patients with "severe" exacerbation (time to event).

Review: Combination formoterol and budesonide as maintenance and reliever therapy versus inhaled steroid maintenance for chronic asthma in adults and children

Comparison: I Adults and Adolescents treated with Single Inhaler Therapy versus Current Best Practice

Outcome: 6 Patients with "severe" exacerbation (time to event)

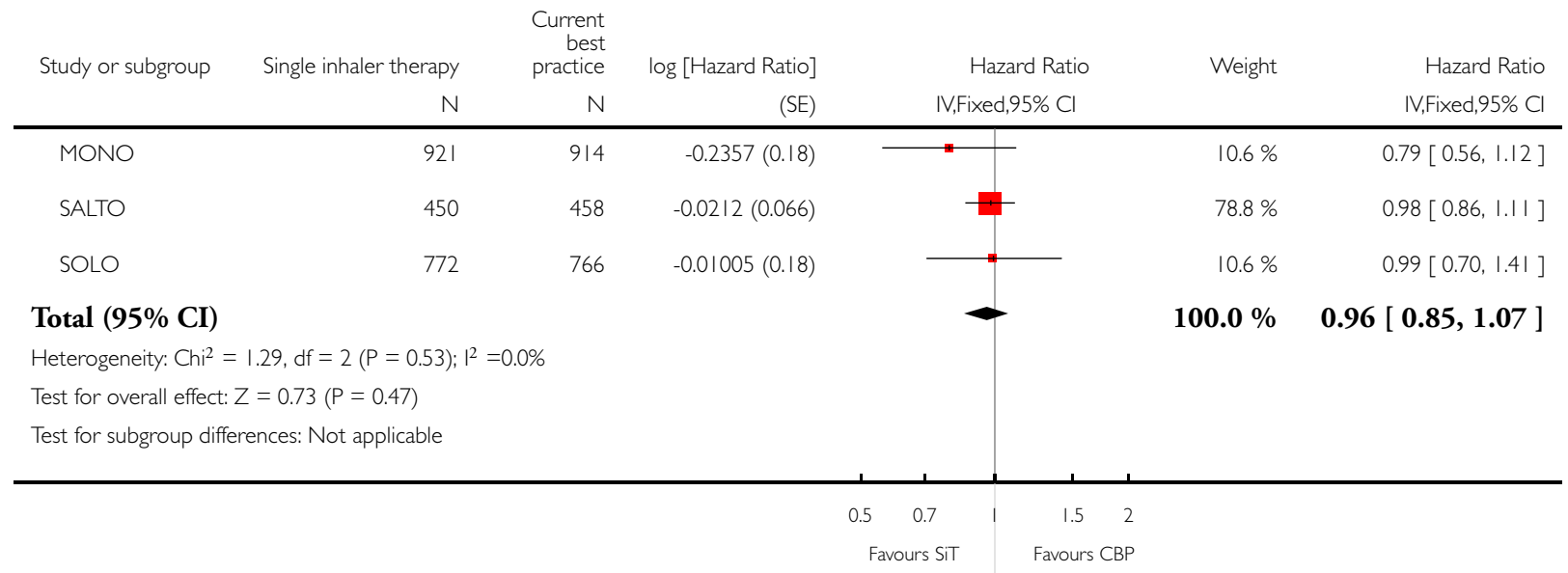


Analysis I.7. Comparison I Adults and Adolescents treated with Single Inhaler Therapy versus Current Best Practice, Outcome 7 Change in PEF (\% predicted).

Review: Combination formoterol and budesonide as maintenance and reliever therapy versus inhaled steroid maintenance for chronic asthma in adults and children

Comparison: I Adults and Adolescents treated with Single Inhaler Therapy versus Current Best Practice

Outcome: 7 Change in PEF (\% predicted)

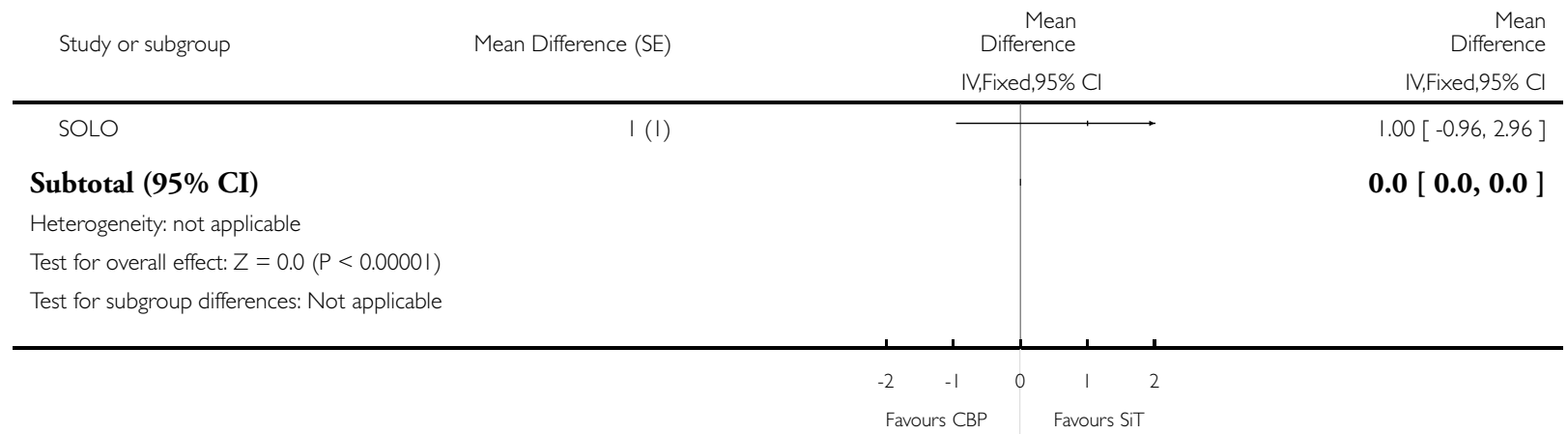

\section{Analysis I.8. Comparison I Adults and Adolescents treated with Single Inhaler Therapy versus Current} Best Practice, Outcome 8 Rescue Medication Use (puffs per day).

Review: Combination formoterol and budesonide as maintenance and reliever therapy versus inhaled steroid maintenance for chronic asthma in adults and children Comparison: I Adults and Adolescents treated with Single Inhaler Therapy versus Current Best Practice

Outcome: 8 Rescue Medication Use (puffs per day)

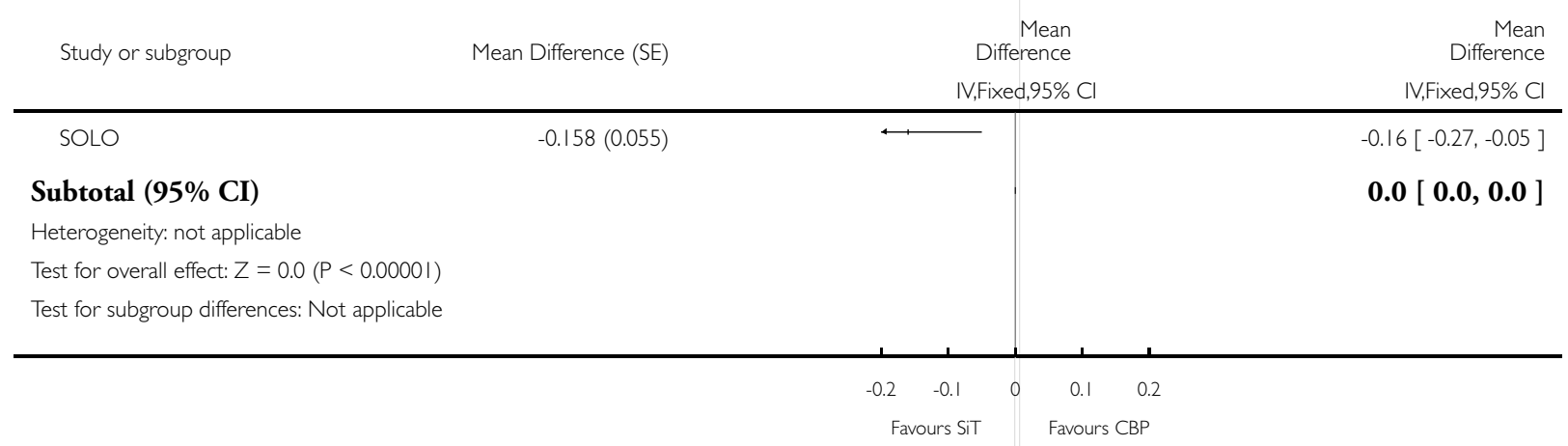

Combination formoterol and budesonide as maintenance and reliever therapy versus inhaled steroid maintenance for chronic asthma in 
Analysis I.9. Comparison I Adults and Adolescents treated with Single Inhaler Therapy versus Current Best Practice, Outcome 9 Quality of Life (Change in ACQ score).

Review: Combination formoterol and budesonide as maintenance and reliever therapy versus inhaled steroid maintenance for chronic asthma in adults and children Comparison: I Adults and Adolescents treated with Single Inhaler Therapy versus Current Best Practice

Outcome: 9 Quality of Life (Change in ACQ score)

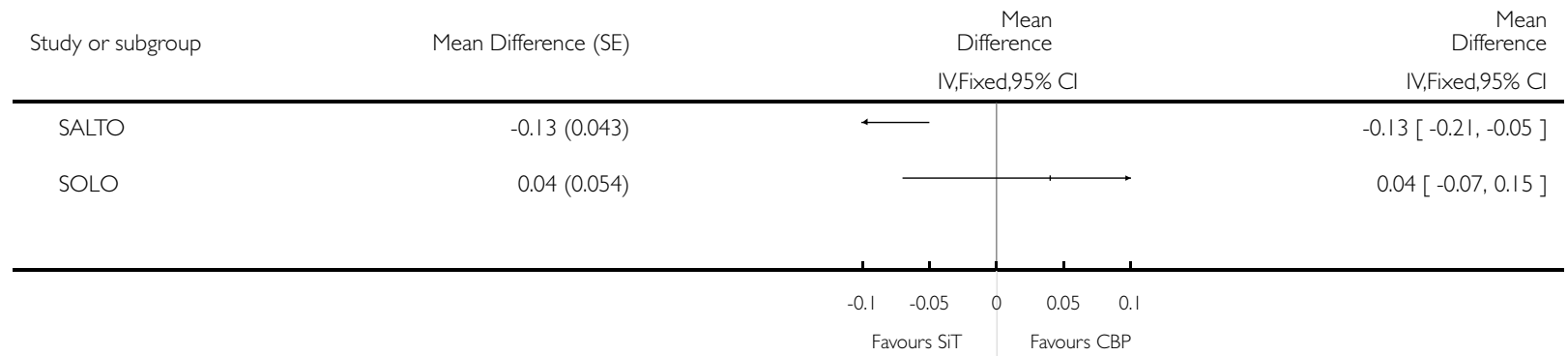

Analysis I.10. Comparison I Adults and Adolescents treated with Single Inhaler Therapy versus Current Best Practice, Outcome 10 ICS dose (micrograms per day).

Review: Combination formoterol and budesonide as maintenance and reliever therapy versus inhaled steroid maintenance for chronic asthma in adults and children Comparison: I Adults and Adolescents treated with Single Inhaler Therapy versus Current Best Practice

Outcome: 10 ICS dose (micrograms per day)

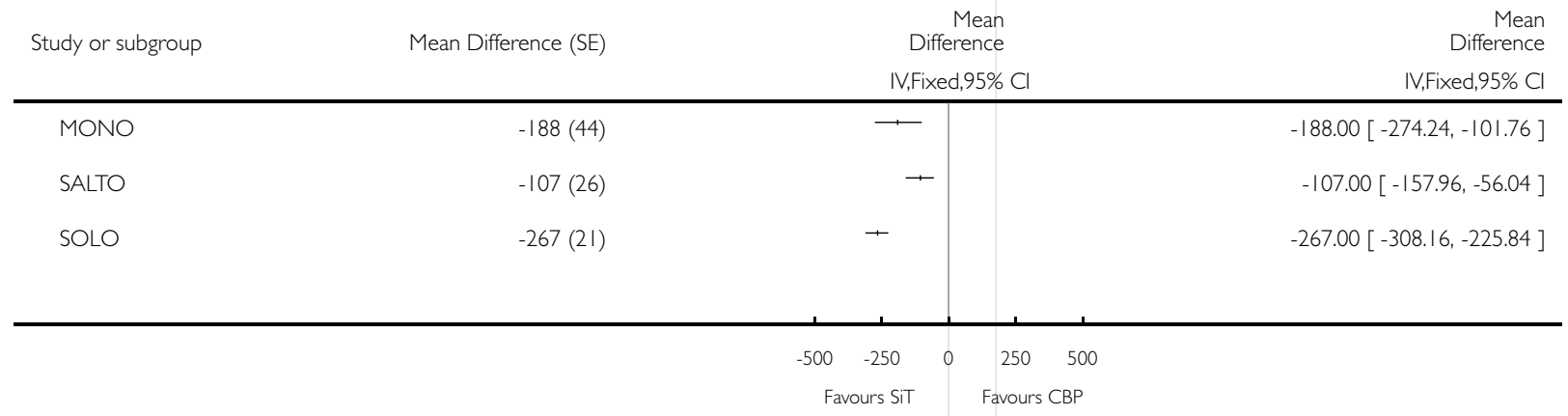


Analysis 2.1. Comparison 2 Adults and Adolescents treated with Single Inhaler Therapy versus fixed dose ICS, Outcome I Patients with exacerbations causing hospitalisation.

Review: Combination formoterol and budesonide as maintenance and reliever therapy versus inhaled steroid maintenance for chronic asthma in adults and children

Comparison: 2 Adults and Adolescents treated with Single Inhaler Therapy versus fixed dose ICS

Outcome: I Patients with exacerbations causing hospitalisation

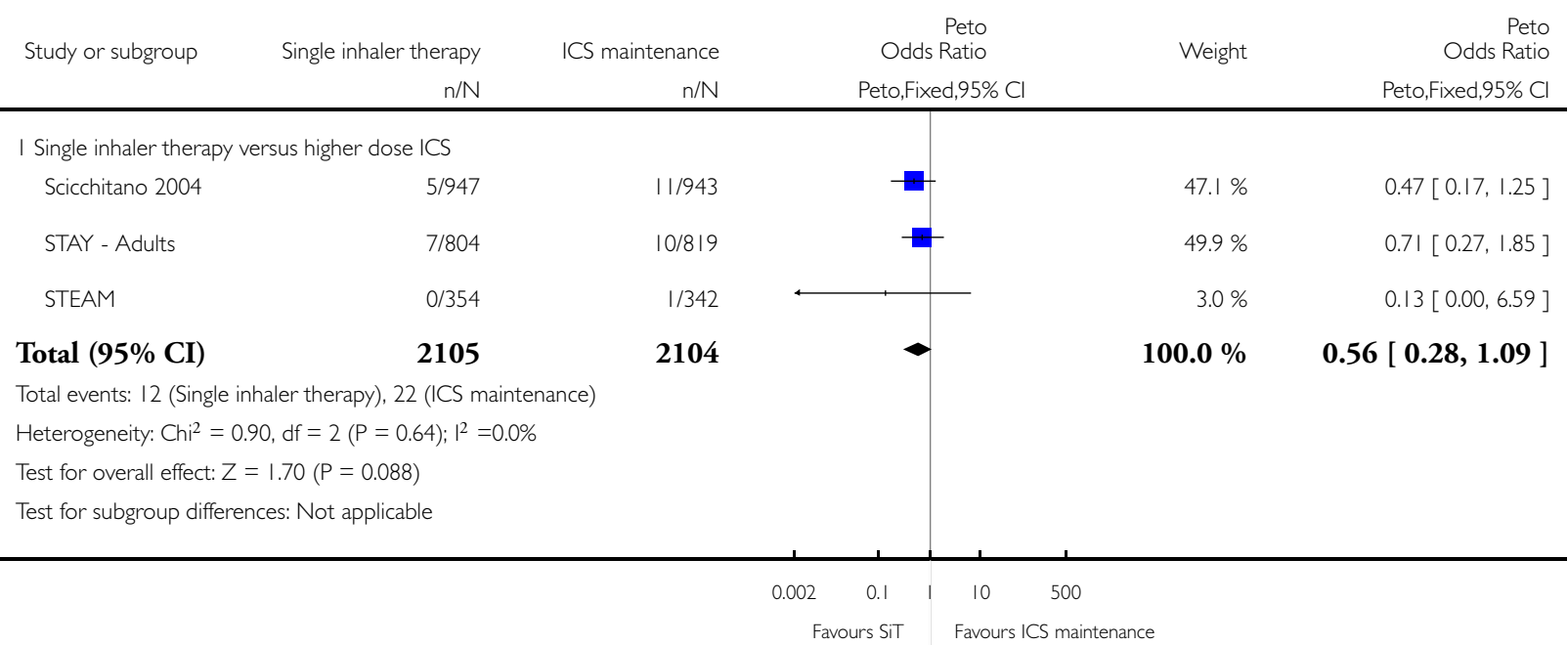

Combination formoterol and budesonide as maintenance and reliever therapy versus inhaled steroid maintenance for chronic asthma in 
Analysis 2.2. Comparison 2 Adults and Adolescents treated with Single Inhaler Therapy versus fixed dose ICS, Outcome 2 Patients with exacerbations treated with oral steroids.

Review: Combination formoterol and budesonide as maintenance and reliever therapy versus inhaled steroid maintenance for chronic asthma in adults and children Comparison: 2 Adults and Adolescents treated with Single Inhaler Therapy versus fixed dose ICS

Outcome: 2 Patients with exacerbations treated with oral steroids

Study or subgroup Single inhaler therapy ICS maintenance Odds Ratio Weight $\mathrm{n} / \mathrm{N}$ $\mathrm{n} / \mathrm{N}$ $\mathrm{M}-\mathrm{H}$, Fixed,95\% Cl $\mathrm{M}-\mathrm{H}, \mathrm{Fixed}, 95 \% \mathrm{Cl}$

I Single inhaler therapy versus higher dose ICS

$29 / 947 \quad 204 / 943$

$149 / 819$

STAY - Adults

$83 / 804$

$31 / 342$

2104

Subtotal (95\% CI)

2105

Total events: 224 (Single inhaler therapy), 384 (ICS maintenance)

Heterogeneity: $\mathrm{Chi}^{2}=1.77, \mathrm{df}=2(\mathrm{P}=0.4 \mathrm{I}) ; \mathrm{I}^{2}=0.0 \%$

Test for overall effect: $Z=6.96(P<0.0000 \mathrm{I})$

2 Single inhaler therapy versus same dose ICS

Sovani 2008

$4 / 35$

Subtotal (95\% CI)

35

$3 / 36$

$+$

Total events: 4 (Single inhaler therapy), 3 (ICS maintenance)

Heterogeneity: not applicable

Test for overall effect: $Z=0.44(P=0.66)$

Total (95\% CI)

2140

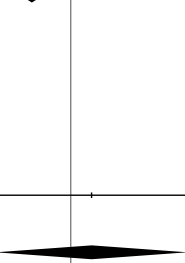

$51.6 \%$

$0.57[0.45,0.73]$

$38.7 \%$

$0.52[0.39,0.69]$

$8.9 \%$

$0.35[0.18,0.70]$

Total events: 228 (Single inhaler therapy), 387 (ICS maintenance)

Heterogeneity: $\mathrm{Ch}^{2}=3.24, \mathrm{df}=3(\mathrm{P}=0.36) ; \mathrm{I}^{2}=7 \%$

Test for overall effect: $Z=6.87(P<0.0000$ I)

$\begin{array}{lllllll}0.1 & 0.2 & 0.5 & 1 & 2 & 5 & 10\end{array}$

Favours SiT Favours ICS maintenance

Combination formoterol and budesonide as maintenance and reliever therapy versus inhaled steroid maintenance for chronic asthma in 
Analysis 2.3. Comparison 2 Adults and Adolescents treated with Single Inhaler Therapy versus fixed dose ICS, Outcome 3 Serious Adverse Events (fatal).

Review: Combination formoterol and budesonide as maintenance and reliever therapy versus inhaled steroid maintenance for chronic asthma in adults and children Comparison: 2 Adults and Adolescents treated with Single Inhaler Therapy versus fixed dose ICS

Outcome: 3 Serious Adverse Events (fatal)

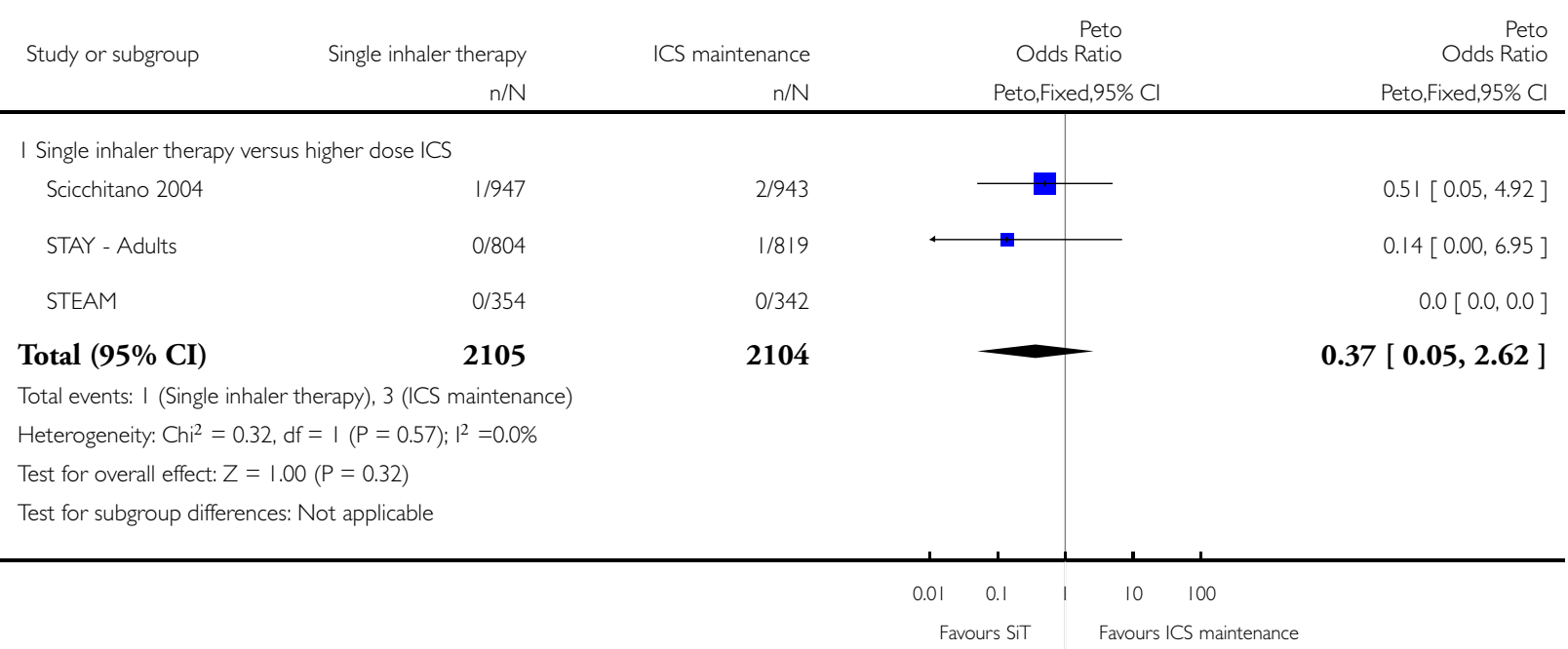

Combination formoterol and budesonide as maintenance and reliever therapy versus inhaled steroid maintenance for chronic asthma in 
Analysis 2.4. Comparison 2 Adults and Adolescents treated with Single Inhaler Therapy versus fixed dose ICS, Outcome 4 Serious Adverse Events (non-fatal).

Review: Combination formoterol and budesonide as maintenance and reliever therapy versus inhaled steroid maintenance for chronic asthma in adults and children Comparison: 2 Adults and Adolescents treated with Single Inhaler Therapy versus fixed dose ICS

Outcome: 4 Serious Adverse Events (non-fatal)

Study or subgroup Single inhaler therapy ICS maintenance Odds Ratio Odds Ratio

$\mathrm{n} / \mathrm{N} \quad \mathrm{n} / \mathrm{N} \quad \mathrm{M}-\mathrm{H}$, Fixed,95\% Cl M-H,Fixed,95\% Cl

I Single inhaler therapy versus higher dose ICS

Scicchitano 2004

STAY - Adults 44/804

STEAM 6/35

Total (95\% CI)

2105

$49.2 \%$

$0.97[0.65,1.46]$

$50 / 943$

$46 / 819$

$6 / 342$

$44.6 \%$

$0.97[0.64,1.49]$

$6 / 342$

2104

$6.2 \%$

$0.97[0.31,3.02]$

Total events: 99 (Single inhaler therapy), 102 (ICS maintenance)

Heterogeneity: $\mathrm{Chi}^{2}=0.00, \mathrm{df}=2(\mathrm{P}=1.00) ; \mathrm{I}^{2}=0.0 \%$

Test for overall effect: $Z=0.19(P=0.85)$

Test for subgroup differences: Not applicable

$\begin{array}{rrr}6.2 \% & 0.97[0.31,3.02] \\ \mathbf{1 0 0 . 0} \% & \mathbf{0 . 9 7}[\mathbf{0 . 7 3}, \mathbf{1 . 2 9}]\end{array}$

Analysis 2.5. Comparison 2 Adults and Adolescents treated with Single Inhaler Therapy versus fixed dose ICS, Outcome 5 Discontinuation due to Adverse Events.

Review: Combination formoterol and budesonide as maintenance and reliever therapy versus inhaled steroid maintenance for chronic asthma in adults and children

Comparison: 2 Adults and Adolescents treated with Single Inhaler Therapy versus fixed dose ICS

Outcome: 5 Discontinuation due to Adverse Events

Study or subgroup Single inhaler therapy ICS maintenance Odds Ratio Odds Ratio

$n / N \quad n / N \quad M-H, F i x e d, 95 \%$ Cl M-H,Fixed,95\% Cl

I Single inhaler therapy versus higher dose ICS

Scicchitano 2004

STEAM

$24 / 947$

$38 / 943$

M.
MH, Fixed, $95 \%$ Cl

Total (95\% CI)

1301

$8 / 342$

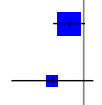

$82.1 \%$

$0.62[0.37,1.04]$

Total events: 27 (Single inhaler therapy), 46 (ICS maintenance)

1285

$17.9 \%$

$0.36[0.09,1.36]$

Heterogeneity: $\mathrm{Chi}^{2}=0.57, \mathrm{df}=\mathrm{I}(\mathrm{P}=0.45) ; \mathrm{I}^{2}=0.0 \%$

Test for overall effect: $Z=2.27(P=0.023)$

Test for subgroup differences: Not applicable

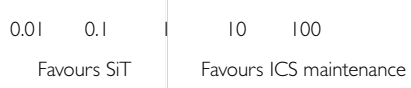

Combination formoterol and budesonide as maintenance and reliever therapy versus inhaled steroid maintenance for chronic asthma in 51 adults and children (Review)

Copyright ( 2010 The Cochrane Collaboration. Published by John Wiley \& Sons, Ltd. 


\section{Analysis 2.6. Comparison 2 Adults and Adolescents treated with Single Inhaler Therapy versus fixed dose}

ICS, Outcome 6 Patients with "severe" exacerbation (time to event).

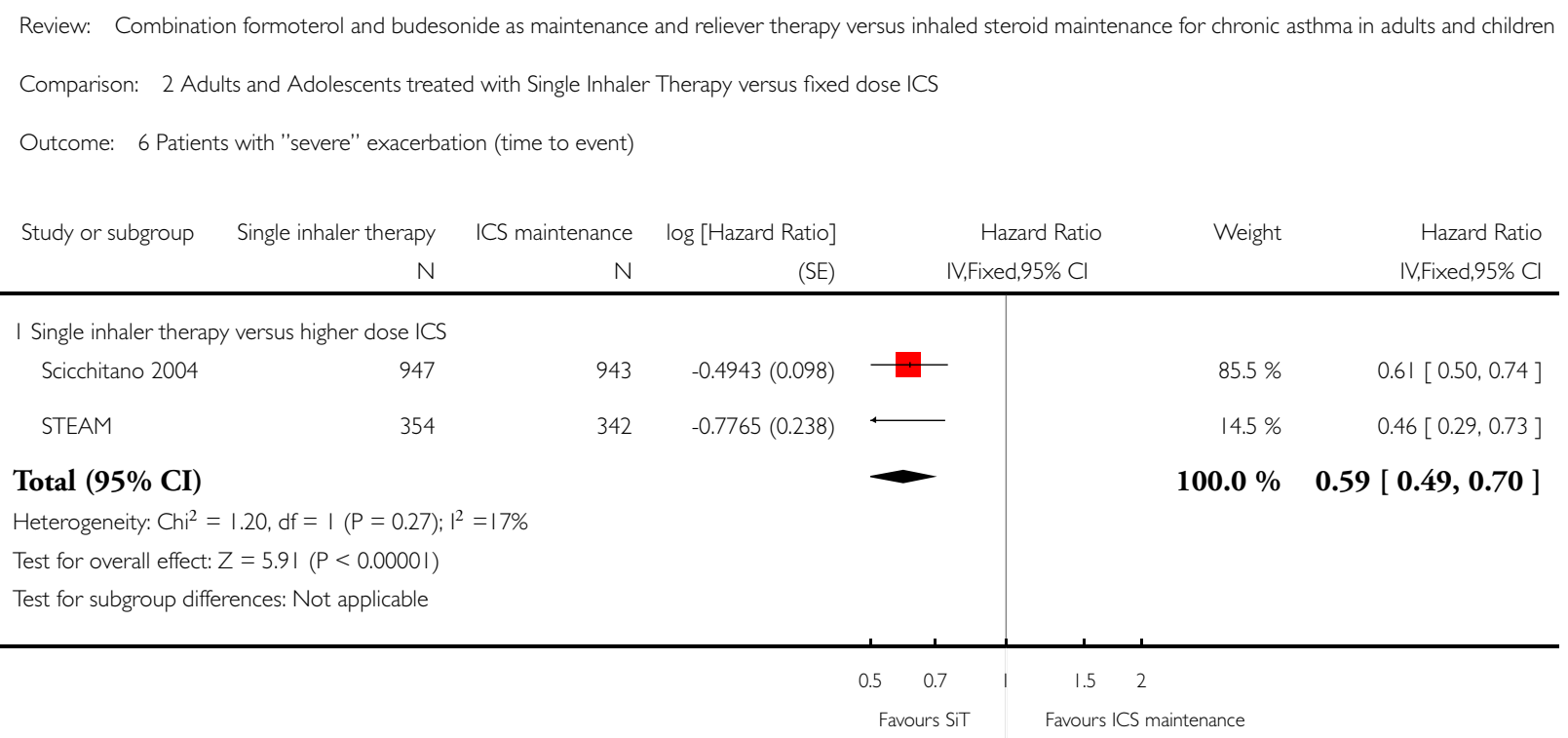


Analysis 2.7. Comparison 2 Adults and Adolescents treated with Single Inhaler Therapy versus fixed dose ICS, Outcome 7 PEF (Litres/min).

Review: Combination formoterol and budesonide as maintenance and reliever therapy versus inhaled steroid maintenance for chronic asthma in adults and children Comparison: 2 Adults and Adolescents treated with Single Inhaler Therapy versus fixed dose ICS

Outcome: 7 PEF (Litres/min)

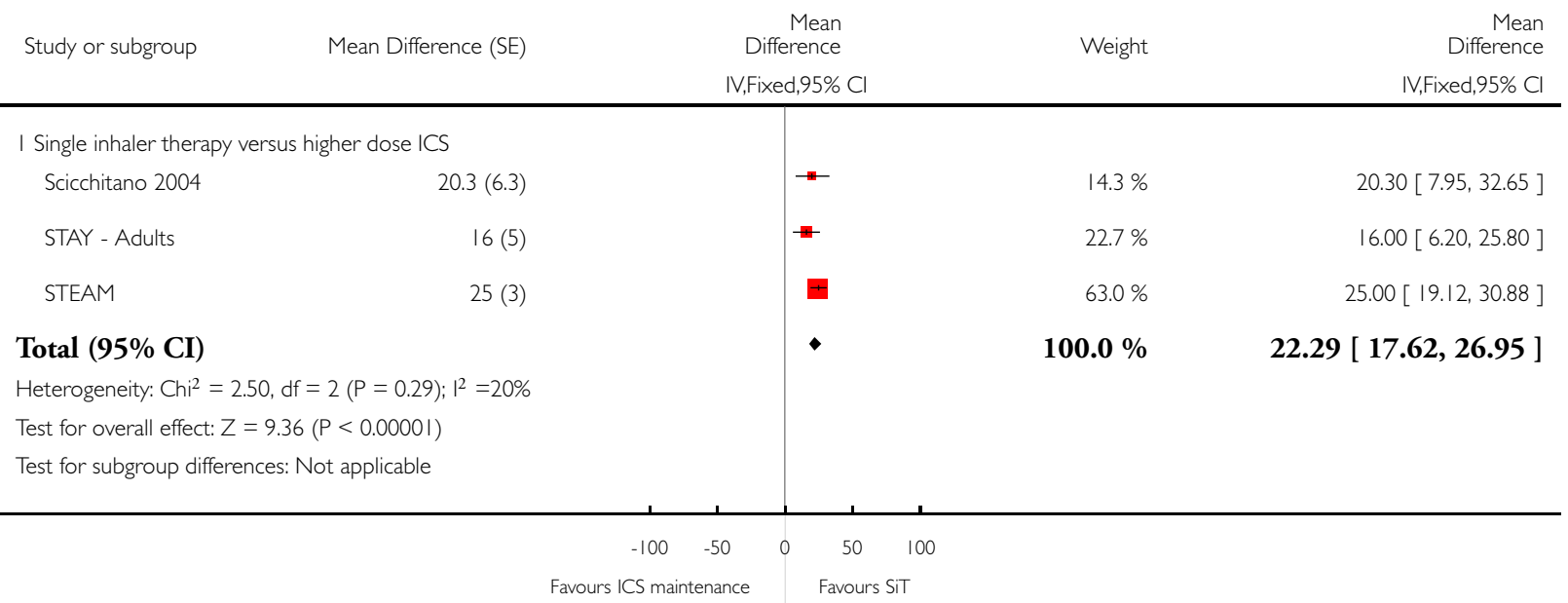

Combination formoterol and budesonide as maintenance and reliever therapy versus inhaled steroid maintenance for chronic asthma in 
Analysis 2.8. Comparison 2 Adults and Adolescents treated with Single Inhaler Therapy versus fixed dose ICS, Outcome 8 FEVI increase (Litres).

Review: Combination formoterol and budesonide as maintenance and reliever therapy versus inhaled steroid maintenance for chronic asthma in adults and children Comparison: 2 Adults and Adolescents treated with Single Inhaler Therapy versus fixed dose ICS

Outcome: $8 \mathrm{FEVI}$ increase (Litres)

$\begin{array}{lrr}\text { Study or subgroup } & \text { Mean } & \text { Mean } \\ \text { Mifference } & \text { Weight } & \text { Difference } \\ \text { IV,Fixed,95\% Cl } & \text { Mixed,95\% Cl }\end{array}$

I Single inhaler therapy versus higher dose ICS

Scicchitano $2004 \quad 0.1(0.015)$

$0.11(0.03)$

$78.6 \%$

$0.10[0.07,0.13]$

STAY - Adults

$\longrightarrow$

$19.6 \%$

$0.11[0.05,0.17]$

Subtotal (95\% CI)

$98.2 \%$

$0.10[0.08,0.13]$

Heterogeneity: $\mathrm{Chi}^{2}=0.09, \mathrm{df}=\mathrm{I}(\mathrm{P}=0.77) ; \mathrm{I}^{2}=0.0 \%$

Test for overall effect: $Z=7.60(P<0.0000$ I)

2 Single inhaler therapy versus same dose ICS

Sovani 2008

$0.01(0.1)$

Subtotal (95\% CI)

Heterogeneity: not applicable

Test for overall effect: $Z=0.10(P=0.92)$

Total (95\% CI)

Heterogeneity: $\mathrm{Chi}^{2}=0.92, \mathrm{df}=2(\mathrm{P}=0.63) ;\left.\right|^{2}=0.0 \%$

Test for overall effect: $Z=7.55(P<0.0000 I)$

Test for subgroup differences: $\mathrm{Chi}^{2}=0.83, \mathrm{df}=\mathrm{I}(\mathrm{P}=0.36), \mathrm{I}^{2}=0.0 \%$

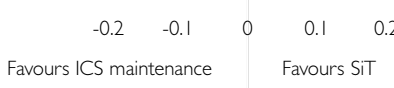


Analysis 2.9. Comparison 2 Adults and Adolescents treated with Single Inhaler Therapy versus fixed dose ICS, Outcome 9 Rescue Medication Use (puffs per day).

Review: Combination formoterol and budesonide as maintenance and reliever therapy versus inhaled steroid maintenance for chronic asthma in adults and children Comparison: 2 Adults and Adolescents treated with Single Inhaler Therapy versus fixed dose ICS

Outcome: 9 Rescue Medication Use (puffs per day)

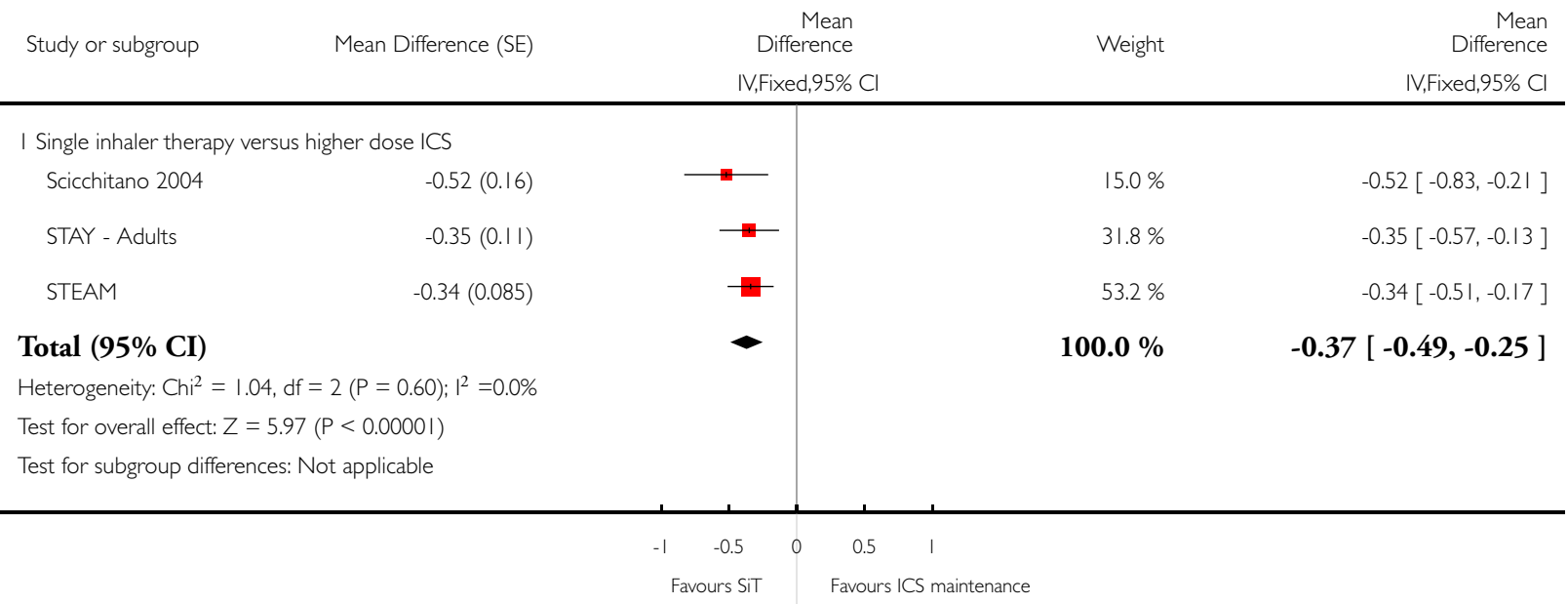

Analysis 2.10. Comparison 2 Adults and Adolescents treated with Single Inhaler Therapy versus fixed dose ICS, Outcome 10 Quality of Life (Fall in ACQ score).

Review: Combination formoterol and budesonide as maintenance and reliever therapy versus inhaled steroid maintenance for chronic asthma in adults and children Comparison: 2 Adults and Adolescents treated with Single Inhaler Therapy versus fixed dose ICS

Outcome: 10 Quality of Life (Fall in ACQ score)

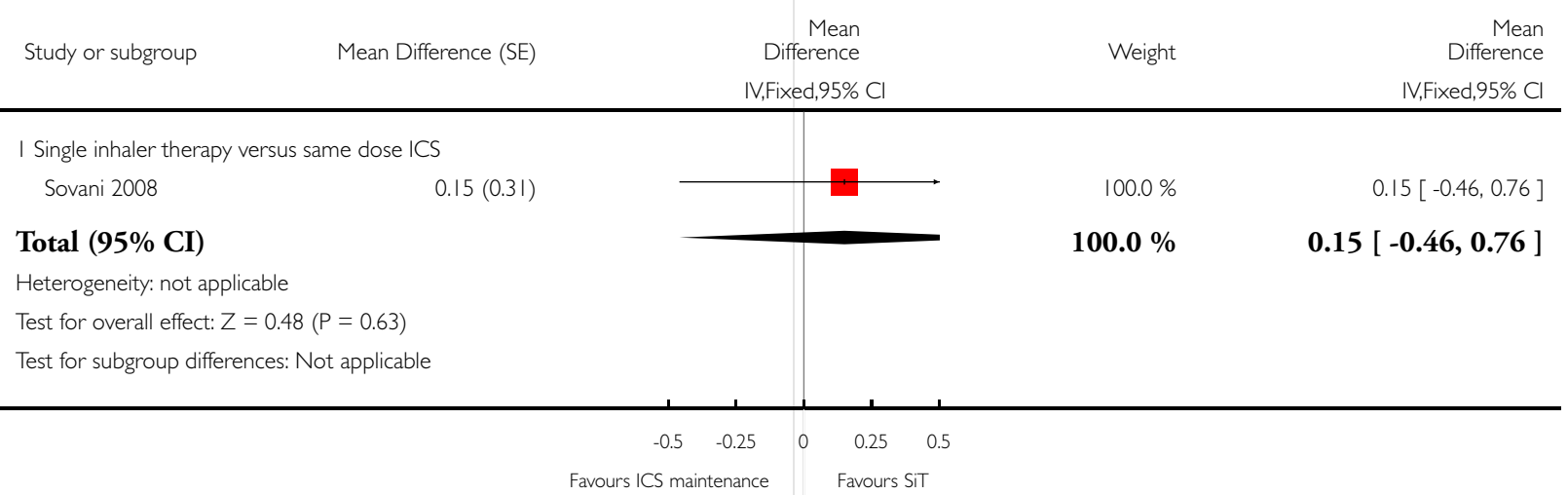

Combination formoterol and budesonide as maintenance and reliever therapy versus inhaled steroid maintenance for chronic asthma in 55 adults and children (Review)

Copyright ( 2010 The Cochrane Collaboration. Published by John Wiley \& Sons, Ltd. 
Analysis 3.I. Comparison 3 Children treated with Single Inhaler Therapy versus higher fixed dose ICS, Outcome I Patients with exacerbations causing hospitalisation.

Review: Combination formoterol and budesonide as maintenance and reliever therapy versus inhaled steroid maintenance for chronic asthma in adults and children

Comparison: 3 Children treated with Single Inhaler Therapy versus higher fixed dose ICS

Outcome: I Patients with exacerbations causing hospitalisation

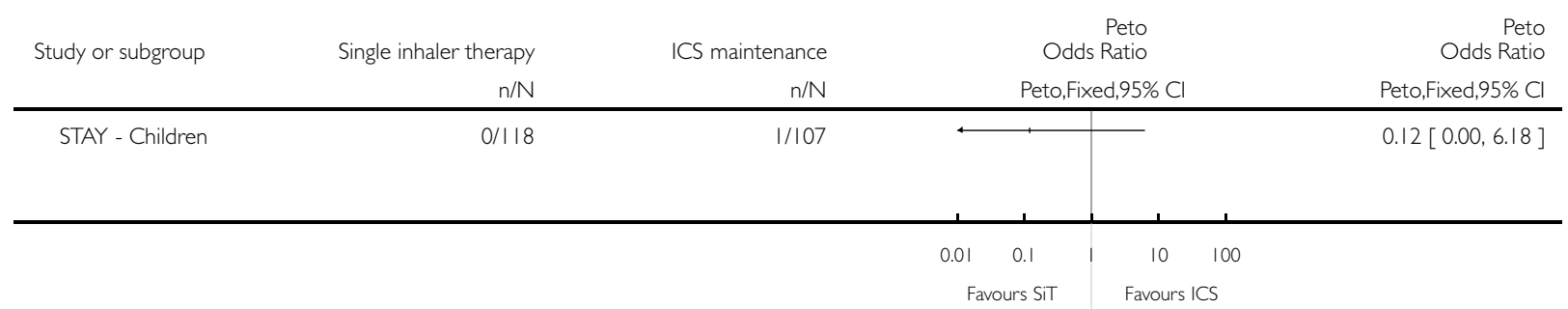

\section{Analysis 3.2. Comparison 3 Children treated with Single Inhaler Therapy versus higher fixed dose ICS,} Outcome 2 Serious Adverse Events (fatal).

Review: Combination formoterol and budesonide as maintenance and reliever therapy versus inhaled steroid maintenance for chronic asthma in adults and children Comparison: 3 Children treated with Single Inhaler Therapy versus higher fixed dose ICS

Outcome: 2 Serious Adverse Events (fatal)

\begin{tabular}{|c|c|c|c|c|}
\hline \multirow[t]{2}{*}{ Study or subgroup } & \multirow{2}{*}{$\begin{array}{r}\text { Single inhaler therapy } \\
n / N\end{array}$} & \multirow{2}{*}{$\begin{array}{r}\text { ICS maintenance } \\
n / N\end{array}$} & \multirow{2}{*}{$\begin{array}{r}\text { Odds Ratio } \\
\text { M-H,Fixed,95\% Cl }\end{array}$} & \multirow{2}{*}{$\begin{array}{r}\text { Odds Ratio } \\
\text { M-H,Fixed,95\% Cl }\end{array}$} \\
\hline & & & & \\
\hline STAY - Children & $0 / 118$ & $0 / 106$ & & $0.0[0.0,0.0]$ \\
\hline Total $(95 \% \mathrm{CI})$ & 118 & 106 & & $0.0[0.0,0.0]$ \\
\hline \multicolumn{5}{|c|}{ Total events: 0 (Single inhaler therapy), 0 (ICS maintenance) } \\
\hline \multicolumn{5}{|c|}{ Heterogeneity: not applicable } \\
\hline \multicolumn{5}{|c|}{ Test for overall effect: $Z=0.0(P<0.0000 I)$} \\
\hline Test for subgroup diffe & applicable & & & \\
\hline
\end{tabular}

$\begin{array}{lllll}0.01 & 0.1 & 1 & 10 & 100\end{array}$

Favours SiT Favours ICS 
Analysis 3.3. Comparison 3 Children treated with Single Inhaler Therapy versus higher fixed dose ICS, Outcome 3 Serious Adverse Events (non-fatal).

Review: Combination formoterol and budesonide as maintenance and reliever therapy versus inhaled steroid maintenance for chronic asthma in adults and children Comparison: 3 Children treated with Single Inhaler Therapy versus higher fixed dose ICS

Outcome: 3 Serious Adverse Events (non-fatal)

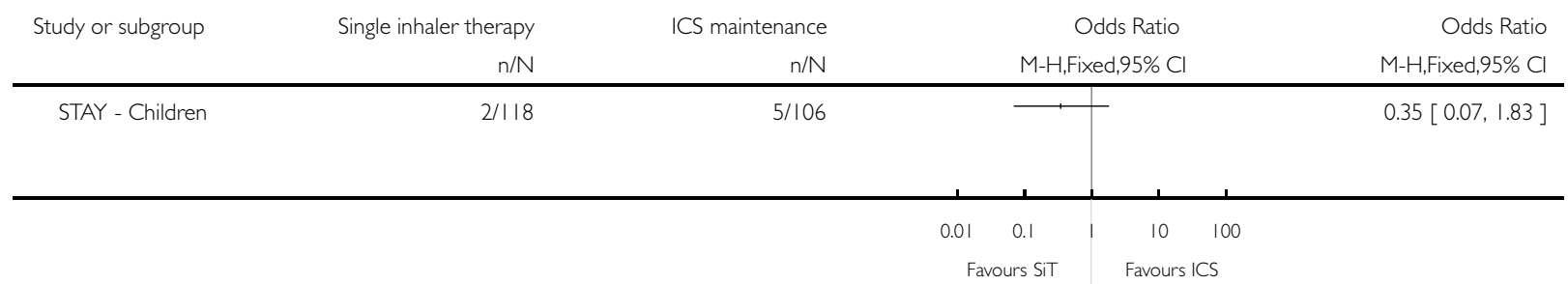

Analysis 3.4. Comparison 3 Children treated with Single Inhaler Therapy versus higher fixed dose ICS, Outcome 4 Annual Height gain (cms).

Review: Combination formoterol and budesonide as maintenance and reliever therapy versus inhaled steroid maintenance for chronic asthma in adults and children Comparison: 3 Children treated with Single Inhaler Therapy versus higher fixed dose ICS

Outcome: 4 Annual Height gain (cms)

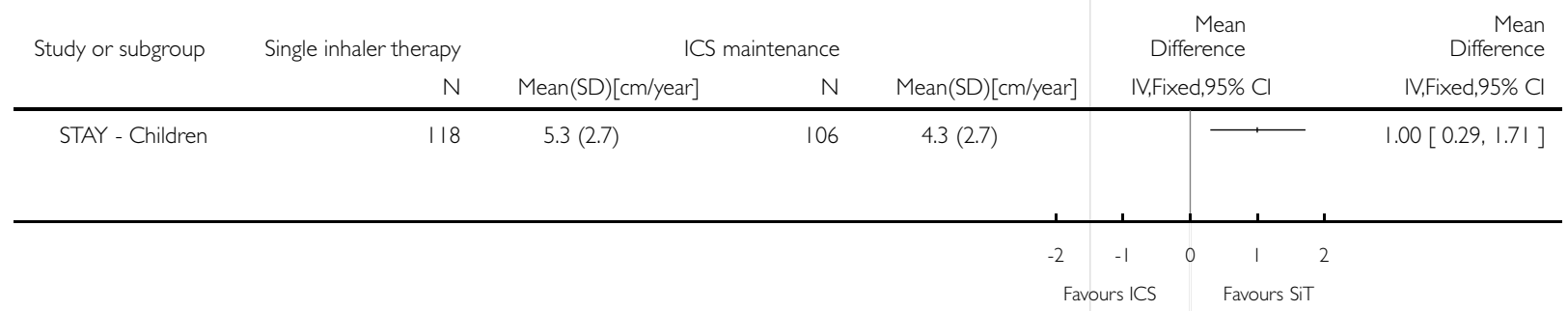


Analysis 3.5. Comparison 3 Children treated with Single Inhaler Therapy versus higher fixed dose ICS, Outcome 5 Children with low plasma cortisol ( $<400 \mathrm{nmol} / \mathrm{L})$.

Review: Combination formoterol and budesonide as maintenance and reliever therapy versus inhaled steroid maintenance for chronic asthma in adults and children

Comparison: 3 Children treated with Single Inhaler Therapy versus higher fixed dose ICS

Outcome: 5 Children with low plasma cortisol $(<400 \mathrm{nmol} / \mathrm{L})$

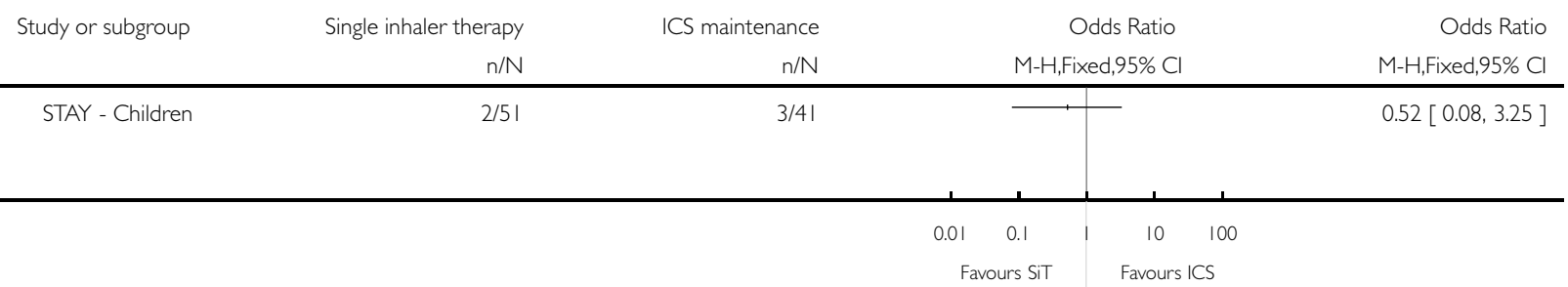

Analysis 3.6. Comparison 3 Children treated with Single Inhaler Therapy versus higher fixed dose ICS, Outcome 6 Patients with an exacerbation requiring increase in ICS or other treatment.

Review: Combination formoterol and budesonide as maintenance and reliever therapy versus inhaled steroid maintenance for chronic asthma in adults and children Comparison: 3 Children treated with Single Inhaler Therapy versus higher fixed dose ICS

Outcome: 6 Patients with an exacerbation requiring increase in ICS or other treatment

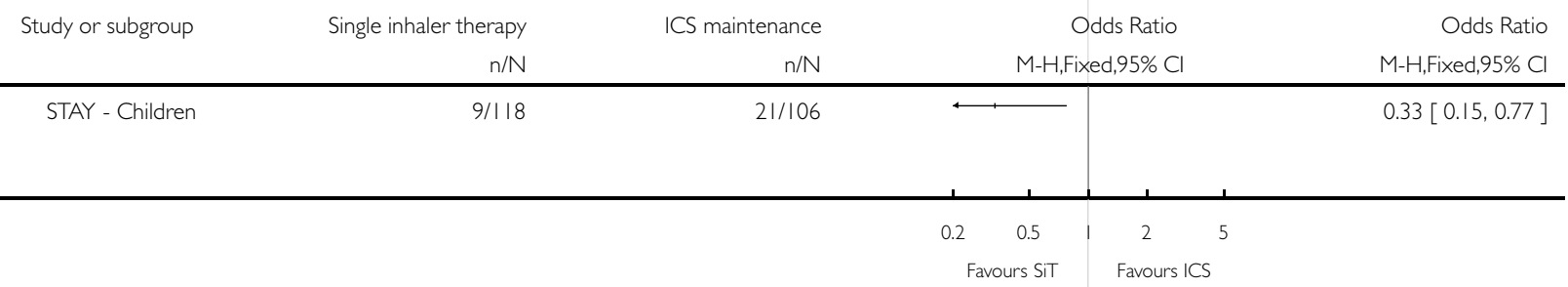


Analysis 3.7. Comparison 3 Children treated with Single Inhaler Therapy versus higher fixed dose ICS, Outcome 7 Change in morning PEF (L/min).

Review: Combination formoterol and budesonide as maintenance and reliever therapy versus inhaled steroid maintenance for chronic asthma in adults and children Comparison: 3 Children treated with Single Inhaler Therapy versus higher fixed dose ICS

Outcome: 7 Change in morning PEF $(L / m i n)$

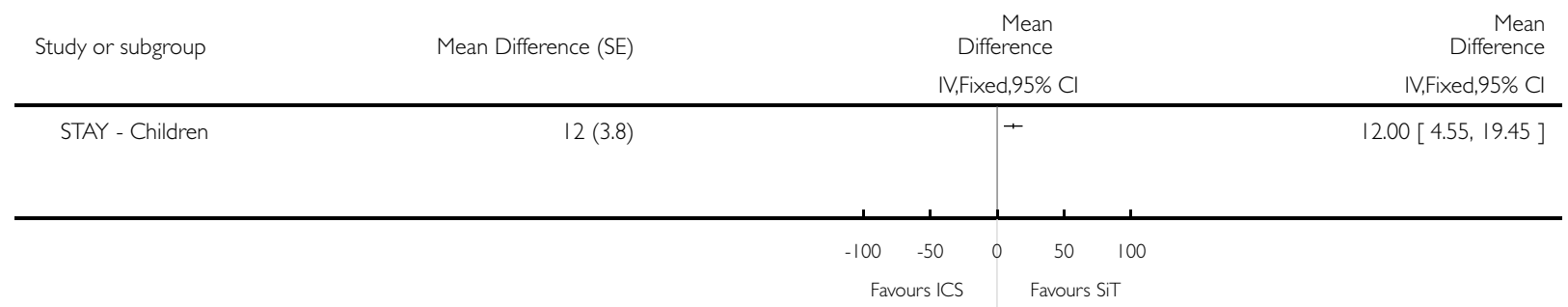

Analysis 3.8. Comparison 3 Children treated with Single Inhaler Therapy versus higher fixed dose ICS, Outcome 8 Change in clinic FEVI(Litres).

Review: Combination formoterol and budesonide as maintenance and reliever therapy versus inhaled steroid maintenance for chronic asthma in adults and children

Comparison: 3 Children treated with Single Inhaler Therapy versus higher fixed dose ICS

Outcome: 8 Change in clinic FEVI(Litres)

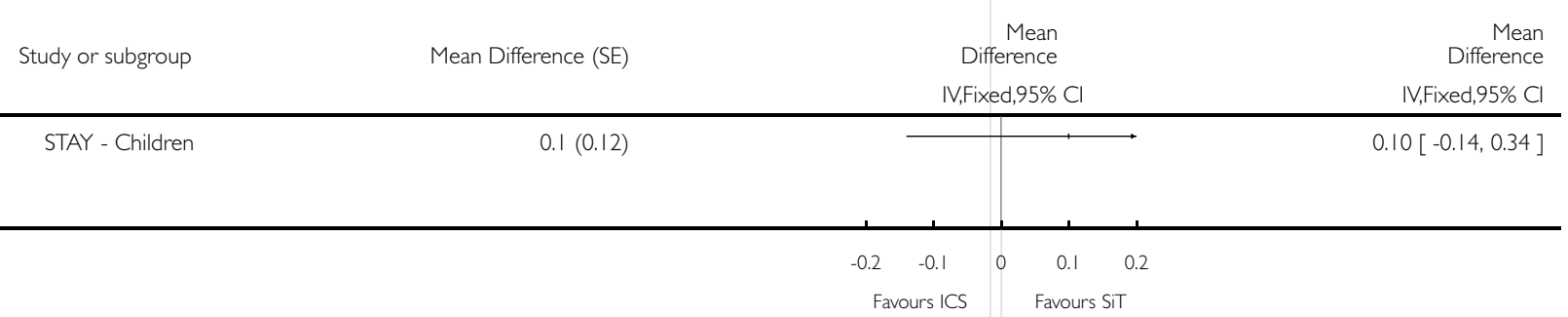


Analysis 3.9. Comparison 3 Children treated with Single Inhaler Therapy versus higher fixed dose ICS, Outcome 9 As needed medication use over 24 hours.

Review: Combination formoterol and budesonide as maintenance and reliever therapy versus inhaled steroid maintenance for chronic asthma in adults and children Comparison: 3 Children treated with Single Inhaler Therapy versus higher fixed dose ICS

Outcome: 9 As needed medication use over 24 hours

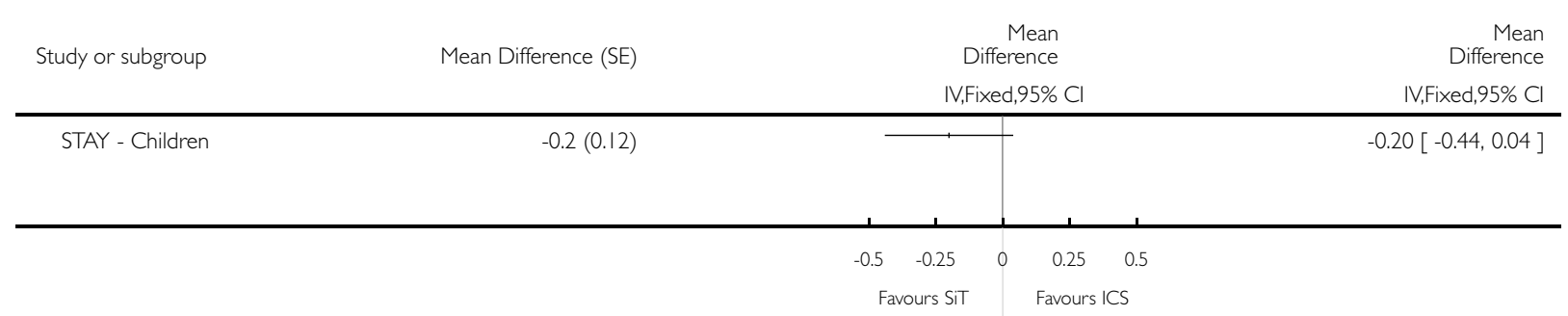

Analysis 3.10. Comparison 3 Children treated with Single Inhaler Therapy versus higher fixed dose ICS, Outcome 10 Nocturnal awakenings.

Review: Combination formoterol and budesonide as maintenance and reliever therapy versus inhaled steroid maintenance for chronic asthma in adults and children Comparison: 3 Children treated with Single Inhaler Therapy versus higher fixed dose ICS

Outcome: 10 Nocturnal awakenings

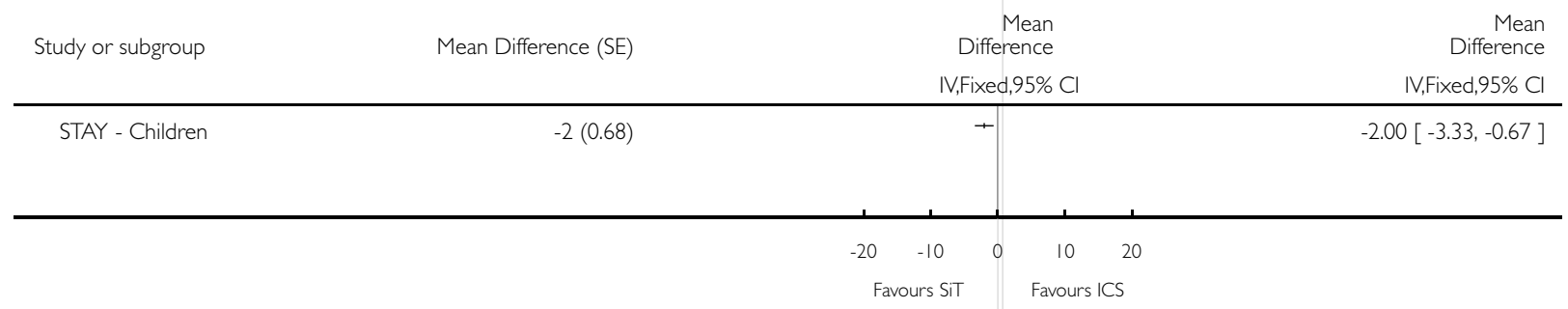

\section{WHAT'S NEW}

Last assessed as up-to-date: 9 February 2009.

Combination formoterol and budesonide as maintenance and reliever therapy versus inhaled steroid maintenance for chronic asthma in 


\begin{tabular}{lll}
\hline Date & Event & Description \\
\hline 11 November 2009 & Amended & $\begin{array}{l}\text { Typological errors corrected (doses corrected to mcg not mg). The Sovani study was designed to } \\
\text { assess compliance with inhaled (not oral) corticosteroids }\end{array}$ \\
\hline
\end{tabular}

\section{H I S T O R Y}

Protocol first published: Issue 3, 2008

Review first published: Issue 2, 2009

\section{CONTRIBUTIONS OF AUTHORS}

Chris Cates and Toby Lasserson conceived of the idea for this review, wrote the protocol, assessed the studies for inclusion, extracted the data from the papers and web reports and co-wrote the review.

\section{DECLARATIONS OF INTEREST}

None known.

\section{SOURCES OF SUPPORT}

\section{Internal sources}

- No sources of support supplied

\section{External sources}

- NHS Cochrane Collaboration Programme Grant Scheme, UK.

\section{DIFFERENCES BETWEEN PROTOCOLANDREVIEW}

This review has been focused on formoterol and budesonide as maintenance and reliever therapy, rather than formoterol with any inhaled corticosteroid. Steroid load and discontinuation due to adverse events were post hoc outcomes, added after the protocol. When zero cells were present for an outcome in any of the included studies the Peto Odds Ratio was used to combine the results, as it does not require a continuity correction to be used. 


\section{NDEX TERMS}

\section{Medical Subject Headings (MeSH)}

Administration, Inhalation; Adrenal Cortex Hormones [*administration \& dosage]; Anti-Asthmatic Agents [*administration $\&$ dosage]; Asthma [*drug therapy]; Bronchodilator Agents [administration \& dosage]; Budesonide [*administration \& dosage]; Chronic Disease; Drug Therapy, Combination; Ethanolamines [*administration \& dosage]; Terbutaline [administration \& dosage]

\section{MeSH check words}

Adult; Child; Humans 